\title{
SOLUBILIDADE E DISPONIBILIDADE DO FÓSFORO DE FOSFATOS NATURAIS COM ORIGENS GEOLÓGICAS DIFERENTES
}

\author{
MÔNICA SARTORI DE CAMARGO
}

Engenheira Agrônoma

Orientador: Prof. Dr.RONALDO IVAN SILVEIRA

\begin{abstract}
Dissertação apresentada à Escola Superior de Agricultura "Luiz de Queiroz", da Universidade de São Paulo, para obtenção do título de Mestre em Agronomia, Área de Concentração: Solos e Nutrição de Plantas.
\end{abstract}

Piracicaba

Estado de São Paulo - Brasil

Novembro - 1997 
Dados Internacionais de Catalogação na Publicação (CIP) DIVISĀO DE BIBLIOTECA E DOCUMENTAÇĀO - Campus "Luiz de Queiroz"/USP

Camargo, Mônica Sartori de

Solubilidade e disponibilidade do fósforo de fosfatos naturais com origens geológicas diferentes / Mônica Sartori de Camargo. - - Piracicaba, 1997.

$100 \mathrm{p}$.

Dissertaçāo (mestrado) - - Escola Superior de Agricultura Luiz de Queiroz, 1997. Bibliografia.

1. Fosfato de rocha 2. Fósforo 3. Macronutriente 4. Matéria seca 5. Milho 6. Nutrição vegetal 7. Química do solo 8. Solubilidade I. Título 


\section{SOLUBILIDADE E DISPONIBILIDADE DO FÓSFORO DE FOSFATOS NATURAIS COM ORIGENS \\ GEOLÓGICAS DIFERENTES}

\section{MÔNICA SARTORI DE CAMARGO}

Aprovada em: 15/12/1997

\section{Comissão Julgadora:}

Prof. Dr. Ronaldo Ivan Silveira

Prof. Dr. Quirino Augusto de Camargo Carmello

Prof. Dr. Edson Luís Mendes Coutinho
ESALQ/USP

ESALQ/USP

FMVAJ/UNESP

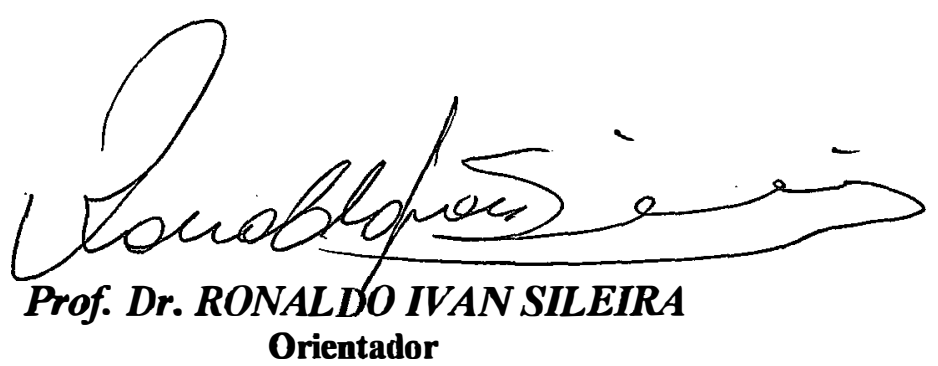




\section{OFEREÇO}

A Deus, pela presença constante em minha vida, permitindo-me alcançar mais uma vitória.

\section{DEDICO}

Aos meus pais, Ângela Sônia e Antônio Fernando, pela oportunidade de estudar e constante paciência, amor e incentivo nas horas mais dificeis. E à minha irmã Fernanda, pela amizade e compreensão. 


\section{AGRADECIMENTOS}

Ao professor Ronaldo Ivan Silveira, pela orientação, paciência, amizade e contribuições à minha formação profissional ;

Aos técnicos de laboratório do Departamento de Ciência do Solo Vanda, Carlos, Mário e Marcos pela inestimável colaboração;

Aos professores do Departamento de Matemática e Estatística, José Eduardo Corrente e Maria Cristina Stolf Nogueira e ao engenheiro agrônomo Marcelo Zacharias, do Centro de Informática na Agricultura, pelo auxílio nas análises estatísticas ;

Às amigas, Carla Rossi e Patrícia Pauletti, pelo auxílio nas revisões ;

À CAPES pela concessão da bolsa de estudos ;

À ESALQ e ao Departamento de Ciência do Solo pela oportunidade ;

A todos aqueles que contribuíram para que este trabalho se tornasse realidade. 


\section{SUMÁRIO}

\section{Página}

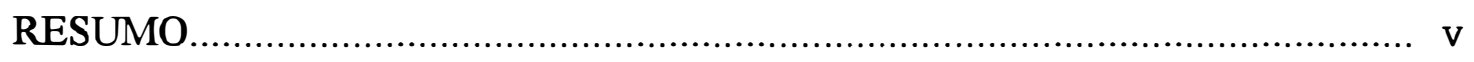

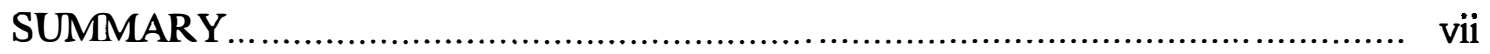

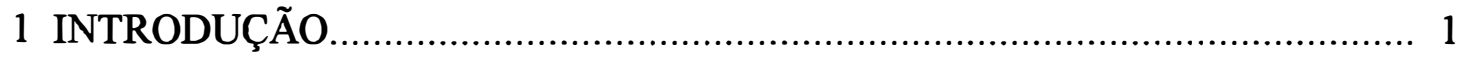

2 REVISÃO DE LITERATURA........................................................... 3

2.1 Fosfatos naturais: jazidas brasileiras e sua reatividade............................. 3

2.2 Efeito dos fosfatos naturais na produção agrícola.................................. 6

2.3 Solubilidade dos fosfatos naturais: métodos de avaliação e sua correlação com a produtividade das culturas................................................. 13

3 MATERIAL E MÉTODOS ............................................................... 16

3.1 Localização do experimento......................................................... 16

3.2 Fosfatos naturais........................................................................ 16

3.2.1 Determinação da solubilidade.............................................. 17

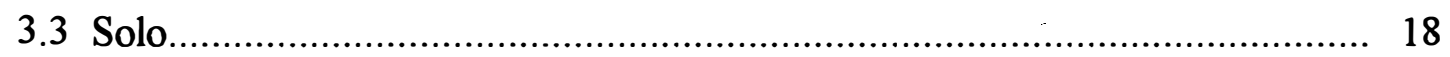

3.4 Tratamentos (Adubação) ............................................................ 19

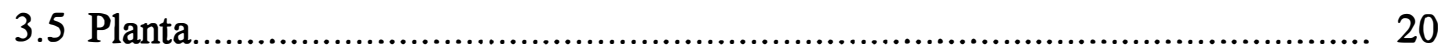

3.6 Instalação e condução do experimento............................................... 21

3.7 Análise química dos macronutrientes absorvidos pelas plantas................... 22

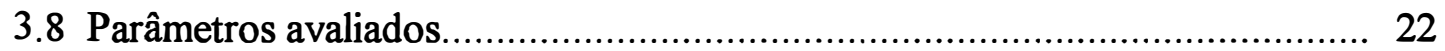

3.9 Delineamento experimental.......................................................... 23

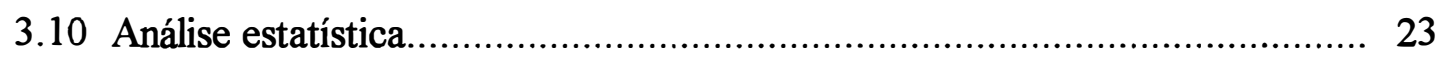

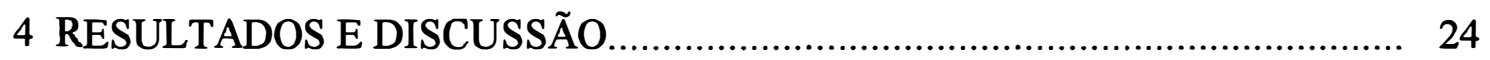

4.1 Solubilidade dos fosfatos naturais em solução de ácido cítrico a 2\%............. 24

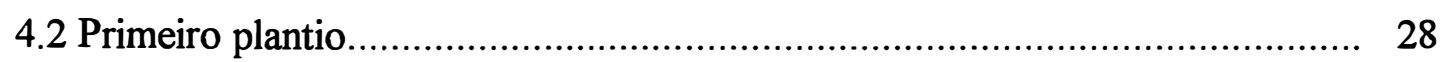

4.2.1 Produção de material seco............................................................ 31

4.2.2 Teor de fósforo..................................................................... 41

4.2.3 Quantidade de fósforo.......................................................... 44

4.2.4 Índice de eficiência agronômica.................................................. 47

4.2.5 Outros macronutrientes...................................................... 50 
4.2.5.1 Teor e quantidade de nitrogênio.......................................... 50

4.2.5.2 Teor e quantidade de potássio.............................................. 52

4.2.5.3 Teor e quantidade de cálcio................................................... 55

4.2.5.4 Teor e quantidade de magnésio........................................... 56

4.2.5.5 Teor e quantidade de enxofre............................................. 60

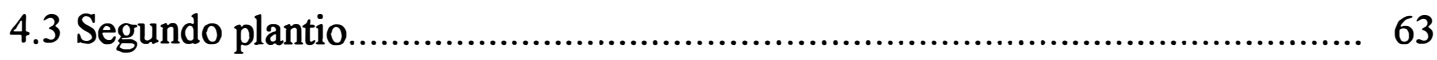

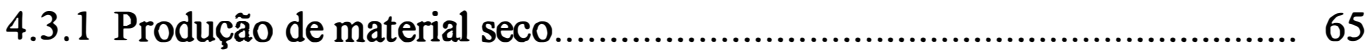

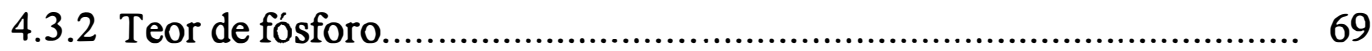

4.3.3 Quantidade de fósforo................................................................ 70

4.3.4 Índice de eficiência agronômica........................................................... 73

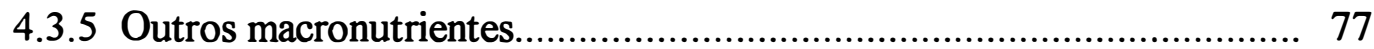

4.3.5.1 Teor e quantidade de nitrogênio............................................ 77

4.3.5.2 Teor e quantidade de potássio............................................. 79

4.3.5.3 Teor e quantidade de cálcio................................................... 82

4.3.5.4 Teor e quantidade de magnésio............................................ 86

4.3.5.5 Teor e quantidade de enxofre............................................. 87

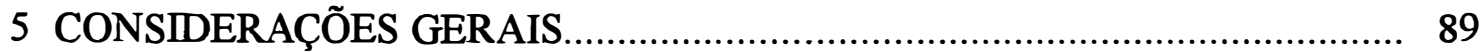

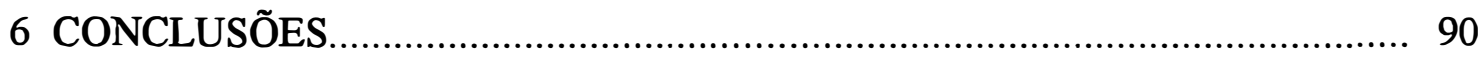

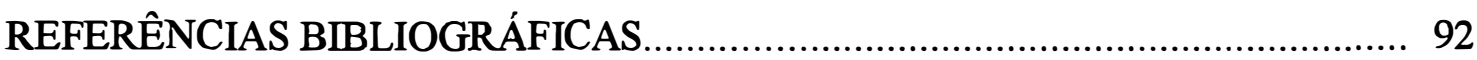




\title{
SOLUBILIDADE E DISPONIBILIDADE DO FÓSFORO DE FOSFATOS NATURAIS COM ORIGENS GEOLÓGICAS DIFERENTES
}

\author{
Autora: MÔNICA SARTORI DE CAMARGo \\ Orientador: Dr. Prof. RONALDO IVAN SILVEIRA
}

\section{RESUMO}

O estudo foi desenvolvido em casa-de-vegetação do Departamento de Ciência do Solo na Escola Superior de Agricultura "Luiz de Queiroz" e o objetivo foi avaliar o comportamento de fosfatos naturais em doses calculadas com base no fósforo solúvel, extraído por diferentes relações fosfato : extrator, quando aplicados ao solo, sobre produção de material seco e absorção de macronutrientes pelo milho.

Inicialmente, foram determinadas as solubilidades dos fosfatos Alvorada, Catalão, Patos e Arad em água, citrato neutro de amônio e ácido cítrico $2 \%$ A solubilidade em ácido cítrico a $2 \%$ foi determinada nas relações de extração : 1:50, 1:100, 1:150, 1:200, $1: 250,1: 300,1: 350$ e 1:400.

Para a avaliação do efeito dos fosfatos, foram utilizadas três doses de $P(100,150$, e $200 \mathrm{mg} \mathrm{kg}^{-1}$ ), calculadas com base nas solubilidades do fosfato nas relações de extração em ácido cítrico a $2 \%: 1: 100,1: 200$ e 1:400. Para a comparação das fontes, foram utilizados dois tratamentos adicionais: o superfosfato triplo na dose de $P$ de $100 \mathrm{mg} \mathrm{kg}^{-1}$ e uma testemunha (sem adição de fósforo).

O milho foi semeado nos vasos com capacidade de $3 \mathrm{~kg}$, contendo terra de um podzólico arenoso, após terem sido realizadas as adubações fosfatadas e com micronutrientes. Após o plantio, o desbaste foi realizado deixando-se 3 plantas por vasos. Foram feitas adubações com nitrogênio e potássio. Para verificação do efeito residual dos fosfatos, o milho foi semeado 28 dias após a primeira coleta da parte aérea do milho e 
foram realizados o desbaste e as adubações nitrogenadas e potássicas, utilizando as mesmas fontes, doses e espaços de tempo. O material seco das duas coletas foi pesado e analisado quimicamente.

O fosfato Alvorada apresentou maior solubilidade em ácido cítrico 2\% (relação 1:100), seguido do fosfato Arad, Patos e Catalão, concordando com a material seco, fósforo absorvido e índice de eficiência agronômica.

A relação de extração 1:100 (fosfato:ácido cítrico 2\%) correspondeu à maior produção de material seco do milho para os fosfatos naturais. $O$ fosfato Alvorada apresentou a maior produção de material seco, superando os demais fosfatos naturais, inclusive o superfosfato triplo.

$\mathrm{O}$ acúmulo de fósforo pelo milho e os índices de eficiência agronômica dos fosfatos corroboraram com a material seco, o que não ocorreu para os teores de fósforo absorvidos.

$\mathrm{O}$ acúmulo de nitrogênio, potássio e magnésio, nos dois plantios, foram maiores para os fosfatos Alvorada, Arad, Catalão e Patos, seguindo as solubilidades dos fosfatos em ácido cítrico (relação 1:100)

Para o fosfato Patos, a baixa solubilidade em ácido cítrico $2 \%$ (1:100) do fosfato Patos não permitiu seu efeito na disponibilidade de fósforo às plantas no plantio inicial. $\mathrm{E}$ para o fosfato Arad, ela não foi útil na determinação da disponibilidade de fósforo às plantas no seu efeito residual, sendo que a granulometria mais grosseira pode interferir no seu efeito residual.

Portanto, a utilização da solubilidade em ácido cítrico $2 \%$ (1:100) é um importante parâmetro para predizer o comportamento de fosfatos naturais de diferentes origens geológicas, avaliados pela material seco, absorção de fósforo e pelo índice de eficência agronômica, no plantio inicial para os fosfatos estudados, exceto Patos e no efeito residual, exceto para Arad. E não se deve recomendar a utilização de doses iguais para fosfatos de distintas origens, sendo importante a determinação do seu conteúdo de fósforo solúvel em ácido cítrico a $2 \%$ antes de sua utilização, pois eles têm comportamento diferente devido às diferenças na sua composição química $\mathrm{e}$ mineralógica. 


\title{
SOLUBILITY AND PHOSPHORUS AVALABILITY OF NATURAL PHOSPHATES FROM DIFFERENT GEOLOGIC ORIGINS
}

\author{
Author: MÔNICA SARTORI DE CAMARGo \\ Adviser: Prof. Dr. RONALdO IVAN SILVEIRA
}

SUMMARY

The study was carried out in glasshouse conditions at Soil Science Department of the Escola Superior de Agricultura "Luiz de Queiroz". The objective was evaluate the performance of natural phosphates applied in soil wich based on different phosphate : citric acid $2 \%$ relatioships with the parameters: dry matter production and macronutrient absorption by maize.

The chemical and granulometric composition of Alvorada, Catalão, Patos and Arad natural phosphates and their solubility in water, neutral ammonium citrate and citric acid $2 \%$ were determined. The natural phosphate and citric acid $2 \%$ relationship were evaluate for the following rates: 1:50,1:100,1:150,1:200,1:250,1:300, 1:350 and $1: 400$.

Three phosphates doses of $P$ were used: 100,150 and $200 \mathrm{mg} \mathrm{kg}^{-1}$, based on the $1: 100,1: 200$ and 1:400 rates (phosphate: citric acid $2 \%$ ) in plant experiment. Triple superphosphate at dose of $\mathrm{P} 100 \mathrm{mg} \mathrm{kg}^{-1}$ and a control treatment were also added to comparison reasons. The experiment was completely randomized with 4 replicates.

Phosphorus and micronutrients $(\mathrm{B}, \mathrm{Cu}, \mathrm{Fe}, \mathrm{Mn}, \mathrm{Zn})$ were added before the sowing of maize. Plants were growing in pots with capacite for $3 \mathrm{~kg}$ of soil that was sample in Piracicaba-SP . Nitrogen (50 and $\left.100 \mathrm{mg} \mathrm{kg}^{-1} \mathrm{~N}\right)$ and potassium $\left(100 \mathrm{mg} \mathrm{kg}^{-1}\right.$ $\mathrm{K})$ were also applied. The residual effect of phosphates was evaluate by planting maize 28 days after the first harvest of aerial part of the plants. 
The Alvorada phosphate showed best solubility in citric acid $2 \%$ at 1:100 rate, followed by Arad, Patos and Catalão phosphates. The 1:100 relation was best dry matter corroborating with citric acid 2\% (1:100) in both harvest. Both plantings showed the best performance to Alvorada phosphate compared with other sources, including triple superphosphate. Phosphorus acummulated and Index of Agronomy Efficiency (IAE) were according with dry matter. The opposite occured for phosphorus concentration.

Total nitrogen, potassium and magnesium absorption were higher for Alvorada, Arad, Catalão and Patos phosphates in according to their solubility in citric acid $2 \%$ at 1:100 rate on both planting of maize. Arad phosphate presented the best calcium and sulfur absorption by maize due to the high content of calcium and sulfur in its chemical compositon.

The utilization of citric acid $2 \%$ solubility at 1:100 rate is an important parameter to predict the efficiency of natural phosphates from different geological origins, evaluated by dry matter, phosphorus absorption and Index of Agronomy Efficiency at first planting to natural phosphates, except Patos and in residual effect, except Arad phosphate.

The recommendation of natural phosphates should not use equall quantities. The phosphorus content soluble in citric acid $2 \%(1: 100)$ must be verified because they have different efficiency due to chemical and mineralogical compositon. 


\section{INTRODUÇÃO}

Os fosfatos naturais são uma fonte alternativa na adubação fosfatada em substituição aos fosfatos acidulados, podendo ser uma das fontes mais baratas e agronomicamente efetivas sob certas condições de solo, cultura e manejo. A sua possível utilização em solos ácidos, com baixos $\mathrm{Ca}$ e $\mathrm{Mg}$ disponíveis e alta capacidade de adsorção, como também a tecnologia de produção simples, os baixos investimentos para moagem e a necessidade de energia ser um terço da consumida pelos solúveis, estão entre as vantagens de sua utilização.

Há grande variabilidade dos fosfatos naturais, entretanto, em relação aos teores de fósforo, comparado aos do superfosfato triplo como fonte de fósforo às plantas. Esta variabilidade pode ser atribuída às suas composições químicas e mineralógicas, que interferem na sua solubilidade quando aplicados ao solo.

A variação da solubilidade dos fosfatos naturais é decorrente de suas características intrínsecas, entre elas o grau de substituição isomórfica de fosfato por carbonato e à sua superficie específica que é dada pela granulometria do material utilizado. A utilização da solubilidade dos fosfatos naturais em extratores inorgânicos pode ser um critério de avaliação do seu potencial como fonte de fósforo às plantas, podendo ser usada como índice da sua reatividade. Os métodos de laboratório, entretanto, devem estar correlacionados com o valor agronômico dos fosfatos. 
No Brasil, a extração com ácido cítrico $2 \%$ é o método oficial para a avaliação da solubilidade dos fosfatos naturais. Entretanto, a utilização de doses previamente fixadas independente do conhecimento da qualidade da fonte ou baseadas unicamente no conteúdo total de fósforo, aliada à sua baixa eficiência, são problemas muito comuns do uso de fosfatos naturais. Isso tem trazido grande variação nos resultados obtidos e, até mesmo, contraditórios.

\section{HIPÓTESE:}

O comportamento dos fosfatos naturais é diferente no solo, mesmo quando são aplicadas quantidades iguais de fósforo solúvel em ácido cítrico a $2 \%$, extraídos por diferentes relações de extração (fosfato:ácido cítrico $2 \%$ ).

\section{OBJETIVOS:}

1) Avaliar o efeito de fosfatos naturais, em doses calculadas com base no fósforo solúvel, extraído por diferentes relações fosfato : extrator, quando aplicados ao solo, sobre a produção de material seco e a absorção de macronutrientes.

2) Determinar qual a relação de extração que melhor se relaciona aos resultados agronômicos, mostrando, assim, a real disponibilidade de fósforo às plantas. 


\section{REVISÃO DE LITERATURA}

\subsection{Fosfatos naturais: jazidas brasileiras e sua reatividade}

Apesar da sua abundância na natureza, os solos brasileiros são deficientes em fósforo. Tanto pela escassez, como pela baixa disponibilidade, necessitam de quantidades maiores de adubos que aquelas exigidas pelas culturas em outras regiões, sendo fundamental ressaltar o uso de melhores fontes de fósforo, em termos de disponibilidade e solubilidade, para o aumento de produtividade (Delazari, 1979). Entretanto, tratar de suas fontes e eficiência de uso é um dos pontos mais polêmicos da adubação fosfatada no Brasil pela existência de consideráveis jazidas de fosfatos naturais e a ocorrência de sensíveis aumentos no custo das fontes solúveis em água (Lopes et al., 1986).

Segundo Magalhães (1993), as jazidas de fosfatos do Brasil podem ser classificadas como jazidas sedimentares, sob forma de fosforita (Olinda e alguns estados do nordeste); jazidas sedimentares-metamórficas (Cedor do Abaeté, Patos de Minas, Quartel de São José); jazidas relacionadas com atividade magmática, sob forma de apatita (Jacupiranga, Ipanema, Juquiá em São Paulo, Tapira, Araxá, Barreiro e Salitro em Minas Gerais, Catalão em Goiás, Anitápolis em Santa Catarina); jazidas de concentração residual e enriquecimento secundário, formando as bauxitas fosforosas (Trauíra e Pirocaua, no Maranhão). 
Os principais depósitos existentes são de origem ígnea e estão, em geral, associados a processos de alteração intempérica, que apresentam complexidade acentuada, além de baixos teores de fósforo. Em todos os depósitos explorados no Brasil, os minérios correspondem ao produto de intemperismo das rochas primárias, nos quais ocorreram modificações mineralógicas significativas (exceção Jacupiranga). Assim, nos depósitos em lavra devem ser constantemente avaliadas as situações específicas decorrentes de exposições de novos tipos de minérios, cuja eventual extração pode ter reflexos sensíveis na composição de pilhas de minério, no desempenho das usinas de concentração e, consequentemente, na disponibilidade de fósforo às plantas, devido à sua variação de composição química.

Segundo Smith \& Sanchez (1982), os principais fatores que influenciam a disponibilidade de fósforo dos fosfatos naturais são: as diferenças inerentes aos fosfatos; a variação entre as culturas na sua habilidade de utilizar o fósforo dos fosfatos naturais; e as propriedades do solo, principalmente a acidez.

Quanto às diferenças inerentes entre os fosfatos, as composições químicas das apatitas refletem as condições da sua origem geoquímica (Mc Clellan \& Gremillion, 1980). Os fosfatos de origem ígnea e metamórfica, por sua estrutura cristalina de dificil intemperização, são de baixa reatividade (Khasawneh \& Doll, 1978). Já os fosfatos naturais originários dos depósitos sedimentares apresentam alto grau de substituição de $\mathrm{PO}_{4}^{-3}$ por $\mathrm{CO}_{3}^{-2}$, sendo assim mais reativos, como os do Norte da África (Argélia), Carolina do Norte, nos EUA (Lehr,1980) e Arad (Israel). Segundo Howeler \& Woodruff (1968), as rochas sedimentares possuem um pequeno grau de cristalização, sendo decompostas mais facilmente que as de origem ígnea. Nas rochas de origem ígnea, há pequena quantidade ou ausência de carbonato, resultando numa estrutura cristalina muito dura e na lenta disponibilização de fósforo.

Outro fator importante, que influencia na solubilização dos fosfatos, é a acidez do solo. Valores baixos de $\mathrm{pH}$ aumentam a dissolução por proverem $\mathrm{H}^{+}$para a acidulação dos fosfatos. Roscoe et al. (1955) estudaram a inlfuência do $\mathrm{pH}$ do meio de cultura da aveia na disponibilidade do fósforo do fosfato de rocha. $\mathrm{O}$ meio foi tratado com $\mathrm{Ca}(\mathrm{OH})_{2}$ de modo a obter uma variação de $\mathrm{pH}$ entre 4,9 e 7,4. As maiores produções com fosfato 
de rocha foram obtidas com $\mathrm{pH} 5,5$ e a elevação de $\mathrm{pH}$ causou decréscimo nas produções.

Blanco et al.(1965), em experimentos em casa-de-vegetação com trigo e soja em sucessão, observaram que as melhores reações dos fosfatos naturais foram na faixa de $\mathrm{pH}$ 5,1 a 5,3 para fosfato natural de Olinda e para os fosfatos Araxá e Alvorada, nas faixas de 4,7 a 5,0 e 4,8 e 5,3, respectivamente. Yost et al. (1976), trabalhando com Brachiaria decumbens, observaram que a calagem, aplicada juntamente com o fosfato de Araxá, diminuiu a produção de matéria seca.

Raij \& Diest (1980) estudaram a capacidade do superfosfato triplo, fosfato Alvorada, fosfato Patos, fosfato de Gafsa e fosfato de alumínio calcinado em suprir fósforo para soja em um oxissol (pH 4,9) com incubação por 3 e 75 dias. O SPT teve sua eficiência reduzida em um período de 75 dias de incubação. Isso pode ser uma evidência de que a mobilização do fosfato natural ocorra durante esse período, desde que a imobilização do fosfato dissolvido em formas não-lábeis em formas lábeis seja apropriada para ter ocorrido.

Cantarutti et al.(1981) estudaram a época de aplicação dos fosfatos naturais Patos e Araxá em relação à calagem num solo com elevado teor de alumínio trocável (Latossolo vermelho amarelo câmbico álico). Verificaram que a acidez do solo exerceu efeito solubilizador sobre os fosfatos e a maior eficiência agronômica foi verificada quando eles foram aplicados trinta dias antes do material corretivo. Viégas (1990), também, estudando o fosfato de Araxá como fonte de fósforo, verificou que sua disponibilidade às plantas foi maior quando sua aplicação e incubação foram feitas em $\mathrm{pH}$ 4,5, comparado com o $\mathrm{pH} 6,5$.

$\mathrm{O}$ aumento da disponibilidade de fósforo dos fosfatos naturais pode ser realizado pela incubação, conforme foi verificado por vários pesquisadores. Souza (1977), trabalhando com dois solos (Cambissolo latossólico eutrófico e Latossolo vermelho escuro), obteve que o aumento do tempo de incubação (90 dias) melhorou a eficiência dos fosfatos naturais, propiciando maior produção de material seco e fósforo absorvido.

De Felipo et al. (1981), também, verificaram que 40 a 90 dias de incubação foram importantes para a liberação de fósforo ao vegetal para os mesmos tipos de solos 
utilizados por Souza (1977). Concluíram que quanto maior o período de incubação, melhor é a eficiência dos fosfatos Araxá e Patos em solos menos férteis e para os fosfatos Tapira e Catalão, isso não ocorreu, devido aos compostos formados apresentarem-se mais estáveis que o original numa forma de P-não-lábil, embora tenha ocorrido a solubilização do fosfato.

Feitosa \& Bittencourt (1979), entretanto, comparando superfosfato triplo, termofosfato, fosfato de Gafsa e apatita de Araxá nas doses de $\mathrm{P}_{2} \mathrm{O}_{5}$ de 30 a $60 \mathrm{~g} \mathrm{~kg}^{-1}$, observaram que os teores de fósforo no milho para os períodos de incubação 10,30 e 120 dias tiveram pouca variação.

\subsection{Efeito dos fosfatos naturais na produção agrícola}

Quanto à comparação de fontes de fósforo, os mais diferentes trabalhos são encontrados. As diferenças encontradas nas condições experimentais como tipo de solo, fontes de fósforo, planta e manejo, entre outros fatores, são os responsáveis pela variabilidade dos resultados.

Blanco et al. (1965) estudaram o comportamento de fertilizantes fosfatados (superfosfato simples, fosfato de Olinda e Alvorada) em duas doses de $\mathrm{P}_{2} \mathrm{O}_{5}$ total $(1,5$ e 3

g vaso ${ }^{-1}$ ), em cultivos sucessivos de trigo (4 meses) e soja (4 meses). Para o efeito residual dos fosfatos, o fosfato Alvorada aumentou sua produção relativa de 90 para 100 $\%$, a apatita de Araxá aumentou de 83,9 para 90 e o SPT diminuiu para 78,8 e $80 \%$, sendo o valor 100 atribuído ao superfosfato simples.

Braga e Yahner (1968) com doses de fósforo aplicadas com base $20 \%$ de $\mathrm{P}_{2} \mathrm{O}_{5}$ solúvel para o superfosfato simples e $5 \%$ solúvel em ácido cítrico para o fosfato Araxá, em Podzólico vermelho amarelo. Verificaram não haver diferença entre as fontes e que o fosfato de Araxá equivalia ao superfosfato triplo desde que usado em dose 4 vezes maior.

Feitosa \& Raij (1975) realizaram experimentos em casa de vegetação com trigo e milho durante 8 semanas, com incubação por 60 dias antes do plantio, em dois solos (Podzólico vermelho amarelo variação Piracicaba e Latossolo vermelho escuro fase 
arenosa), utilizando a adubação com base na porcentagem de $\mathrm{P}_{2} \mathrm{O}_{5}$ total. Observaram que o superfosfato triplo e o fosfato Araxá apresentaram os menores valores, não diferindo da testemunha para o milho quando comparados com superfosfato simples, fosfato diamônio, termofosfato e hiperfosfato para os dois solos utilizados.

Borkert et al. (1978), estudando a eficiência de diversos fosfatos naturais brasileiros num Latossolo Bruno distrófico, em condições de primeiro cultivo de soja, constataram que os fosfatos Patos, Olinda e o termofosfato IPT aplicados a lanço como fosfatagem, mostraram uma eficiência comparável à do superfosfato triplo (eficiência relativa em torno de 80), principalmente com a aplicação suplementar de $\mathrm{P}_{2} \mathrm{O}_{5}$ de $100 \mathrm{~kg}$ $\mathrm{ha}^{-1}$ na forma de superfosfato triplo, nos sulcos de semeadura. Os fosfatos Araxá e Catalão foram os menos eficientes.

Mais tarde, Goepfert \& Moura (1979), avaliando a eficiência agronômica dos fosfatos de Gafsa, Rhenamia e superfosfato triplo nos níveis de $\mathrm{P}_{2} \mathrm{O}_{5}$ total de $0,60,120$, 180,240 e $480 \mathrm{~kg} \mathrm{ha}^{-1}$, não obtiveram diferença entre eles. Kluthcouski et al. (1979), também, obtiveram maior produtividade do arroz para o fosfato de Patos, seguido de termofosfato magnesiano e da fórmula 4-30-16, aplicados no sulco e a lanço, em solo com $\mathrm{pH} 5,7$ pobre em fósforo (1,8 ppm $\mathrm{P})$. Os autores atribuíram o resultado na produção de grãos quando o fosfato Patos é aplicado em grandes quantidades devido à sua lenta solubilização, o que proporciona menor fixação do elemento no solo, sendo absorvido à medida que é solubilizado e colocado à disposição da cultura.

Já Goedert \& Lobato (1980) estudaram 11 fontes de fósforo em condições de campo em Latossolo vermelho escuro, durante 4 anos. Foi feita a avaliação da eficiência agronômica desses fosfatos, utilizando-se sequência de cultivos anuais de trigo, soja e arroz. No primeiro ano, para trigo observaram que a produção de matéria seca foi maior para o fosfato Gafsa, que superou termofosfato magnesiano,termofosfato IPT, Pirocaua, Araxá e Patos (ordem decrescente).

Resultados positivos quanto ao uso de fosfatos naturais, também foram encontrados por Nakayama et al. (1985), que apresentaram resultados do estudo da eficiência dos fosfatos Patos e Gafsa com superfosfato triplo nas doses de $\mathrm{P}_{2} \mathrm{O}_{5}$ de 0 , $160,320,480$ e $640 \mathrm{~kg} \mathrm{ha}^{-1}$, aplicado a lanço no primeiro ano, usando a cultivar de soja 
Santa Rosa. No segundo ano, as parcelas foram subdivididas para a observação do efeito residual e do residual associado com manutenção. Concluíram que, independente dos sistemas usados (residual ou residual e manutenção), o fosfato de Gafsa foi tão eficiente quanto o superfosfato. Foi verificado, também, que as doses de fósforo a lanço que proporcionaram rendimento relativo de $80 \%$, aliado à utilização de adubação de manutenção de fósforo de $70 \mathrm{~kg} \mathrm{ha}^{-1}$, foram de 160,160 e $320 \mathrm{~kg} \mathrm{ha}^{-1}$, para superfosfato, Gafsa e Patos.

Mais recentemente, Coutinho et al. (1991), estudando a eficiência agronômica de fertilizantes fosfatados durante 2 anos consecutivos, em Latossolo vermelho escuro de textura média, obtiveram que o superfosfato triplo, fosfato natural de Gafsa e termofosfato apresentaram comportamento similar no solo e o fosfato Patos teve comportamento inferior. Cáceres et al. (1993), também, compararam a eficiência do superfosfato simples, multifosfato magnesiano, termofosfato, fosfato natural de Gafsa e fosfato de Araxá nas doses de $\mathrm{P}_{2} \mathrm{O}_{5}$ de 0,50 e $150 \mathrm{mg} \mathrm{kg}^{-1}$, em Latossolo vermelho álico, $\mathrm{pH} 4,2$. Verificaram que em todas as doses apenas o fosfato de Araxá foi inferior na produção de matéria seca de arroz obtida após 60 dias.

Ressaltando os aspectos negativos dos fosfatos naturais, há também vários trabalhos. Wutke et al. (1962) estudaram a disponibilidade de fósforo de fosfatos naturais em função do $\mathrm{pH}$ do solo, observando que na presença e ausência da calagem, no campo ou em vasos, o superfosfato simples obteve maior resultado comparado aos fosfatos naturais utilizados nos experimentos. Experimentos realizados por Gomes et al.(1961) e Miranda et al. (1970), também, mostraram que o superfosfato foi sempre o melhor fertilizante fosfatado para a cultura do milho comparados aos fosfatos de Olinda, hiperfosfato, fosfato da Flórida, fosfato do Morro do Serrote e de Araxá.

Feitosa \& Raij (1975) realizaram vários experimentos com trigo e milho em dois solos, nos quais foram aplicados superfosfato triplo, superfosfato simples fosfato diamônio (DAP), termofosfato, fosfato de Gafsa e apatita de Araxá visando o estudo da disponibilidade de fósforo. Os resultados mostraram que os fosfatos solúveis foram melhores que os fosfatos naturais. 
Feitosa et al. (1978) estudaram o comportamentos de nove fontes de fosfato em 4 doses de $\mathrm{P}_{2} \mathrm{O}_{5}$ total $\left(0,40,100\right.$ e $\left.200 \mathrm{mg} \mathrm{kg}^{-1}\right)$, cultivando trigo em Latossolo vermelho amarelo. Observaram que o superfosfato triplo foi melhor de todas as fontes estudadas. $\mathrm{O}$ fosfato Alvorada apresentou melhor produção que os outros fosfatos naturais (Araxá, Jacupiranga, Patos, Catalão, Abaeté, Olinda, Ipanema, Tapira), os quais não diferiram da testemunha. Os resultados positivos para Alvorada foram observados por Ramos (1982) que, avaliando a eficiência de oito fosfatos para as culturas de trigo e soja em Latossolo vermelho escuro, relatou que o fosfato Alvorada sobressaiu-se a partir do segundo ano, sendo mais eficiente que os superfosfatos. Sua melhor eficiência, segundo o mesmo, pode estar relacionada a aspectos qualitativos (como mineralogia) dos compostos fosfatados, pois em termos quantitativos não se diferencia do fosfato de Gafsa.

Efeitos melhores com a utilização de solúveis também foram mostrados por Dynia et al. (1979), que estudaram a eficiência do superfosfato triplo em comparação com Catalão, Gafsa, Patos de Minas e Pirocaua como fontes de fósforo para o trigo cultivado durante 25 dias. Concluíram que o solúvel foi mais eficiente que Gafsa e este, mais que Pirocaua, sendo Catalão e Patos ineficientes. Biasi \& Suhett (1979), também, estudando o efeito de superfosfato triplo, termofosfato magnesiano $\left(19 \% \mathrm{P}_{2} \mathrm{O}_{5}\right)$ e apatita de Araxá ( $\left.8 \% \mathrm{P}_{2} \mathrm{O}_{5}\right)$ em 5 níveis de fósforo $\left(0,100,200,300\right.$ e $\left.400 \mathrm{~kg} \mathrm{ha}^{-1}\right)$, observaram que o termofosfato e superfosfato foram superiores aos fosfatos naturais.

O Centro de Pesquisa Agropecuária do Cerrado (C.P.A.C.,1981) estudou a produção de arroz obtida com a aplicação de $200 \mathrm{~kg} \mathrm{P}_{2} \mathrm{O}_{5} \mathrm{ha}^{-1}$, a lanço. Obteve que a produção relativa dos fosfatos Arad, Rhenania, Alvorada e Patos, foi 70, 53, 36 e $17 \%$, respectivamente, em comparação com o tratamento do superfosfato triplo (100\%).

No mesmo ano, Tanaka et al. (1981), também, obtiveram o efeito de 5 níveis de fósforo $\left(\mathrm{P}_{2} \mathrm{O}_{5}\right.$ total $)$ do fosfato Patos $\left(0,870,1740,2610 \mathrm{e} 3840 \mathrm{~kg} \mathrm{ha}^{-1}\right)$ na produção de matéria seca e absorção de fósforo pelo milho em casa-de-vegetação em Latossolo roxo distrófico $(\mathrm{pH}=4,9)$. Obtiveram maior absorção de $\mathrm{P}$ proveniente do superfosfato simples que do fosfato Patos para o milho, indicando a curto prazo menos disponibilidade de $\mathrm{P}$ deste último. $\mathrm{O}$ fosfato Patos proporcionou resposta quadrática à produção de matéria seca e a produção máxima alcançada de $\mathrm{P}_{2} \mathrm{O}_{5}$ foi de $4,02 \mathrm{~g}$ vaso $^{-1}$. Todavia, a comparação 
entre médias de produção em função dos diferentes níveis de fosfato revelou que todas diferiram estatisticamente da testemunha, mas não entre si.

A respeito do efeito residual dos fosfatos naturais, afirmou ser necessário considerar as vantagens decorrentes de seu uso, pois à medida que vai sendo preenchido o reservatório de fósforo não disponível, há maior disponibilidade às plantas na solução do solo (Cavalcanti, 1974). O seu efeito residual, entretanto, depende da natureza dos fosfatos (Feitosa et al., 1978) e da quantidade aplicada no primeiro ano (Nakayama et al., 1985) e do tipo de solo utilizado (com maior ou menor capacidade tampão).

Um dos principais problemas do estudo do efeito residual de fosfatos naturais, no entanto, é a realização de experimentos de longa duração, o que tem limitado o número de trabalhos realizados. Resultados positivos de efeiciência agronômica foram encontrados em vários trabalhos.

Viégas et al. (1961) estudaram a eficiência agronômica de fosfatos naturais durante 3 anos, aplicados na dose de $100 \mathrm{~kg} \mathrm{ha}^{-1}$ baseados no teor de fósforo total dos fosfatos. Verificaram que o fosfato natural de Gafsa e de Olinda foram inferiores ao superfosfato simples e fosfato bicálcico nos primeiros dois anos, mas no terceiro ano não foram observadas diferenças entre eles.

Abrão \& Grim (1975), avaliaram o efeito residual da adubação fosfatada durante 3 anos de cultivo de trigo e 5 cortes de alfafa em oxissolo. Constataram que houve efeito dos fosfatos naturais sobre o rendimento de trigo e feno de alfafa, mas a partir do segundo ano de cultivo de trigo, diminuiu bruscamente, para após tender à estabilização.

Cordeiro et al. (1979), entretanto, observaram que o fosfato de Gafsa teve uma eficiência média de $95 \%$ em relação ao SPT no residual e quando se utilizou uma manutenção de $\mathrm{P}$ solúvel, sua eficiência foi superior ao solúvel, passando de 62 para 83 $\%$ para fosfato de Patos.

Goedert \& Lobato (1979) testaram 11 fontes de fósforo em Latossolo vermelho escuro (Haplustox) na região de cerrado. Durante 4 anos foi feita a avaliação agronômica de fosfatos utilizando-se a sequência de trigo, soja, soja, arroz como cultivos anuais. Classificaram os fosfatos estudados em 4 categorias de solubilidade: rápida (superfosfato 
triplo, fosfato de Gafsa, termofosfato magnesiano ); média (termofosfato IPT, Pirocaua, fosfato Flórida e Tenesee); lenta ( Patos, Araxá, Abaeté) ; muito lenta (Catalão).

Quanto à eficiência das rochas fosfáticas em culturas anuais, Espinoza et al. (1983), afirmou que seria de 20 a $25 \%$ do SPT no primeiro ano, aumentando até $45 \%$ após 3 ou 4 anos, requerendo além das rochas (Araxá de igual eficiência que Patos e estes, maiores que Catalão), fontes solúveis na cova.

Goedert (1983), durante 6 anos, estudaram a eficiência agronômica de fosfatos naturais em dois experimentos de campo com cultivos anuais, aplicando no início $44 \mathrm{ppm}$ de $\mathrm{P}_{2} \mathrm{O}_{5}$ total $\left(200 \mathrm{~kg} \mathrm{ha}^{-1}\right)$. Obtiveram índices de eficiência para o fosfato Patos de $84 \mathrm{a}$ 89, de $82 \%$ para Araxá e 69\% para Catalão. Goedert (1983), estudando a eficiência agronômica de fosfatos naturais em dois experimentos de campo com trigo aplicando no início $44 \mathrm{ppm}$ de $\mathrm{P}\left(200 \mathrm{~kg} \mathrm{P}_{2} \mathrm{O}_{5}\right.$ total ha $\left.{ }^{-1}\right)$, também obtiveram IEA(\%) relativa para o SPT para os fosfatos Araxá, Patos e Catalão de 23,16 e 8, porém a testemunha não diferiu de Catalão.

Goedert \& Lobato (1984), durante oito anos, avaliaram a eficiência agronômica de 11 fontes de fósforo, em uma sucessão de cultivos trigo, soja, soja, arroz, sorgo e capim-andropogon (três anos), com experimentos de campo localizado em Latossolo vermelho escuro. Com base na quantidade de fósforo extraídos pelos cultivos, foram calculados índices relativos de eficiência agronômica dos fosfatos, tendo como referência o superfosfato triplo. As fontes de fósforo podem ser relacionadas em ordem decrescente de eficiência: termosfato magnesiano, fosfato de Gafsa, fosfato da Flórida, Fosfato de Tenessee, fosfato de Pirocaua (tratamento térmico), fosfato Patos, fosfato Araxá, fosfato Abaeté e fosfato Catalão. Após o quinto cultivo, os índices foram similares para todos os fosfatos naturais, apresentando efeito residual após oito anos de cultivo. A solubilidade inicial foi lenta para as fontes nacionais.

Léon et al. (1986) avaliaram, por métodos de laboratório e através de respostas de 3 cultivos de Panicum moximum, o potencial de rochas fosfáticas nas doses de $\mathbf{P}$ de $50,100,200$ e $400 \mathrm{mg}$ vaso $^{-1}$. Os resultados mostraram que os fosfatos poderiam ser divididos em 4 grupos quanto à reatividade: alta (Bayovar, Arad), média (Huila e Pesca), baixa (Sardinata, Patos, Labatera, Araxá e Abaeté) e muito baixa (Catalão, Jacupiranga, 
Tapira). $\mathrm{O}$ aumento das doses, também, produziu aumento de matéria seca, sendo uma resposta quadrática para Catalão até 200 e Patos foi melhor que Catalão, aumentando sua produção até $400 \mathrm{mg}$ vaso $^{-1}$. O fosfato Patos superou Araxá, Abaeté, Jacupiranga, Catalão e Tapira.

Mais tarde, Goedert et al. (1990) estudando Araxá, Patos, Tapira, Catalão e Anitápolis na cultura da soja em comparação com superfosfato triplo, afirmaram que suas eficiências não aumentavam com o tempo. Bolland et al. (1990), também, avaliaram o efeito do superfosfato e fosfato natural aplicado em 10 anos (um experimento) e 4 anos em diferentes solos lateríticos do sudoeste da Austrália e com diversas plantas. Obtiveram aumento do efeito residual do fosfato (70 a 80\%) após 11 colheitas.

Braga et al. (1991) compararam 9 fosfatos, em Latossolo vermelho escuro textura média, avaliando 4 cultivos de soja na dose de $\mathrm{P}_{2} \mathrm{O}_{5}$ total de $400 \mathrm{~kg} \mathrm{ha}^{-1}$. Obtiveram, no primeiro ciclo de produção, IEA(\%) de 28 para Catalão e de 8 para Patos e nos demais ciclos, Patos $(30,22,0$ e 15$)$ superou Catalão $(0,8,0$ e 9$)$.

Koter et al. (1992) estudou o efeito da aplicação de fertilizantes fosfatados todo ano, na forma de superfosfato, ou aplicado a cada 2 anos ou 4 anos, na forma de superfosfato, silicofosfato e fosfato natural na produção de culturas em rotação. Comparado com aplicação anual de superfosfato, houve aumento de produção de grãos quando o superfosfato e silicofosfato foram aplicados a cada 2 ou 4 anos, tendo-se resultados semelhantes quando os fosfatos naturais foram usados neste período.

A importância dos estudos de comparação de fosfatos está na maximização da sua eficiência de acordo com as condições de solo, clima, cultura e manejo empregados. É necessário, no entanto, os estudos sobre a avaliação da solubilidade das fontes e disponilidade de fósforo às plantas. 


\subsection{Solubilidade dos fosfatos naturais: métodos de avaliação e sua correlação com a produtividade das culturas.}

Os estudos sobre os fertilizantes fosfatados incluem a verificação do grau de eficiência de cada fosfato para as produções agrícolas. Uma das formas largamente empregadas é através do uso de solventes químicos que determinam o seu grau de solubilidade.

Sauchelli (1965) relata que qualquer método químico de laboratório para determinar o valor fertilizante de um fosfato é um processo empírico. Sua utilidade para avaliar a disponibilidade de fósforo no solo depende do grau de correlação entre os resultados de laboratório e a resposta da planta à aplicação de fosfatos (Braithwaite et al.,1992).

A avaliação do fósforo contido nos fertilizantes, pode ser feita segundo o teor total, teor solúvel em água, citrato neutro de amônio, ácido cítrico a $2 \%$, ácido fórmico a $2 \%$ e pelo índice de solubilidade absoluta em citrato (ACS).

$\mathrm{O}$ teor total abrange as diferentes formas de fósforo existente no fosfato, sem fornecer a quantidade de cada uma delas, indicando a sua riqueza potencial (Catani \& Nascimento, 1952). Não há possibilidade, no entanto, de avaliar a disponibilidade de fósforo através do teor total de fósforo para os vegetais (Catani, 1970 ; Malavolta et al., 1976). Já o teor solúvel em água representa a forma monocálcica nos fosfatos de cálcio e o teor solúvel em solução neutra de citrato de amônio indica a forma de fosfato bicálcico dos fertilizantes que receberam um tratamento ácido durante a fabricação (Catani \& Nascimento, 1952).

O teor solúvel em ácido cítrico $2 \%$ pode indicar maior ou menor rigidez da rede cristalina do fosfato, auxiliando na investigação do tipo de fosfato (Korndörfer, 1978). No Brasil, a extração em ácido cítrico a $2 \%$ vinha sendo utilizada na relação 1:100 (sólido:ácido cítrico $2 \%$ ), para determinar a solubilidade do fósforo dos fosfatos natural até o ano de 1961, sendo alterada para a relação 1:300 até 1975. Atualmente, a legislação brasileira sobre fertilizantes adotou a relação 1:100 para determinar a disponibilidade de fósforo dos fosfatos naturais. (Brasil, 1983). 
Segundo Catani (1947), já em 1894, Dyer propôs o ácido cítrico a $1 \%$ como solução extratora de fosfatos, admitindo que sua acidez era próxima a das radicelas das plantas, no fenômeno de nutrição mineral. Esse modo de extrair e suas variações têm sido mais usados não só na extração de fosfatos como qualquer outro nutriente. No caso particular de fosfatos, essa extração com ácido cítrico a $0,5,1$ e $2 \%$, encontrou na escola alemã franca aceitação, tanto que os trabalhos de Lemmerman em 1923 e de seus colaboradores são clássicos .

A solução de ácido cítrico a $2 \%$ foi proposta por Wagner, em 1899, para avaliar a disponibilidade de fósforo em escórias básicas. A descrição detalhada da técnica só foi realizada em 1903 por Wagner e seus colaboradores (Ponchio, 1978).

Catani \& Nascimento (1952) estudaram a solubilidade de nove tipos de fosfatos em solução de ácido cítrico $2 \%$ e em várias relações, concluindo que esta solução permite estabelecer uma diferença entre os diferentes tipos de fosfato. Catani et al. (1956) estudaram a solubilidade de 29 tipos de fosfatos na solução de ácido cítrico a $2 \%$, nas relações 1:100 e 1:200 e na solução de citrato neutro de amônio. A classificação para os fertilizantes fosfatados foi indicada baseada na solubilidade em ácido cítrico $2 \%$, pois o citrato neutro de amônio não permitiu distinguir os diferentes tipos de rocha fosfatada.

Brasil Sobrinho et al. (1965) observaram que os diferentes fosfatos aumentam sua solubilidade quando a razão fertilizante : ácido cítrico $2 \%$ varia de 1:100 até 1:1000. Os fosfatos mais solúves atingiram a mais alta solubilidade na relação 1:100, enquanto que os de média solubilidade a 1:400 e os menos solúveis ainda continuavam a subir até a relação 1:1000.

Ponchio (1978) estudou a solubilidade de rochas fosfatadas brasileiras em vários extratores químicos e diferentes condições de extração, concluindo que a diminuição da relação entre peso do material fosfatado e volume da solução extratora causava aumento na solubilidade dos materiais, principalmente para fosfatos de origem sedimentar. Os fosfatos de Olinda, Patos, Abaeté, Alvorada e Araxá mostraram razoável solubilidade e, aparentemente, úteis à aplicação.

Há vários estudos sobre a correlação entre métodos de laboratório para avaliação de disponibilidade de fósforo no solo e sua correlação com a resposta das plantas. Caro 
\& Hilll (1956) correlacionaram a produção de alfafa com vários critérios de laboratório e obtiveram altas correlações para o teor de carbonato ligado ao fósforo e à solubilidade em ácido cítrico $2 \%$.

Armiger \& Fried (1957),também, encontraram estreita correlação entre solubilidade dos fosfatos em ácido cítrico $2 \%$ e citrato de amônio e o crescimento de alfafa e trigo.

Finalmente, Oliveira et al. (1984), avaliando a eficiência agronômica, dos fosfatos Araxá, Catalão, Alvorada em duas doses de $\mathrm{P}_{2} \mathrm{O}_{5}$ total (100 e $400 \mathrm{~kg} \mathrm{ha}^{-1}$ ) encontraram estreita relação entre a eficiência relativa dos fosfatos naturais e sua solubilidade em ácido cítrico 2 \% (relação 1:100), sendo este um parâmetro satisfatório para a comparação de fosfatos naturais. 


\section{MATERIAL E MÉTODOS}

\subsection{Localização do experimento}

O experimento foi conduzido em casa-de-vegetação, pertencente ao Departamento de Ciência do Solo da Escola Superior de Agricultura "Luiz de Queiroz", nas coordenadas geográficas de $22^{\circ} 42^{\prime} 30^{\prime \prime} \mathrm{LS}$ e $47^{\circ} 38^{\prime} 00^{\prime \prime} \mathrm{LW}$, município de Piracicaba, estado de São Paulo.

\subsection{Fosfatos naturais}

Os fosfatos naturais utilizados foram:

a) Alvorada : jazida de origem ígnea-residual ${ }^{1}$, localizada no município de Registro (SP).

b)Catalão : jazida de origem ígnea, localizada no município de Catalão (GO).

c)Patos de Minas: jazida sedimentar, localizada no município de Patos de Minas (MG).

d)Arad: é o fosfato encontrado no comércio de fertilizantes com o nome de fosfato de Arad, tendo jazida de origem sedimentar, localizada em Israel.

Tabela 1 Composição química dos fosfatos naturais.

\begin{tabular}{|c|c|c|c|c|c|c|c|c|}
\hline \multirow[t]{2}{*}{ Fosfato } & $\mathbf{K}^{*}$ & $\mathbf{C a}$ & $\mathbf{M g}$ & $\mathbf{S}$ & $\mathbf{F e}$ & Mn & $\mathbf{C u}$ & $\mathbf{Z n}$ \\
\hline & \multicolumn{8}{|c|}{$\mathrm{g} \mathrm{kg}^{-1}$} \\
\hline Alvorada & 0,08 & 353,80 & 1,50 & 3,00 & 49,30 & 6,30 & 0,10 & 0,10 \\
\hline Catalão & 0,08 & 328,00 & 1,30 & 5,50 & 41,80 & 1,70 & 0,10 & 0,20 \\
\hline Patos & 0,25 & 267,80 & 1,50 & 3,40 & 14,80 & 0,70 & 0,10 & 0,10 \\
\hline Arad & 0,17 & 387,00 & 2,00 & 8,70 & 0,80 & 0,10 & 0,10 & 0,50 \\
\hline
\end{tabular}

* Extraído em água; os demais, teor total.

\footnotetext{
${ }^{1}$ Comunicação pessoal segundo o fabricante.
} 
Tabela 2 Composição granulométrica dos fosfatos

\begin{tabular}{|c|c|c|c|c|c|}
\hline \multirow[t]{2}{*}{ Fosfatos } & $\begin{array}{r}\text { ABNT } 50 \\
(0,297 \mathrm{~mm})\end{array}$ & $\begin{array}{r}\text { ABNT 80 } \\
(\mathbf{0 , 0 7 0} \mathrm{mm})\end{array}$ & $\begin{array}{r}<\text { ABNT 150 } \\
(0,041 \text { mm })\end{array}$ & $\begin{array}{r}\text { ABNT } 200 \\
(0,029 \text { mm })\end{array}$ & $<$ ABNT 200 \\
\hline & \multicolumn{5}{|c|}{$\mathrm{g} \mathrm{kg}^{-1}$} \\
\hline Alvorada & ---------- & 5,50 & 103,50 & 262,50 & 625,50 \\
\hline Catalão & & 2,50 & 25,30 & 40,00 & 932,20 \\
\hline Patos & 5,80 & 12,50 & 687,40 & 113,10 & 181,80 \\
\hline Arad & 340,00 & 320,00 & 213,50 & 61,20 & 65,30 \\
\hline
\end{tabular}

\subsubsection{Determinação da solubilidade}

Foram determinadas as solubilidades em água, citrato neutro de amônio, e $\mathrm{HCl}$ $1+1$ (fósforo total) e ácido cítrico a $2 \%$ dos fosfatos naturais segundo os procedimentos da A.O.A.C. (1970) e adotado pela legislação brasileira sobre inspeção e fiscalização da produção e comércio de fertilizantes, corretivos e inoculantes (Brasil, 1983).

Para determinação do fósforo solúvel em ácido cítrico $2 \%$, foi utilizado o método vanado molibdico. Foram utilizadas as seguintes relações de extração: 1:50, 1:100, 1:150, $1: 200,1: 250,1: 300,1: 350$ e 1:400. Para cada relação de extração foi utilizado $1 \mathrm{~g}$ de fosfato natural e quantidade de ácido cítrico $2 \%(\mathrm{ml})$ para obtenção da relação desejada.

Após a agitação em agitador tipo Wagner por 30 minutos de agitação, o extrato foi filtrado e $2 \mathrm{ml}$ foram passados para balão volumétrico de $100 \mathrm{ml}$, ao qual juntou-se 50 $\mathrm{ml}$ de água destilada, $20 \mathrm{ml}$ de vanado molibdico e completou-se o volume. Depois de uma agitação para homogeneização, deixou-se em repouso por 20 minutos e foram realizadas as leituras no espectrofotômetro com filtro de $420 \mu \mathrm{m}$. A partir das leituras, as quantidades de fósforo solúvel em ácido cítrico $2 \%$ foram calculadas utilizando a reta padrão em ácido cítrico a $2 \%$. 


\subsection{Solo}

O solo utilizado, classificado como grande grupo podzólico, série Cruz Alta, foi coletado no município de Piracicaba, estado de São Paulo (Ranzani,1966). As amostras de solo foram coletadas à profundidade de 0 a $20 \mathrm{~cm}$, secas ao ar, passadas em peneira 2 mm de abertura de malha, homogeneizadas e depositadas em vasos com capacidade para $3 \mathrm{~kg}$ de terra.

A análise química do solo para fins de fertilidade foi realizada segundo a metodologia usada pelo Instituto Agronômico de Campinas (tabela 3). $\mathrm{O} \mathrm{pH}$ do solo foi determinado potenciometricamente em suspensão de 1:2,5 (solo : $\mathrm{CaCl}_{2}$ 0,01M). A determinação da matéria orgânica foi realizada pelo método colorimétrico e o fósforo, potássio, cálcio e magnésio, extraídos com resina trocadora de íons e, posteriormente, determinados no colorímetro, fotômetro de chama, respectivamente (RAIJ et al., 1987).

A análise fisica do solo é apresentada na tabela 4 e foi feita, segundo o método de Bouyoucos (Khiel, 1979).

Tabela 3 Características químicas do solo utilizado no experimento

\begin{tabular}{|c|c|c|c|c|c|c|c|c|}
\hline pH & m.o.* & $\mathbf{K}$ & $\mathbf{C a}$ & Mg & AI & $\mathbf{H}+\mathbf{A l}$ & SB & $\mathbf{T}$ \\
\hline $\mathrm{CaCl}_{2}$ & $\mathrm{~g} \mathrm{dm}^{-3}$ & \multicolumn{7}{|c|}{$\mathrm{mmol}_{\mathrm{c}} \mathrm{dm}^{-3}$} \\
\hline 3,9 & 14 & 0,08 & 0,6 & 0,1 & 0,9 & 4,7 & 0,8 & 5,5 \\
\hline $\mathbf{P}$ & S-S04 & B & $\mathbf{C u}$ & $\mathbf{F e}$ & Mn & $\mathbf{Z n}$ & $\mathbf{N a}$ & $\begin{array}{ll}\mathbf{V} & \mathbf{m}\end{array}$ \\
\hline \multicolumn{2}{|c|}{$\mathrm{mg} \mathrm{dm}^{-3}$} & \multicolumn{6}{|c|}{$\mathrm{mg} \mathrm{kg}^{-1}$} & $\%$ \\
\hline 4 & 20,08 & 0,22 & 0,66 & 97 & 8,72 & 16,28 & 4,6 & $\begin{array}{ll}53 \\
53\end{array}$ \\
\hline
\end{tabular}

Tabela 4 Características granulométricas do solo utilizado no experimento

\begin{tabular}{cccc}
\hline Areia & Silte & Argila & Classe de Textura \\
\cline { 1 - 2 } $\mathbf{g ~ k g}^{-1}$ & & \\
\hline 860 & 20 & 120 & Arenosa \\
\hline
\end{tabular}




\section{4 Tratamentos (Adubação)}

Para a avaliação do efeito dos fosfatos nos dois plantios consecutivos de milho, foram utilizadas 3 doses de $P\left(100,150\right.$ e $\left.200 \mathrm{mg} \mathrm{kg}^{-1}\right)$, calculadas com base nas solubilidades dos fosfatos $\left(\mathrm{g} \mathrm{ml}^{-1}\right)$ em ácido cítrico a $2 \%$, máxima do experimento (1:400), intermediária (1:200) e padrão (1:100). Para a comparação das fontes, foram utilizados dois tratamentos adicionais: o superfosfato triplo na dose de $\mathrm{P}$ de $100 \mathrm{mg} \mathrm{kg}^{-1}$, calculada com base no contéudo de fósforo total, e uma testemunha (sem adição de fósforo). Os tratamentos encontram-se na tabela 5.

\subsection{Planta}

A planta utilizada para a avaliação da produção de material seco e a absorção de nutrientes dos diferentes tratamentos foi o milho (Zea mays L.) híbrido simples modificado Zeneca 8501 devido à sua homogeneidade de produção comparado ao híbrido duplo. 
Tabela 5. Quantidades dos fosfatos utilizados no experimento

\begin{tabular}{|c|c|c|c|c|}
\hline \multirow[t]{2}{*}{$\mathbf{N}^{\mathbf{o}}$} & \multicolumn{3}{|c|}{ Tratamento } & \multirow{2}{*}{$\begin{array}{l}\text { Quantidade de } \\
\text { fosfato } \\
\text { (g vaso }^{-1} \text { ) }\end{array}$} \\
\hline & Fosfato & Relação (fosfato:ácido cítrico $2 \%$ ) & Dose de P (mg kg $\left.{ }^{-1}\right)$ & \\
\hline 1 & Alvorada & $1: 100$ & 100 & 8,00 \\
\hline 2 & & $1: 100$ & 150 & 12,00 \\
\hline 3 & & $1: 100$ & 200 & 16,00 \\
\hline 4 & & $1: 200$ & 100 & 5,58 \\
\hline 5 & & $1: 200$ & 150 & 8,37 \\
\hline 6 & & $1: 200$ & 200 & 11,16 \\
\hline 7 & & $1: 400$ & 100 & 3,70 \\
\hline 8 & & $1: 400$ & 150 & 5,55 \\
\hline 9 & & $1: 400$ & 200 & 7,40 \\
\hline 10 & Catalão & $1: 100$ & 100 & 20,98 \\
\hline 11 & & $1: 100$ & 150 & 31,47 \\
\hline 12 & & $1: 100$ & 200 & 41,97 \\
\hline 13 & & $1: 200$ & 100 & 9,70 \\
\hline 14 & & $1: 200$ & 150 & 14,56 \\
\hline 15 & & $1: 200$ & 200 & 19,41 \\
\hline 16 & & $1: 400$ & 100 & 6,74 \\
\hline 17 & & $1: 400$ & 150 & 10,11 \\
\hline 18 & & $1: 400$ & 200 & 13,48 \\
\hline 19 & Patos & $1: 100$ & 100 & 16,00 \\
\hline 20 & & $1: 100$ & 150 & 24,00 \\
\hline 21 & & $1: 100$ & 200 & 32,00 \\
\hline 22 & & $1: 200$ & 100 & 12,60 \\
\hline 23 & & $1: 200$ & 150 & 18,90 \\
\hline 24 & & $1: 200$ & 200 & 25,21 \\
\hline 25 & & $1: 400$ & 100 & 8,02 \\
\hline 26 & & $1: 400$ & 150 & 12,03 \\
\hline 27 & & $1: 400$ & 200 & 16,04 \\
\hline 28 & Arad & $1: 100$ & 100 & 8,35 \\
\hline 29 & & $1: 100$ & 150 & 12,53 \\
\hline 30 & & $1: 100$ & 200 & 16,70 \\
\hline 31 & & $1: 200$ & 100 & 4,62 \\
\hline 32 & & $1: 200$ & 150 & 6,93 \\
\hline 33 & & $1: 200$ & 200 & 9,24 \\
\hline 34 & & $1: 400$ & 100 & 3,09 \\
\hline 35 & & $1: 400$ & 150 & 4,63 \\
\hline 36 & & $1: 400$ & 200 & 6,17 \\
\hline 37 & SPT & $1: 100$ & 100 & 10,30 \\
\hline 38 & Testemunha & -..-- & .... & ... \\
\hline
\end{tabular}




\subsection{Instalação e condução do experimento}

Inicialmente, as amostras de solo foram pesadas $(3 \mathrm{~kg})$ e transferidas para sacos plásticos. Foram realizadas a adubação com fosfatos e, posteriormente, com micronutrientes. A homogeneização das amostras correspondentes a cada tratamento foi feita por agitação manual dos sacos pláticos. Após isso, as amostras foram colocadas nos vasos. As quantidades e fontes de micronutrientes utilizadas estão apresentadas na tabela 6.

O primeiro plantio foi realizado em 19 de outubro de 1996, utilizando-se 10 sementes por vaso na profundidade de $3 \mathrm{~cm}$. Aos 10 dias após o plantio, procedeu-se o desbaste, deixando-se 3 plantas por vaso, sendo realizadas a adubação nitrogenada na dose de $\mathrm{N}$ de $50 \mathrm{mg} \mathrm{kg}^{-1}$ e potássica na dose de $\mathrm{K}$ de $100 \mathrm{mg} \mathrm{kg}^{-1} \mathrm{e}$ aos 38 dias após o plantio, foi realizada a segunda adubação nitrogenada $\left(100 \mathrm{mg} \mathrm{kg}^{-1}\right)$. As fontes de nitrogênio e potássio utilizadas foram o nitrato de amônio $\left(\mathrm{NH}_{4} \mathrm{NO}_{3}\right)$ e o cloreto de potássio $(\mathrm{KCl})$.

A colheita da parte área das plantas, ocorreu aos 51 dias após o plantio. $\mathrm{O}$ material foi colocado em sacos de papel, submetendo-no à secagem em estufa de circulação forçada com temperatura média de $60^{\circ} \mathrm{C}$ até atingir peso constante. $\mathrm{O}$ material seco foi pesado e em seguida, levado para o moinho tipo Willey, para o procedimento da análise química dos nutrientes absorvidos pelo milho.

Para a verificação do efeito residual dos fosfatos, foi feito um segundo plantio de milho, 28 dias após a primeira colheita, no dia 7 de janeiro de 1997. Aos 10 dias após o plantio, procedeu-se o desbaste, deixando-se 3 plantas por vaso. Foram realizadas as adubações nitrogenadas e potássica utilizando as mesmas fontes, doses e espaço de tempo. A colheita ocorreu 51 dias após o plantio.

Tabela 6. Quantidades dos micronutrientes utilizados.

\begin{tabular}{lcc}
\hline Micronutriente & Concentração $\left(\mathrm{mg} \mathrm{kg}^{-1}\right)$ & Fonte \\
\hline Ferro & 10 & $\mathrm{FeSO}_{4} \cdot 7 \mathrm{H}_{2} \mathrm{O}$ \\
Manganês & 10 & $\mathrm{MnSO}_{4} \cdot \mathrm{H}_{2} \mathrm{O}$ \\
Zinco & 10 & $\mathrm{ZnSO}_{4} \cdot 7 \mathrm{H}_{2} \mathrm{O}$ \\
Cobre & 5 & $\mathrm{CuSO}_{4} \cdot 5 \mathrm{H}_{2} \mathrm{O}$ \\
Boro & 5 & $\mathrm{H}_{3} \mathrm{BO}_{3}$ \\
Molibdênio & 1 & $\mathrm{NaMoO}_{4} \cdot 4 \mathrm{H}_{2} \mathrm{O}$ \\
\hline
\end{tabular}




\subsection{Análise química dos macronutrientes absorvidos pelas plantas}

Foram realizadas analíses químicas para determinação dos teores de nutrientes presentes no material seco pelos métodos da digestão sulfúrica e nítrico-perclórica (Malavolta et al., 1989; Sarruge \& Haag, 1974).

O teor de nitrogênio total foi determinado pela digestão sulfúrica, destilação e titulação. E os teores totais de fósforo, cálcio, magnésio, potássio e enxofre foram extraídos pela digestão nítrico-perclórica. No extrato obtido, foram quantificados o fósforo total pelo método fotocolorimétrico de molibdato vanadato, cálcio, magnésio e potássio por espectrofotometria de absorção atômica, e enxofre por turbidimetria do sulfato de bário e determinado por fotocolorimetria.

\subsection{Parâmetros avaliados}

As variáveis resposta avaliadas foram a produção de material seco, concentração e quantidade de macronutrientes absorvida. Para determinar $o$ índice de eficiência agronômica, foi utilizada a produção de material seco. Ele pode ser expresso:

$$
\mathbb{E A}=\frac{\mathrm{mst}-\mathrm{t}}{\mathrm{mspt}-\mathrm{t}} \times 100
$$

onde: $\mathrm{mst}=$ material seco produzido com o tratamento $\mathbf{t}=$ material seco produzido no tratamento testemunha $\mathrm{mspt}=$ material seco produzido com o superfosfato triplo 


\subsection{Delineamento experimental}

O delineamento experimental utilizado foi em blocos inteiramente casualizados em esquema fatorial ( $4 \times 3 \times 3$ ). Foram utilizados 4 fosfatos ( Alvorada, Catalão, Patos e Arad) em três doses de $P\left(100,150\right.$ e $\left.200 \mathrm{mg} \mathrm{kg}^{-1}\right)$, calculadas com base em 3 relações de extração de fósforo em ácido cítrico $2 \%\left(\mathrm{~g} \mathrm{ml}^{-1}\right): 1: 100,1: 200$ e 1:400. O superfosfato triplo na dose de $\mathrm{P}$ de $100 \mathrm{mg} \mathrm{kg}^{-1} \mathrm{e}$ o tratamento controle (testemunha), foram usados para o cálculo do índice de eficiência agronômica dos fosfatos naturais. Para cada tratamento foram feitas 4 repetições.

\subsection{Análise estatística}

Foram realizadas análises de variância, regressão e teste de médias para as variáveis resposta, utilizando-se o programa Statistical Analysis System (SAS).

Os resultados foram submetidos à análise de variância (teste $\mathrm{F}$ ) de acordo com o delineamento proposto. Os resultados das interações triplas significativas foram decompostos em regressões até $2^{\circ}$ grau para cada fosfato. Se não houve efeito da interação tripla, foi feita a decomposição da interação dupla. Quando ocorreu apenas efeito dos fatores simples, os tratamentos foram comparados através dos testes de médias Tukey ou Duncan (Gomes, 1990). 


\section{RESULTADOS E DISCUSSÃO}

\subsection{Solubilidade dos fosfatos naturais em solução de ácido cítrico a $2 \%$.}

Os conteúdos de fósforo total, de fósforo solúvel em água e em citrato neutro de amônio dos fosfatos naturais encontram-se na tabela 7. Os resultados obtidos com a solução de ácido cítrico a $2 \%$ e as porcentagens de $\mathrm{P}$ solubilizado em função do teor total estão nas tabelas 8 e 9 .

Os fosfatos naturais têm solubilidade em água e em ácidos minerais variada, demonstrando suas características próprias e o seu comportamento agronômico diferente, de acordo com a cultura e tipo de solo. Quanto aos fosfatos mais solúveis em água, citrato de amônio e ácido cítrico, eles são os mais assimiláveis pelas plantas, mas não se pode agrupá-los sob o mesmo ponto de vista químico e agronômico (Brasil Sobrinho et al., 1965).

Quanto à solubilidade em $\mathrm{HCl}(1+1)$, o fosfato Catalão possui maior quantidade de fósforo total $\left(170,60 \mathrm{~g} \mathrm{~kg}^{-1}\right)$ que os fosfatos de Patos $(164,20)$, Alvorada $(159,60)$ e Arad $(110,90)$. Entretanto, o teor de fósforo total não possibilita a avaliação da disponibilidade de fósforo dos fosfatos naturais às plantas, pois ele solubiliza todas as formas de fósforo presentes no fosfato (Catani, 1970 ; Malavolta et al.,1976).

A solubilidade em água dos fosfatos naturais é muito baixa, conforme o esperado, devido a água somente extrair o fosfato monocálcico (Sauchelli, 1965). 
A solubilidade em citrato neutro de amônio foi menor que em ácido cítrico $2 \%$. A tendência de solubilidade (Catalão $>$ Alvorada $>$ Patos $>$ Arad) não concorda com os resultados de fósforo total, sendo os valores encontrados menores que os encontrados com a utilização da solução de ácido cítrico $2 \%$. Isso ocorreu devido à solução de citrato neutro formar complexos mais intensamente ligados com alumínio e ferro que com o cálcio, o qual predomina nas fluorapatitas estudadas (Ponchio, 1978).

Tabela 7. Quantidades de $P\left(\mathrm{~g} \mathrm{~kg}^{-1}\right)$ total, solúveis em água e em citrato neutro de amônio (CNA). Médias de 4 repetições.

\begin{tabular}{llcc}
\hline \multicolumn{1}{c}{ Fertilizantes } & P total & P em água & P em CNA \\
\cline { 2 - 4 } & & P $\left(\mathrm{g} \mathrm{kg}^{-1}\right)$ & \\
\hline Fosfato Alvorada & 159,60 & 0,40 & 14,93 \\
Fosfato Catalão & 170,60 & 0,17 & 17,42 \\
Fosfato Patos & 164,20 & 0,26 & 6,03 \\
Fosfato Arad & 110,90 & 0,35 & 5,24 \\
\hline
\end{tabular}

A solubilidade em ácido cítrico $2 \%$ permite distinguir os diferentes tipos de rocha fosfatada, o que não é possível através do teor total, da solubilidade em água ou em citrato neutro de amônio (Catani e Nascimento, 1952). A solubilidade em ácido cítrico $2 \%$ foi proposta por Wagner em 1899 e representa a quantidade de fósforo que as plantas conseguem absorver (Jacob \& Hill ${ }^{2}$, citados por Ponchio (1978), que é diferente dos resultados de fósforo total.

$\mathrm{Na}$ relação 1:100, o fosfato Alvorada apresentou as maiores quantidades de fósforo solúvel em ácido cítrico a $2 \%$ comparada a apresentada pelos fosfatos Alvorada, Patos e Catalão. A partir da relação 1:150, o fosfato Arad superou os fosfatos Alvorada, Catalão e Patos. A maior ou menor solubilidade em ácido cítrico a $2 \%$ não pode ser justificada apenas pela origem do fosfato, mas também por sua estrutura cristalográfica (determinada por difração de Raio $\mathrm{X}$ ) e composição química. Os fosfatos de origens sedimentar e ígnea-residual (Arad e Alvorada) foram os que apresentaram maior

2 JACOB;K.D.; HILL, W.L. Laboratory evaluation of phosphate fertilizers. In: PIERRE, W.H.; NORMAN, A.G. Soil and fertilizer phosphorus in crop nutrition. New York: Academic Press, 1953. p. 299-35. 
solubilidade. Apesar da sua origem sedimentar, o fosfato Patos mostrou a menor solubilidade em ácido cítrico a $2 \%$, o que pode ser resultado da variação da sua composição química, pois as jazidas apresentam variabilidade. A curva de solubilidade em ácido cítrico a $2 \%$ é apresentada na figura 1 .

A solubilidade do fosfato Arad aumentou a partir da relação adubo:ácido de 1:50, em que $16,22 \%$ do fósforo total é solúvel até a relação 1:400, em que 87,63 \% solubilizou-se. $\mathrm{O}$ fosfato Arad foi seguido pelo fosfato Alvorada, que também teve solubilidade aumentada passando de $15,13 \%$ do $\mathrm{P}$ total solúvel para $50,74 \%$. Os fosfatos Catalão e Patos foram os adubos menos solúveis, tendo curvas de solubilidades em ácido cítrico $2 \%$ em função do teor total bastante semelhantes.

A porcentagem de solubilidade em ácido cítrico em relação ao fósforo total seguiu a mesma tendência observada em ácido cítrico, sendo obtidos resultados maiores para Arad, seguido de Alvorada, Catalão e Patos (Figura 2). Entretanto, há uma maior diferença entre os resultados do fosfato Arad e Alvorada, o qual foi inferior, diferente do ocorrido com a solubilidade em ácido cítrico. Já os fosfatos Catalão e Patos, continuaram com a mesma tendência, podendo ser agrupados, sob o ponto de vista químico, em um mesmo grupo de solubilidade e porcentagem do total, solúvel em ácido cítrico $2 \%$.

Tabela 8. Quantidade de $P\left(\mathrm{~g} \mathrm{~kg}^{-1}\right)$ solubilizada pela solução de ácido cítrico a $2 \%$ (média de 4 repeticões).

\begin{tabular}{|c|c|c|c|c|}
\hline \multirow{2}{*}{$\begin{array}{l}\text { Volume da solução } \\
\text { de ácido cítrico } 2 \%(\mathrm{ml})\end{array}$} & Alvorada & Catalão & Patos & Arad \\
\hline & \multicolumn{4}{|c|}{$\mathrm{P}\left(\mathrm{g} \mathrm{kg}^{-1}\right)$} \\
\hline 50 & 24,15 & 9,28 & 7,15 & 17,99 \\
\hline 100 & 37,48 & 14,30 & 18,74 & 35,92 \\
\hline 150 & 43,80 & 22,51 & 20,31 & 50,97 \\
\hline 200 & 53,80 & 30,92 & 23,80 & 64,94 \\
\hline 250 & 63,58 & 34,76 & 28,59 & 77,65 \\
\hline 300 & 69,08 & 38,48 & 32,22 & 85,34 \\
\hline 350 & 76,58 & 42,21 & 37,07 & 95,46 \\
\hline 400 & 81,00 & 44,52 & 37,41 & 97,20 \\
\hline
\end{tabular}


Tabela 9. Porcentagem de $P$ solubilizada pela solução de ácido cítrico a $2 \%$, em função do teor total.

\begin{tabular}{ccccc}
\hline $\begin{array}{c}\text { Volume da solução de } \\
\text { ácido cítrico } \%(\mathrm{ml})\end{array}$ & Alvorada & Catalão & Patos & Arad \\
\hline 50 & 15,126 & 5,438 & 4,354 & 16,220 \\
100 & 23,479 & 8,382 & 11,415 & 32,386 \\
150 & 27,434 & 13,198 & 12,370 & 45,957 \\
200 & 33,698 & 18,126 & 14,497 & 58,547 \\
250 & 39,825 & 20,379 & 17,415 & 70,008 \\
300 & 43,271 & 22,560 & 19,625 & 76,945 \\
350 & 47,968 & 24,749 & 22,580 & 86,063 \\
400 & 50,739 & 26,101 & 22,787 & 87,630 \\
\hline
\end{tabular}

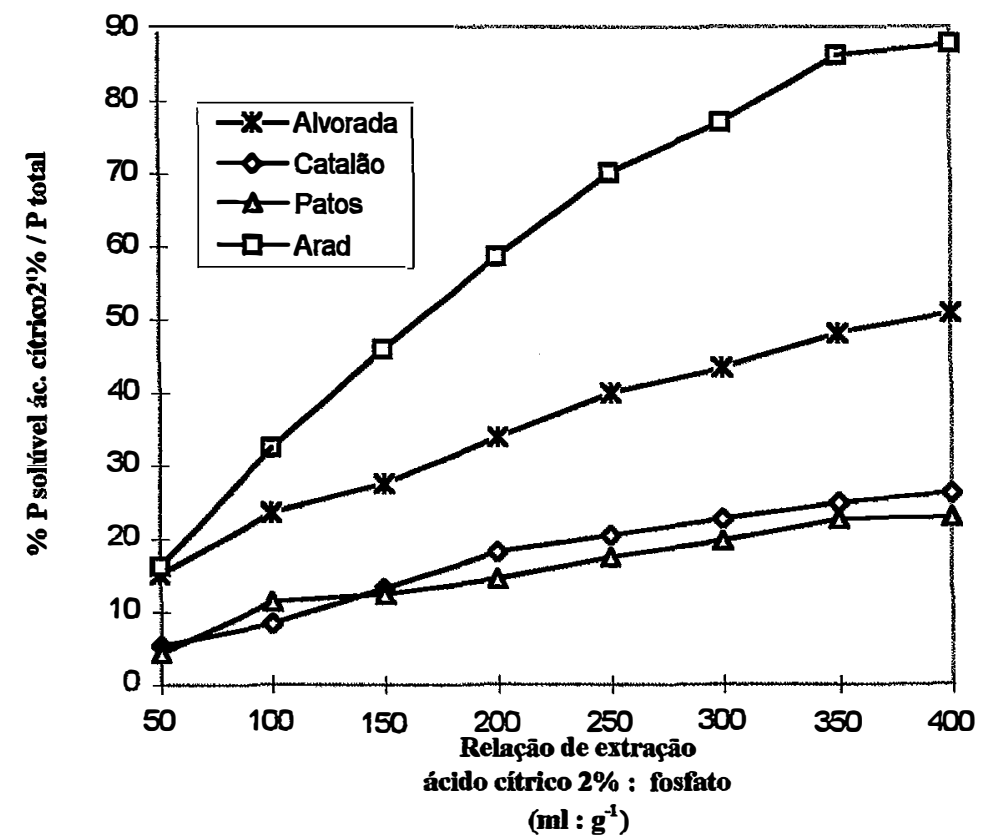

Figura 1 - Curva de solubilidade em solução de ácido cítrico a $2 \%$ dos fosfatos naturais Alvorada, Catalão, Patos e Arad. 


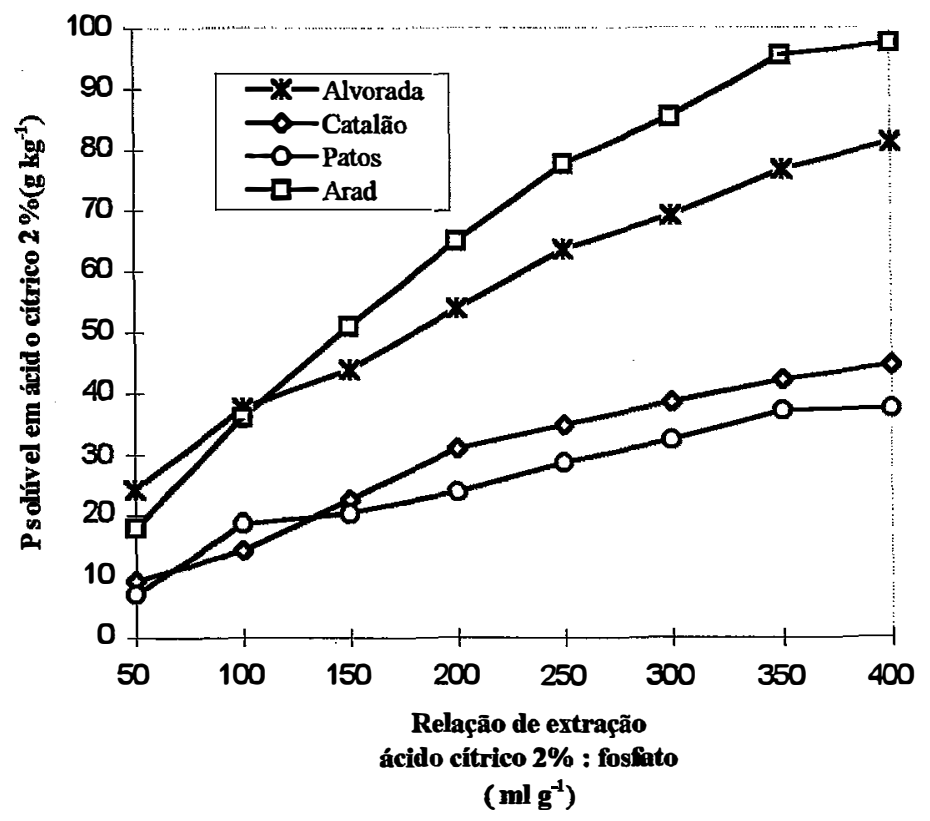

Figura 2 - Curva de solubilidade em solução de ácido cítrico a 2 \% solúvel em função teor total de fósforo dos fosfatos naturais Alvorada, Catalão, Patos e Arad.

\subsection{Primeiro Plantio}

O crescimento do milho, avaliado pela produção de material seco, pelo acúmulo de nutrientes e índice de eficiência agronômica encontram-se nas tabelas 10 e 11. E os resultados das análises de variância estão resumidos na tabela 12. 
Tabela 10. Produção de material seco e concentração de nutrientes absorvidos pelo milho no primeiro plantio (média de 4

\begin{tabular}{|c|c|c|c|c|c|c|c|c|}
\hline \multirow[t]{2}{*}{ Trt. } & \multirow[t]{2}{*}{ Fosf. } & \multirow{2}{*}{$\begin{array}{c}\text { Material } \\
\text { Seco } \\
\left(\text { (g vaso }^{-1}\right)\end{array}$} & $\mathbf{N}$ & $\mathbf{P}$ & $\mathbf{K}$ & $\mathbf{C a}$ & $\mathbf{M g}$ & $\mathbf{S}$ \\
\hline & & & \multicolumn{6}{|c|}{$\left(\mathrm{g} \mathrm{kg}^{-1}\right)$} \\
\hline 1 & A & 21,14 & 13,34 & 0,85 & 14,17 & 1,53 & 0,93 & 0,95 \\
\hline 2 & L & 24,18 & 11,72 & 1,15 & 15,52 & 1,56 & 0,92 & 0,73 \\
\hline 3 & V & 26,49 & 10,75 & 1,25 & 11,51 & 1,37 & 0,89 & 0,69 \\
\hline 4 & $\mathbf{O}$ & 20,04 & 12,17 & 0,99 & 16,83 & 1,61 & 1,06 & 0,92 \\
\hline 5 & $\mathbf{R}$ & 21,97 & 12,07 & 0,99 & 15,41 & 1,74 & 1,07 & 1,05 \\
\hline 6 & $\mathbf{A}$ & 25,05 & 11,40 & 1,04 & 13,39 & 1,79 & 0,95 & 0,88 \\
\hline 7 & D & 17,32 & 12,67 & 0,85 & 15,18 & 1,75 & 0,89 & 1,09 \\
\hline 8 & A & 20,96 & 11,35 & 0,94 & 16,09 & 1,91 & 1,15 & 0,96 \\
\hline 9 & & 22,11 & 11,80 & 1,12 & 13,81 & 1,45 & 0,93 & 0,97 \\
\hline 10 & & 12,08 & 17,25 & 0,76 & 21,85 & 1,83 & 0,82 & 1,54 \\
\hline 11 & C & 18,61 & 12,20 & 0,87 & 18,26 & 1,93 & 1,07 & 0,96 \\
\hline 12 & A & 18,17 & 11,25 & 0,76 & 17,69 & 1,85 & 0,94 & 0,68 \\
\hline 13 & $\mathrm{~T}$ & 6,35 & 19,62 & 1,12 & 34,76 & 1,73 & 0,99 & 1,44 \\
\hline 14 & A & 8,86 & 16,92 & 1,04 & 26,98 & 1,74 & 0,91 & 1,08 \\
\hline 15 & L & 14,03 & 14,42 & 0,99 & 24,04 & 1,92 & 0,87 & 1,14 \\
\hline 16 & $\tilde{A}$ & 2,93 & 25,10 & 1,31 & 53,78 & 1,74 & 1,15 & 2,31 \\
\hline 17 & $\mathbf{O}$ & 5,45 & 17,65 & 1,07 & 33,22 & 2,05 & 1,19 & 1,47 \\
\hline 18 & & 7,95 & 17,12 & 1,04 & 27,66 & 1,58 & 0,71 & 1,34 \\
\hline 19 & & 6,41 & 17,13 & 1,22 & 32,32 & 1,84 & 1,02 & 1,53 \\
\hline 20 & & 7,13 & 17,32 & 1,22 & 31,14 & 1,83 & 0,85 & 1,56 \\
\hline 21 & $\mathbf{P}$ & 7,27 & 18,02 & 0,90 & 30,32 & 1,70 & 0,85 & 2,02 \\
\hline 22 & A & 5,15 & 22,25 & 1,19 & 34,60 & 1,49 & 0,91 & 1,87 \\
\hline 23 & $\mathrm{~T}$ & 5,80 & 24,17 & 0,82 & 41,20 & 1,62 & 0,97 & 2,96 \\
\hline 24 & $\mathbf{O}$ & 6,00 & 17,87 & 1,12 & 37,52 & 1,66 & 1,02 & 3,09 \\
\hline 25 & $\mathbf{S}$ & 4,37 & 23,55 & 1,11 & 41,37 & 1,45 & 0,91 & 1,75 \\
\hline 26 & & 4,69 & 23,65 & 0,97 & 43,46 & 1,70 & 1,09 & 2,18 \\
\hline 27 & & 5,94 & 20,15 & 1,02 & 45,69 & 1,97 & 1,13 & 2,86 \\
\hline 28 & & 23,31 & 15,87 & 0,88 & 14,19 & 2,35 & 1,00 & 1,24 \\
\hline 29 & & 22,48 & 12,25 & 0,99 & 14,82 & 2,52 & 1,15 & 1,38 \\
\hline 30 & & 23,91 & 12,07 & 0,99 & 13,89 & 2,28 & 1,05 & 1,04 \\
\hline 31 & A & 17,75 & 14,42 & 0,81 & 15,98 & 2,40 & 1,03 & 1,19 \\
\hline 32 & $\mathbf{R}$ & 19,38 & 14,27 & 0,70 & 16,68 & 2,31 & 1,09 & 1,25 \\
\hline 33 & A & 20,68 & 13,02 & 0,90 & 13,71 & 2,39 & 1,01 & 1,09 \\
\hline 34 & D & 14,67 & 16,82 & 0,79 & 16,04 & 2,23 & 0,91 & 1,42 \\
\hline 35 & & 17,36 & 16,27 & 0,75 & 15,97 & 2,58 & 1,29 & 1,48 \\
\hline 36 & & 20,54 & 13,90 & 0,88 & 13,10 & 2,39 & 0,93 & 1,07 \\
\hline 37 & SPT & 18,12 & 15,35 & 0,77 & 15,75 & 0,79 & 1,17 & 1,43 \\
\hline 38 & $\mathrm{TE}^{*}$ & 1,32 & 30,97 & 0,68 & 6,10 & 1,19 & 2,47 & 3,08 \\
\hline
\end{tabular}

$\mathrm{TE}^{*}=$ Testemunha 
Tabela 11 Índice de eficiência agronômica e acúmulo de nutrientes pelo milloo no primeiro plantio (média de 4 repeticōes).

\begin{tabular}{|c|c|c|c|c|c|c|c|c|}
\hline \multirow[t]{2}{*}{ Trt. } & \multirow[t]{2}{*}{ Fosf. } & \multirow{2}{*}{$\begin{array}{l}\text { IEA } \\
(\%)\end{array}$} & $\mathbf{N}$ & $\mathbf{P}$ & $\mathbf{K}$ & $\mathbf{C a}$ & $\mathrm{Mg}$ & $\mathbf{S}$ \\
\hline & & & \multicolumn{6}{|c|}{ (mg/vaso) } \\
\hline 1 & $\mathrm{~A}$ & 118,95 & 282,86 & 18,05 & 295,20 & 31,97 & 19,81 & 20,88 \\
\hline 2 & L & 136,66 & 282,64 & 27,81 & 375,50 & 37,85 & 21,91 & 19,17 \\
\hline 3 & V & 154,91 & 283,36 & 33,22 & 304,70 & 36,25 & 23,61 & 20,18 \\
\hline 4 & $\mathbf{O}$ & 113,22 & 244,64 & 19,97 & 337,50 & 32,32 & 21,38 & 19,24 \\
\hline 5 & $\mathbf{R}$ & 124,13 & 264,58 & 21,76 & 332,70 & 38,19 & 23,57 & 23,07 \\
\hline 6 & A & 145,90 & 283,55 & 25,86 & 330,20 & 44,72 & 23,50 & 23,36 \\
\hline 7 & D & 97,80 & 219,25 & 14,77 & 264,10 & 30,37 & 15,42 & 17,80 \\
\hline 8 & A & 119,21 & 237,56 & 19,63 & 336,20 & 39,86 & 23,94 & 20,97 \\
\hline 9 & & 124,10 & 260,08 & 24,87 & 302,60 & 42,61 & 20,51 & 22,54 \\
\hline 10 & & 64,46 & 207,77 & 9,39 & 256,00 & 21,95 & 9,76 & 16,99 \\
\hline 11 & C & 103,70 & 227,49 & 16,16 & 335,70 & 35,59 & 19,96 & 18,53 \\
\hline 12 & A & 102,54 & 204,47 & 13,91 & 321,10 & 33,51 & 17,05 & 13,86 \\
\hline 13 & $T$ & 31,55 & 122,53 & 7,04 & 219,60 & 10,86 & 6,12 & 8,89 \\
\hline 14 & A & 45,59 & 150,34 & 9,29 & 238,70 & 15,36 & 7,89 & 9,35 \\
\hline 15 & L & 76,28 & 201,78 & 13,55 & 338,10 & 27,09 & 12,21 & 15,27 \\
\hline 16 & $\tilde{A}$ & 9,70 & 73,07 & 3,84 & 155,70 & 5,09 & 3,31 & 6,19 \\
\hline 17 & O & 25,40 & 96,19 & 5,90 & 181,30 & 10,97 & 6,32 & 8,05 \\
\hline 18 & & 40,19 & 133,58 & 8,19 & 210,90 & 12,51 & 5,61 & 10,40 \\
\hline 19 & & 30,33 & 109,66 & 7,76 & 207,60 & 11,49 & 6,31 & 9,32 \\
\hline 20 & & 34,74 & 120,63 & 8,57 & 214,60 & 12,57 & 5,87 & 10,49 \\
\hline 21 & $\mathbf{P}$ & 35,89 & 130,14 & 6,57 & 218,80 & 12,25 & 6,06 & 13,17 \\
\hline 22 & A & 23,22 & 114,85 & 6,19 & 177,70 & 7,70 & 4,76 & 8,97 \\
\hline 23 & $\mathrm{~T}$ & 26,87 & 140,15 & 4,70 & 239,50 & 9,41 & 5,64 & 14,48 \\
\hline 24 & $\mathbf{O}$ & 28,84 & 105,86 & 6,77 & 223,30 & 9,82 & 6,05 & 15,91 \\
\hline 25 & $\mathbf{S}$ & 18,58 & 103,33 & 4,81 & 182,00 & 6,35 & 3,99 & 7,56 \\
\hline 26 & & 20,13 & 110,24 & 4,60 & 203,30 & 8,03 & 5,16 & 9,10 \\
\hline 27 & & 28,04 & 119,79 & 6,03 & 270,50 & 11,70 & 6,71 & 15,03 \\
\hline 28 & & 132,67 & 371,28 & 20,45 & 328,80 & 54,82 & 23,40 & 27,58 \\
\hline 29 & & 128,06 . & 275,23 & 22,09 & 331,80 & 56,47 & 25,83 & 30,22 \\
\hline 30 & & 137,02 & 288,74 & 23,90 & 332,00 & 54,77 & 25,10 & 24,09 \\
\hline 31 & A & 98,18 & 253,91 & 14,21 & 278,70 & 42,35 & 18,02 & 19,88 \\
\hline 32 & $\mathrm{R}$ & 109,38 & 277,25 & 13,53 & 320,60 & 45,67 & 21,38 & 22,45 \\
\hline 33 & A & 116,70 & 267,04 & 18,67 & 280,40 & 48,54 & 20,56 & 21,80 \\
\hline 34 & D & 80,66 & 246,22 & 11,49 & 231,60 & 32,26 & 13,15 & 19,06 \\
\hline 35 & & 97,92 & 282,36 & 12,94 & 274,70 & 44,29 & 22,07 & 23,66 \\
\hline 36 & & 116,22 & 285,89 & 18,06 & 269,40 & 47,82 & 19,14 & 20,82 \\
\hline 37 & SPT & 100,00 & 274,69 & 14,00 & 278,50 & 14,15 & 21,31 & 25,13 \\
\hline 38 & $\mathrm{TE}^{*}$ & - & 40,60 & 0,90 & 80,10 & 1,57 & 3,26 & 4,18 \\
\hline
\end{tabular}

TE* $=$ Testemunha

Tabela 12 Resmmo das análises da variância de material seco, índice de eficiência agronômica dos fosfatos (IEA) e acúmulo de macronutrientes na parte aérea do milho do primeiro plantio.

\begin{tabular}{|c|c|c|c|c|c|c|c|c|c|}
\hline \multirow{2}{*}{$\begin{array}{l}\text { Causa da } \\
\text { Variaçāo }\end{array}$} & \multicolumn{9}{|c|}{ Valor F } \\
\hline & GL & $\begin{array}{c}\text { Material } \\
\text { Seco }\end{array}$ & IEA(\%) & $\mathbf{N}$ & $\mathbf{P}$ & $\mathbf{K}$ & $\mathbf{C a}$ & $\mathbf{M g}$ & $\overline{\mathbf{S}}$ \\
\hline Fosfato(F) & 3 & $461,55 * *$ & $390,16 * *$ & $197,52^{* *}$ & $362,17^{* *}$ & $59,58^{* *}$ & $407,36 * *$ & $304,89 * *$ & $128,83 * *$ \\
\hline Dose de P(D) & 2 & $36,98 * *$ & $34,39 * *$ & $3,29 *$ & $56,82 * *$ & $18,15^{* *}$ & $30,61^{* *}$ & $26,84 * *$ & $10,51 * *$ \\
\hline Relação de extração(R) & 2 & $86,44 * *$ & $67,45 * *$ & $27,23 * *$ & $80,69 * *$ & $27,21^{* * *}$ & $38,82 * *$ & $39,24^{* * *}$ & $15,55 * *$ \\
\hline Bloco(B) & 3 & $2,10 \mathrm{~ns}$ & $17,79 * *$ & $3,76^{*}$ & $5.60 * *$ & $1,98 \mathrm{~ns}$ & $0, .93 \mathrm{~ns}$ & $4,47 * *$ & 1,67 n.s. \\
\hline$F \times D$ & 6 & $4,26 * *$ & $2,80 *$ & $1,60 \mathrm{~ns}$ & $10,29 * *$ & $3,28 * *$ & $1,92 \mathrm{~ns}$ & $2,17 \mathrm{~ns}$ & $2,84 * *$ \\
\hline $\mathbf{F} \times \mathbf{R}$ & 6 & $9,25 * *$ & $8,27 * *$ & $5,54 * *$ & $4,42 * *$ & $7,66^{* *}$ & $13,34 * *$ & $9,45 * *$ & $7,54 * *$ \\
\hline $\mathrm{D} \times \mathrm{R}$ & 4 & 0,81 n.s & $0,39 \mathrm{~ns}$ & $3,37 *$ & $3,81^{* *}$ & $1,38 \mathrm{~ns}$ & $2,65 *$ & $1,61 \mathrm{~ns}$ & $4,20 * *$ \\
\hline$F \times D \times R$ & 12 & $1,20 \mathrm{~ns}$ & $1,10 \mathrm{~ns}$ & $1,68 \mathrm{~ns}$ & $1,62 \mathrm{~ns}$ & $2,10 *$ & $1,28 \mathrm{~ns}$ & $2,02 *$ & 0,94 n.s. \\
\hline
\end{tabular}

**Significativo ao nivel de $1 \%$ de probabilidade

* Significativo ao nível de $5 \%$ de probabilidade

n.s. Não significativos ao nível de $5 \%$ de probabilidade. 


\subsubsection{Produção de material seco}

A produção de material seco apresentou efeito para todos os fatores estudados, exceto para a interação fosfato $x$ dose $x$ relação de extração (Tabela 12). Houve diferença apenas nas interações entre doses $\mathrm{x}$ fosfatos e relações de extração $\mathrm{x}$ fosfatos.

Segundo Smith \& Sanchez (1982), os principais fatores que influenciam a disponibilidade de fósforo dos fosfatos naturais são as diferenças inerentes aos fosfatos, a variação entre culturas na sua habilidade de utilizar o fósforo dos fosfatos naturais e as propriedades do solo, principalmente a acidez. Neste trabalho, foram utilizados fosfatos de origens geológicas diferentes em condições de acidez para se ter melhoria da eficiência, que varia entre solos e com distintos graus de acidez, conforme são apresentados resultados de diferentes trabalhos.

Blanco et al.(1965) observaram que as melhores reações dos fosfatos naturais foram na faixa de $\mathrm{pH} 5,1$ a 5,3 para Olinda e para os fosfatos Araxá e Alvorada nas faixas de 4,7 a 5,0 e 4,8 a 5,3, respectivamente. De acordo com Cantarutti et al. (1981), a acidez do solo, também, exerceu efeito solubilizador sobre os fosfatos Patos e Araxá e a maior eficiência ocorreu quando eles foram aplicados trinta dias antes do corretivo. Já Viégas (1990), verificou que a disponibilidade do fosfato Patos às plantas foi maior quando sua aplicação e incubação foram feitas a pH 4,5 quando comparado com o pH 6,5 .

A interação entre fosfato $x$ dose $x$ relação de extração pode não ter ocorrido no primeiro plantio pelo pouco tempo decorrido para a reação de solubilização dos fosfatos, pois não foi realizada a incubação dos fosfatos no solo. 0 tempo de contato desses fosfatos com o solo poderia aumentar a disponiblidade de fósforo às plantas e sua reatividade (Novelino, 1984), conforme mostram os resultados de vários pesquisadores.

Souza (1977) obtiveram que o aumento do tempo de incubação (90 dias), melhorou a eficiência dos fosfatos naturais como fonte de fósforo, propiciando maior produção de material seco e fósforo absorvido, concordando com De Felipo et al.(1981), que verificaram esse resultado para os fosfatos Araxá e Patos. Para os fosfatos Tapira e Catalão, isso não ocorreu, devido aos compostos formados apresentarem-se mais estáveis 
que o original, numa forma de P-não lábil, embora tenha havido a solubilização do fosfato. Esse resultado foi diferente do que ocorreu com o fosfato Catalão no presente trabalho, provavelmente, pela sua composição química e pois a maior parte da suas partículas estarem concentradas em partículas de menor diâmetro, comparado ao fosfato Patos.

Tabela 13 Material seco produzido pelo milho no primeiro plantio para os fosfatos utilizados.

\begin{tabular}{lcc}
\hline Fosfatos & Média $\left(\mathrm{g} \mathrm{vaso}^{-1}\right)$ & Teste Duncan \\
\hline Alvorada & 22,14 & A \\
Arad & 20,69 & B \\
SPT & 18,12 & B \\
Catalão & 10,49 & C \\
Patos & 6,04 & D \\
Testemunha & 1,31 & E \\
\hline
\end{tabular}

Médias seguidas da mesma letra não diferem entre si .

A produção de material seco do fosfato Alvorada superou os fosfatos Arad e SPT, Catalão, Patos e testemunha (Tabela 13). Os fosfatos com maior solubilidade em ácido cítrico $2 \%$ (relação $1: 100$ ) foram os que proporcionaram maior produção de material seco, seguindo a ordem de solubilidade. A correlação entre resultados de solubilidade em ácido cítrico $2 \%$ dos fosfatos e a resposta de crescimento de plantas já foi realizada por vários pesquisadores. Eles mostraram que o ácido cítrico parece ser eficiente na predição do valor relativo dos fosfatos naturais como fonte de fósforo (Armiger \& Fried,1956; Chien \& Hammond, 1978; Goedert et al., 1990). Franco et al. (1979), também, concluíram que tanto o ácido cítrico como o ácido fórmico oferecem condições para avaliação do teor de $\mathrm{P}_{2} \mathrm{O}_{5}$ disponível nos fosfatos de Patos e Araxá, em relação à produção de material seco e fósforo absorvido por plantas de sorgo, a vários níveis de acidulação parcial. Em condições de campo, Oliveira et al. (1984) apresentaram estreita relação entre a eficiência relativa dos fosfatos naturais e sua solubilidade em ácido cítrico $2 \%$ (relação $1: 100$ ).

O superfosfato triplo supera, geralmente, os fosfatos naturais no primeiro plantio pela sua maior solubilidade em água, conforme mostraram os trabalhos de Blanco et al. (1965) e Feitosa et al. (1978). Gomes et al.(1961) e Miranda et al. (1970), também, 
mostraram que o superfosfato foi sempre o melhor fertilizante fosfatado para a cultura do milho quando comparado aos fosfatos de Olinda, hiperfosfato, fosfato da Flórida, fosfato do Morro do Serrote e de Araxá.

Os resultados de material seco produzida pelo superfosfato triplo, no entanto, foram inferiores aos do fosfato Alvorada, diferentes dos trabalhos encontrados na literatura. Essa diferença pode ser atribuída à acidez do solo, que pode ter favorecido a solubilização dos fosfatos Alvorada e Arad e ter reduzido a eficiência do SPT, conforme verificado por Raij \& Diest (1980).

O comportamento do fosfato Alvorada foi superior aos demais, semelhantes aos resultados encontrados por vários pesquisadores. Feitosa et al. (1978) verificaram que o fosfato Alvorada apresentou melhor produção que os outros fosfatos naturais (Araxá, Jacupiranga, Patos, Catalão, Abaeté, Olinda, Ipanema, Tapira), confirmando as observações de Viégas et al. (1970) e Wutke et al. (1962). Sua melhor eficiência, de acordo com os primeiros autores, pode estar relacionada a aspectos qualitativos (como mineralogia) dos compostos fosfatados, pois em termos quantitativos ele não se diferencia do fosfato de Gafsa. Ramos (1982),contudo, relatou que o fosfato Alvorada apenas se sobressaiu no segundo ano na cultura de trigo seguido de soja, o que pode ser atribuído à sua granulometria.

Quanto aos demais fosfatos estudados, a produção de material seco foi diretamente relacionada à solubilidade em ácido cítrico a $2 \%$.

As doses de fosfato utilizadas, que foram baseadas na solubilidade em ácido cítrico a $2 \%$, também influenciaram o material seco produzindo o seu incremento com a elevação dos níveis de fósforo aplicado. $\mathrm{O}$ fosfato Alvorada superou os fosfatos Arad e Catalão (Figura 3). Para o fosfato Patos, as doses não tiveram efeito.

Cáceres et al. (1993), também, verificou que o aumento das doses foi traduzido em aumento de produção de material seco quando utilizou o superfosfato simples, multifosfato magnesiano, termofosfato, fosfato de Araxá e fosfato de Gafsa nas doses de fósforo total de 0, 50 e $150 \mathrm{mg} \mathrm{kg}^{-1}$ em Latossolo vermelho álico. Já Feitosa et al.(1978) utilizando doses de $\mathrm{P}_{2} \mathrm{O}_{5}$ total de $0,50,100,200$ e $400 \mathrm{mg} \mathrm{kg}^{-1}$ não tiveram diferença de produção de material seco dos fosfatos Catalão, Araxá, Patos, Ipanema, Abaeté, 
Jacupiranga e Olinda, não diferindo da testemunha. A diferença dos resultados dos trabalhos pode ser atribuída ao tipo de solo do segundo trabalho, que pode ser suficiente em fósforo ou pode ser tão deficiente que doses baseadas em fósforo total dos fosfatos foram insuficientes à obtenção de maiores produções que a testemunha.

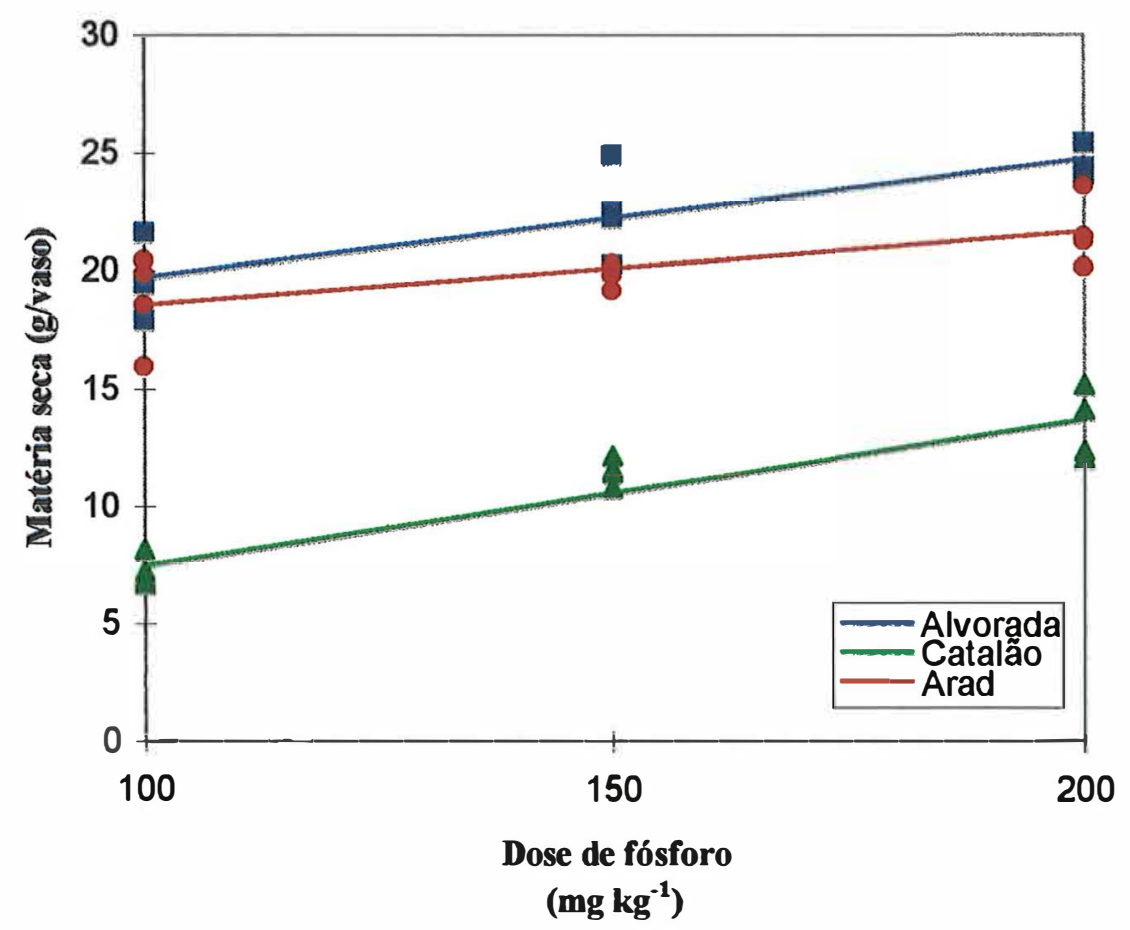

Figura 3 - Produção de material seco (g/vaso) obtida no primeiro plantio de milho para os fosfatos Alvorada, Catalão e Arad em diferentes doses de fósforo.

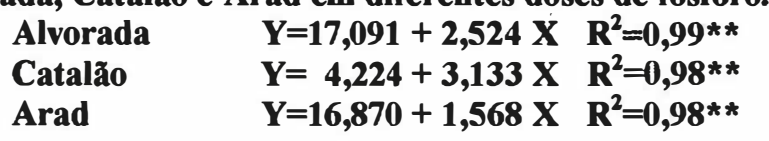

Os resultados obtidos com o fosfato Patos foram devidos à sua menor reatividade (Cantarutti et al., 1981) por ser um fosfato apatítico com pequeno grau de substituição isomórfica de fosfato por carbonato na estrutura cristalina, sendo assim menos solubilizado (Magalhães et al.,1987).

Aliado a esses fatores, as doses do fosfato Patos utilizadas no presente trabalho, mesmo calculadas com base na solubilidade em ácido cítrico a $2 \%$, podem ter sido insuficientes conforme ocorreu em vários trabalhos. Tanaka et al. (1981) não obtiveram também diferença entre as médias de produção de material seco e absorção de fósforo, 
quando utilizaram 5 doses de $\mathrm{P}_{2} \mathrm{O}_{5}$ total do fosfato Patos $(0,870,1740,2610$ e $3840 \mathrm{~kg}$ $\mathrm{ha}^{-1}$ ), diferindo apenas da testemunha. Oliveira et al.(1984) verificaram que o fosfato Patos superou Alvorada e Catalão apenas quando foi utilizado na dose de $\mathrm{P}_{2} \mathrm{O}_{5}$ total de $400 \mathrm{mg} \mathrm{kg}^{-1}$. Finalmente, não houve efeito do fosfato Patos devido a sua lenta solubilização, aliado à sua granulometria mais grosseira comparada a do fosfato Catalão e à composição química dos fosfatos, pois há grande variabilidade de acordo com o local da jazida em que coletado o fosfato.

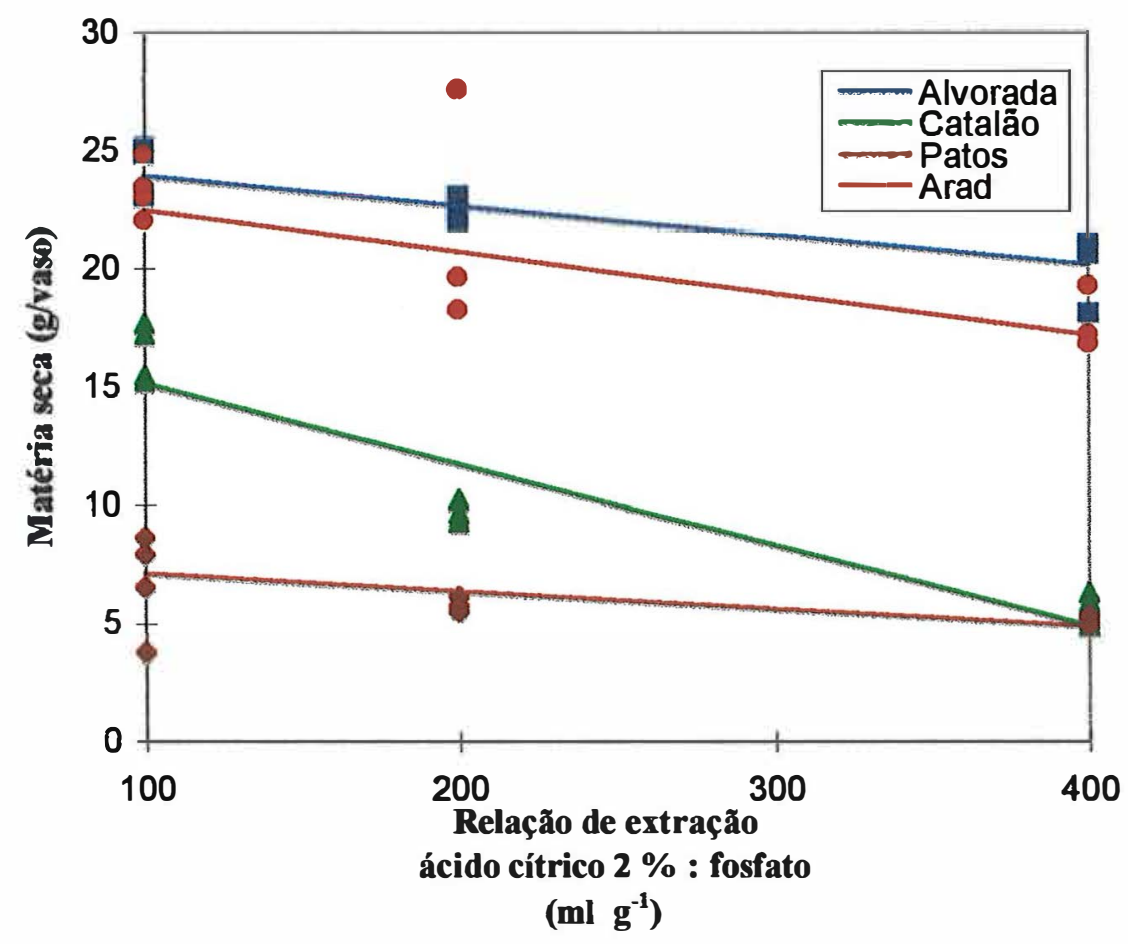

Figura 4 - Produção de material seco (g/vaso) obtida no primeiro plantio de milho em diferentes relações de extração para os fosfatos Alvorada, Catalão, Patos e Arad.

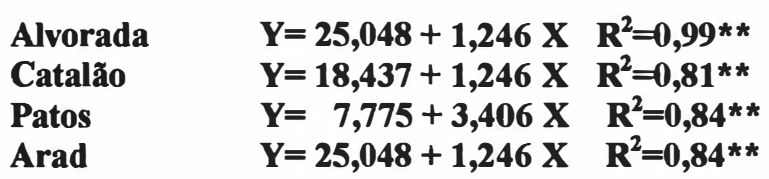


A produção de material seco também foi influenciada pelas relações de extração, sendo decrescentes e lineares para o fosfato Alvorada, Arad e Catalão, seguindo a solubilidade em ácido cítrico $2 \%$ na relação 1:100. E a relação 1:100 (fosfato: ácido cítrico $2 \%$ ) correspondeu à de maior resultado obtido, verificando-se a sua importância, porque representou a máxima quantidade de fosfato aplicada no experimento que proporcionou maior produção de material seco no primeiro plantio, apresentada na figura 4. O fosfato Patos não teve efeito, provavelmente, devido a sua menor solubilidade.

Comparando as quantidades de fósforo solúvel em ácido cítrico obtidas em laboratório, para as diversas relações de extração e em cada dose, elas são semelhantes para cada fosfato (Tabela 14). Entretanto, o comportamento dos fosfatos na produção de material seco foi diferente. Isso ocorreu porque sua composição química e, principalmente, cristalográfica influenciou na solubilidade em ácido cítrico $2 \% \mathrm{e}$, consequentemente, na quantidade de fosfato aplicada e sua dissolução no solo.

Quanto maior a solubilidade em ácido cítrico $2 \%$, maior conteúdo de $\mathrm{P}$ é extraído e menor quantidade de $\mathbf{P}$ é aplicado. Assim, a relação de extração 1:100 foi a de maior quantidade de fosfato aplicada e maior produção de material seco para os fosfatos Alvorada, Arad e Catalão.

Os fosfatos Alvorada e Arad, entretanto, com quantidades inferiores aos demais, superaram em produção de material seco devido à sua estrutura cristalográfica e composição química, que lhes conferem maior reatividade e solubilidade no solo mais rápida que Patos e Catalão. 
Tabela 14 Quantidade de fósforo solúvel dos fosfatos.

\begin{tabular}{|c|c|c|c|c|}
\hline Fosfato & $\begin{array}{c}\text { Dose de P } \\
\left(\mathrm{mg} \mathrm{kg}^{-1}\right)\end{array}$ & $\begin{array}{c}\text { Relaçãode extração } \\
\text { fosfato:ácido cítrico } \\
\text { a } 2 \%\left(\mathrm{gl}^{-1}\right)\end{array}$ & $\begin{array}{c}\text { Fosfato } \\
\left(\text { g vaso }^{-1}\right)\end{array}$ & $\begin{array}{c}\text { P solúvel em ácido } \\
\text { cítrico a } 2 \% \\
\left(m g \text { vaso }^{-1}\right)\end{array}$ \\
\hline $\mathbf{A}$ & 100 & $1: 100$ & 8,00 & 299,88 \\
\hline $\mathbf{L}$ & & $1: 200$ & 5,58 & 300,32 \\
\hline $\mathbf{V}$ & & $1: 400$ & 3,70 & 299,72 \\
\hline $\mathbf{0}$ & 150 & $1: 100$ & 12,00 & 449,82 \\
\hline $\mathbf{R}$ & & $1: 200$ & 8,37 & 450,30 \\
\hline $\mathbf{A}$ & & $1: 400$ & 5,55 & 449,57 \\
\hline D & 200 & $1: 100$ & 16,00 & 599,76 \\
\hline \multirow[t]{3}{*}{$\mathbf{A}$} & & $1: 200$ & 11,16 & 600,05 \\
\hline & & $1: 400$ & 7,40 & 599,43 \\
\hline & 100 & $1: 100$ & 20,98 & 299,95 \\
\hline $\mathbf{C}$ & & $1: 200$ & 9,70 & 29989 \\
\hline $\mathbf{A}$ & & $1: 400$ & 6,74 & 300,06 \\
\hline $\mathbf{T}$ & 150 & $1: 100$ & 31,47 & 449,92 \\
\hline $\mathbf{A}$ & & $1: 200$ & 14,56 & 450,15 \\
\hline $\mathbf{L}$ & & $1: 400$ & 10,11 & 450,09 \\
\hline$\tilde{\mathbf{A}}$ & 200 & $1: 100$ & 41,97 & 600,04 \\
\hline \multirow[t]{4}{*}{$\mathbf{0}$} & & $1: 200$ & 19,41 & 600,10 \\
\hline & & $1: 400$ & 13,48 & 600,13 \\
\hline & 100 & $1: 100$ & 16,00 & 299,88 \\
\hline & & $1: 200$ & 12,60 & 297,67 \\
\hline $\mathbf{P}$ & & $1: 400$ & 8,02 & 300,06 \\
\hline $\mathbf{A}$ & 150 & $1: 100$ & 24,00 & 449,82 \\
\hline $\mathbf{T}$ & & $1: 200$ & 18,90 & 446,50 \\
\hline 0 & & $1: 400$ & 12,03 & 450,10 \\
\hline \multirow[t]{5}{*}{$\mathbf{S}$} & 200 & $1: 100$ & 32,00 & 599,76 \\
\hline & & $1: 200$ & 25,21 & 595,57 \\
\hline & & $1: 400$ & 16,04 & 600,03 \\
\hline & 100 & $1: 100$ & 8,35 & 299,94 \\
\hline & & $1: 200$ & 4,62 & 300,02 \\
\hline $\mathbf{A}$ & & $1: 400$ & 3,09 & 300,34 \\
\hline $\mathbf{R}$ & 150 & $1: 100$ & 12,53 & 450,10 \\
\hline $\mathbf{A}$ & & $1: 200$ & 6,93 & 450,03 \\
\hline \multirow[t]{4}{*}{ D } & & $1: 400$ & 4,63 & 450,02 \\
\hline & 200 & $1: 100$ & 16,70 & 599,89 \\
\hline & & $1: 200$ & 9,24 & 600,04 \\
\hline & & $1: 400$ & 6,17 & 599,70 \\
\hline
\end{tabular}




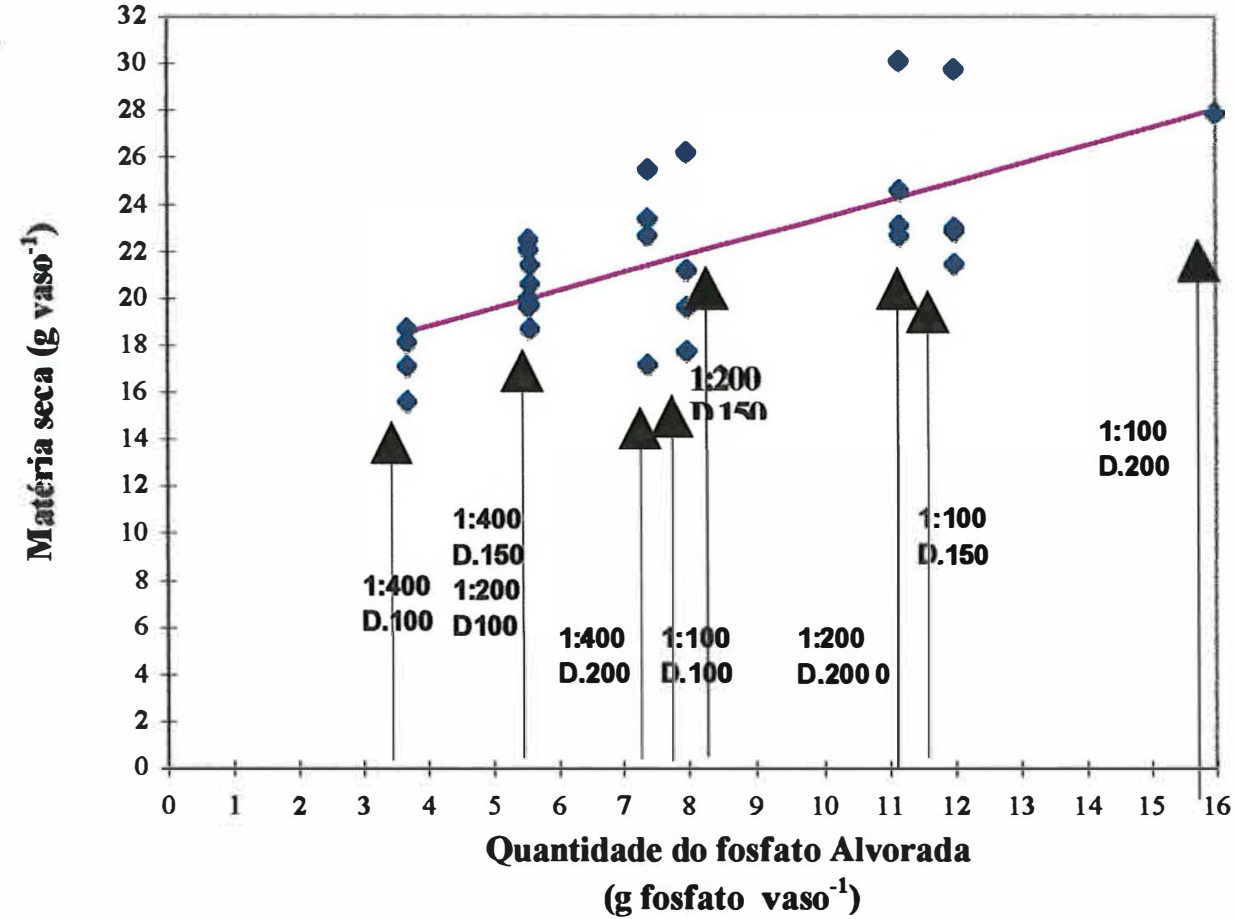

Figura 5 - Produção de material seco em função da quantidade do fosfato Alvorada no primeiro plantio.

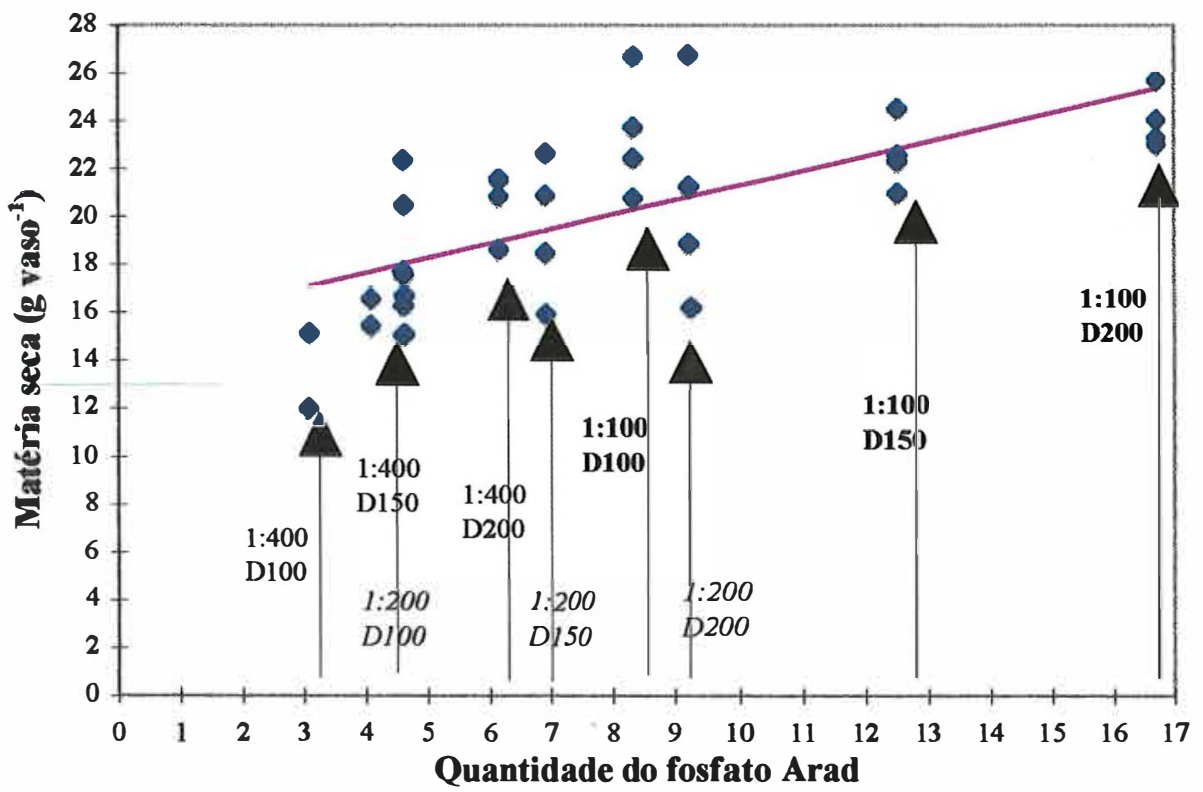

$\left(\right.$ g vaso $^{-1}$ )

Figura 6 - Produção de material seco em função da quantidade do fosfato Arad no primeiro plantio. 
Quanto às diferenças entre os fosfatos Alvorada e Arad, o fosfato Alvorada apresentou produção de material seco superior, apesar das quantidades semelhantes de fosfato utilizadas e do fosfato Arad ser de origem sedimentar. Nas demais relações, o fosfato Arad mostrou maior solubilidade, sendo que sua granulometria mais grosseira não interferiu na maior extração de fósforo (Figuras 5 e 6). Isso ocorreu, porque à medida que aumentou a quantidade de ácido ć́trico $2 \%$, aumentou o conteúdo de $\mathrm{P}$ extraído, mas isso não corresponde à sua real disponibilidade no solo no primeiro plantio. No caso de Arad, a granulometria mais grosseira diminuiu sua solubilidade em ácido cítrico $2 \%$ (relação 1:100) e ele foi inferior ao fosfato Alvorada.

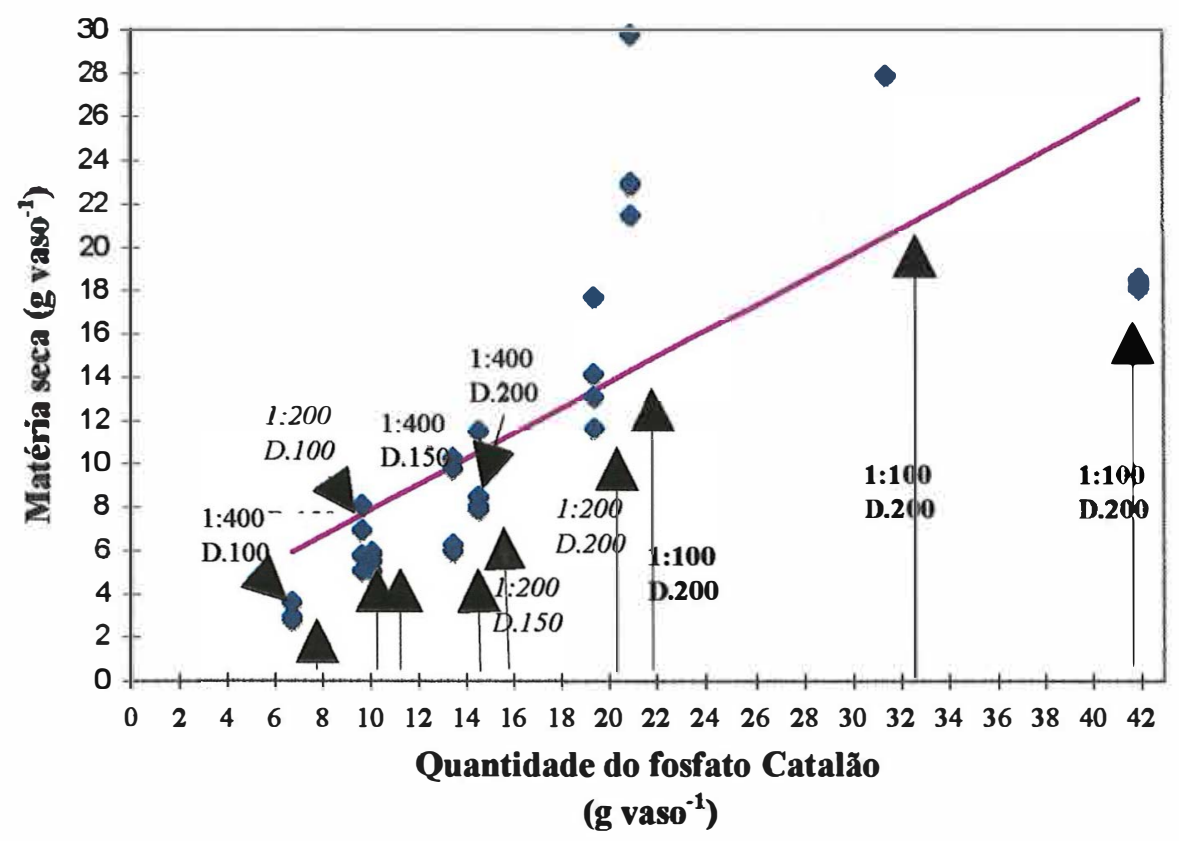

Figura 7 - Produção de material seco em função da quantidade do fosfato Catalão no primeiro plantio 


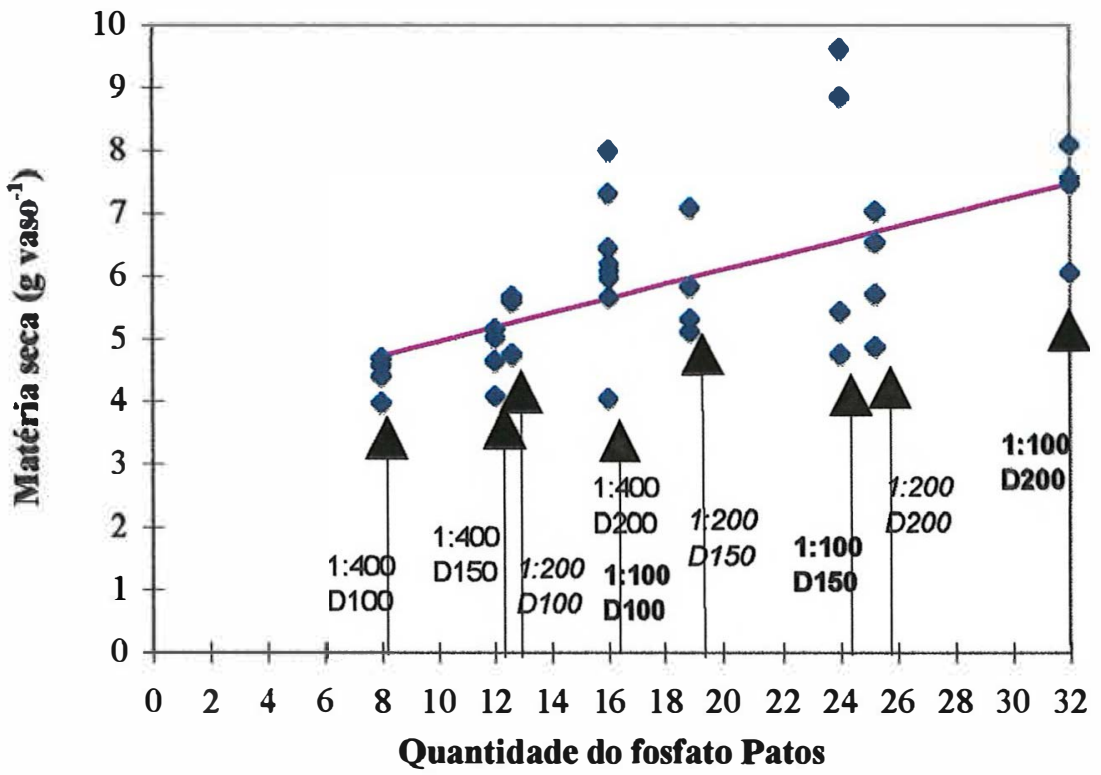

(g vaso-1)

Figura 8 - Produção de material seco em função da quantidade do fosfato Patos no primeiro plantio.

Para os fosfatos Catalão (origem ígnea) e Patos (sedimentar), a diferença obtida na produção de material seco, também, está associada à solubilidade em ácido cítrico (relação 1:100). Mesmo quando são utilizadas quantidades de fosfato semelhantes, as produções do fosfato Patos foram inferiores às do fosfato Catalão. Isso se deve, provavelmente, às suas diferenças na composição química e cristalográfica, que influiu na disponibilidade de fósforo às plantas no primeiro plantio (Figuras 7 e 8).

A utilização de doses de fosfato baseando-se em quantidades previamente fixadas e iguais para todos os fosfatos (independente da origem) ou no teor total de $\mathrm{P}_{2} \mathrm{O}_{5}$, poderia resultar em produção de material seco inferior, como tem sido visto na maioria dos trabalhos da literatura. Portanto, a solubilidade em ácido cítrico 1:100 de cada fosfato pode ser um parâmetro na predição do comportamento de fosfatos naturais de diferentes origens geológicas e granulometrias, quando aplicados no solo. 


\subsubsection{Teor de fósforo}

Os teores médios de fósforo, absorvidos pela parte aérea do milho, foram maiores para os fosfatos Patos, Alvorada e Catalão (que não diferiram entre si), seguidos do fosfato Arad e superfosfato triplo (SPT), que também não diferiram entre si. E os menores teores foram encontrados na testemunha (Tabela 15).

De acordo com Malavolta et al. (1974), os teores normais da parte aérea do milho (colmo + bainha + folha), aos 60 dias, variam de 1 a $3 \mathrm{~g} \mathrm{~kg}^{-1}$. Os teores obtidos com os fosfatos Arad, SPT foram baixos devido ao efeito de diluição do material seco, porém, apenas as plantas do tratamento controle (testemunha) apresentaram sintomas de deficiência de fósforo.

Braga et al. (1991), entretanto, verificaram que a utilização dos fosfatos Catalão, Patos, Gafsa, Araxá, termofosfatos e fosfatos calcinados e superfosfato triplo não mostraram efeitos significativos nos teores de $\mathrm{P}$ das folhas. Em valores numéricos, apenas a dose de $\mathrm{P}_{2} \mathrm{O}_{5}$ de $400 \mathrm{~kg} \mathrm{ha}^{-1}$ para as fontes mais solúveis aproximaram-se dos valores normais de $P$ nas folhas de soja.

Tabela 15 Teores de fósforo absorvidos pelo milho no primeiro plantio para os fosfatos utilizados.

\begin{tabular}{lcc}
\hline Fosfatos & Módia $\left(\mathrm{g} \mathrm{kg}^{-1}\right)$ & Teste Duncan \\
\hline Patos & 1,067 & A \\
Alvorada & 1,023 & A \\
Catalão & 0,997 & A \\
Arad & 0,854 & B \\
SPT & 0,772 & BC \\
Testemunha & 0,680 & C \\
\hline
\end{tabular}

Médias seguidas pela mesma letra não diferem entre si.

Somente o fosfato Catalão foi influenciado pela interação fosfato $\mathrm{x}$ dose $\mathrm{x}$ relação e utilizando a maior dose de $\mathrm{P}\left(200 \mathrm{mg} \mathrm{kg}^{-1}\right)$. Os teores encontrados foram crescentes com as relações de extração, ou seja, a relação de extração 1:400 (13,48 g vaso-1, a menor quantidade de fosfato) apresentou o maior teor de fósforo para a dose de $\mathrm{P}$ de 200 $\mathrm{mg} \mathrm{kg}^{-1}$. Já a maior quantidade de fosfato utilizada (relação $1 ; 100$ ) é que foi a de maior produção de material seco (Figura 9). 


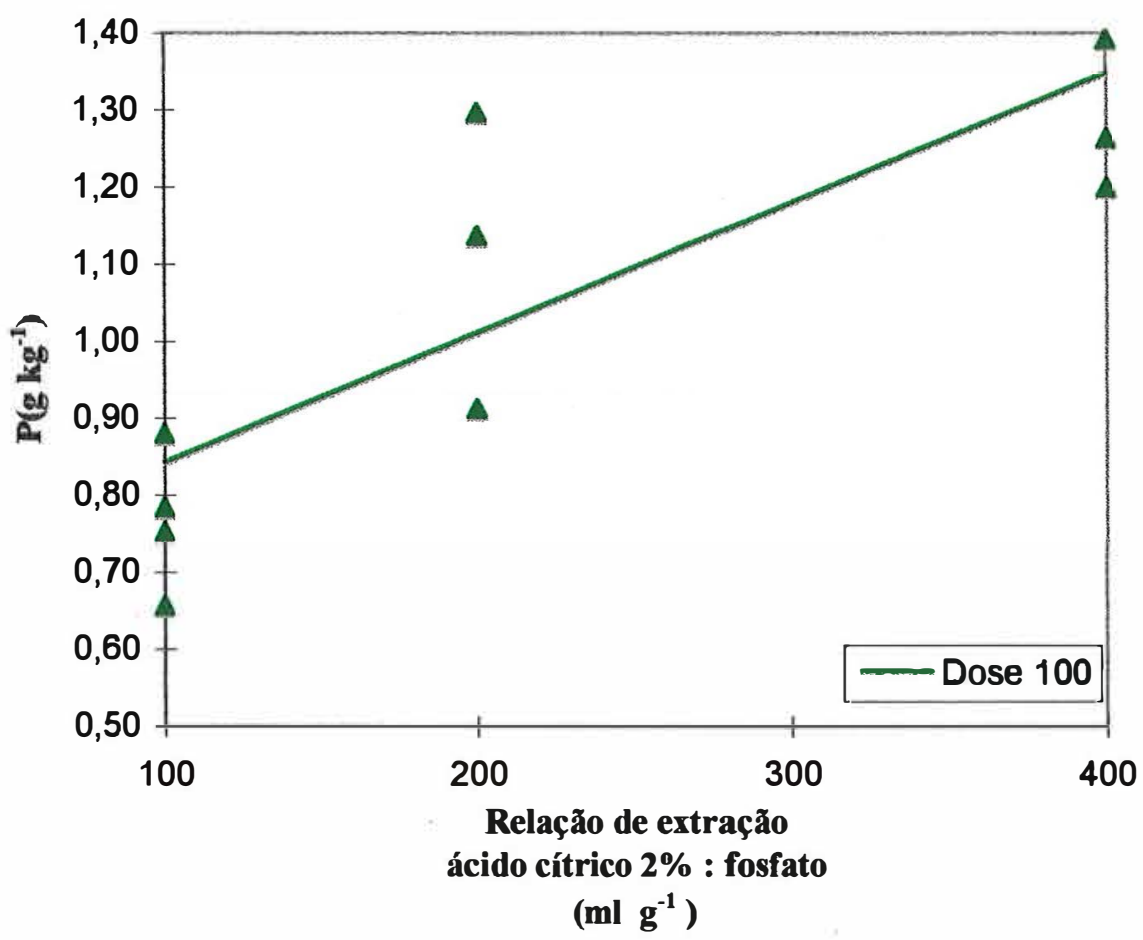

Figura 9 - Teores de fósforo obtidos no primeiro plantio de milho, em diferentes relações de extração, para a dose $200 \mathrm{mg} \mathrm{kg}^{-1}$ do fosfato Catalão.

Catalão $\quad Y=0,670+0,169 \times R^{2}=0,87^{* *}$

Os teores de fósforo nas plantas, obtidos com os fosfatos Patos e Arad, foram influenciados de modo diferente pelas relações de extração e doses, separadamente. Eles decresceram à medida que foram aumentando as relações de extração, sendo a relação 1:100 a de maior teor de fósforo absorvido, ou seja, quanto maior a quantidade de fosfato aplicado, mais fósforo foi absorvido. $\mathrm{O}$ teor encontrado nas plantas para o fosfato Patos foi maior que para Arad pela maior quantidade de fósforo aplicada (Figura 10) e, para o fosfato Alvorada, os teores de fósforo não foram influenciados pelas relações de extração. 


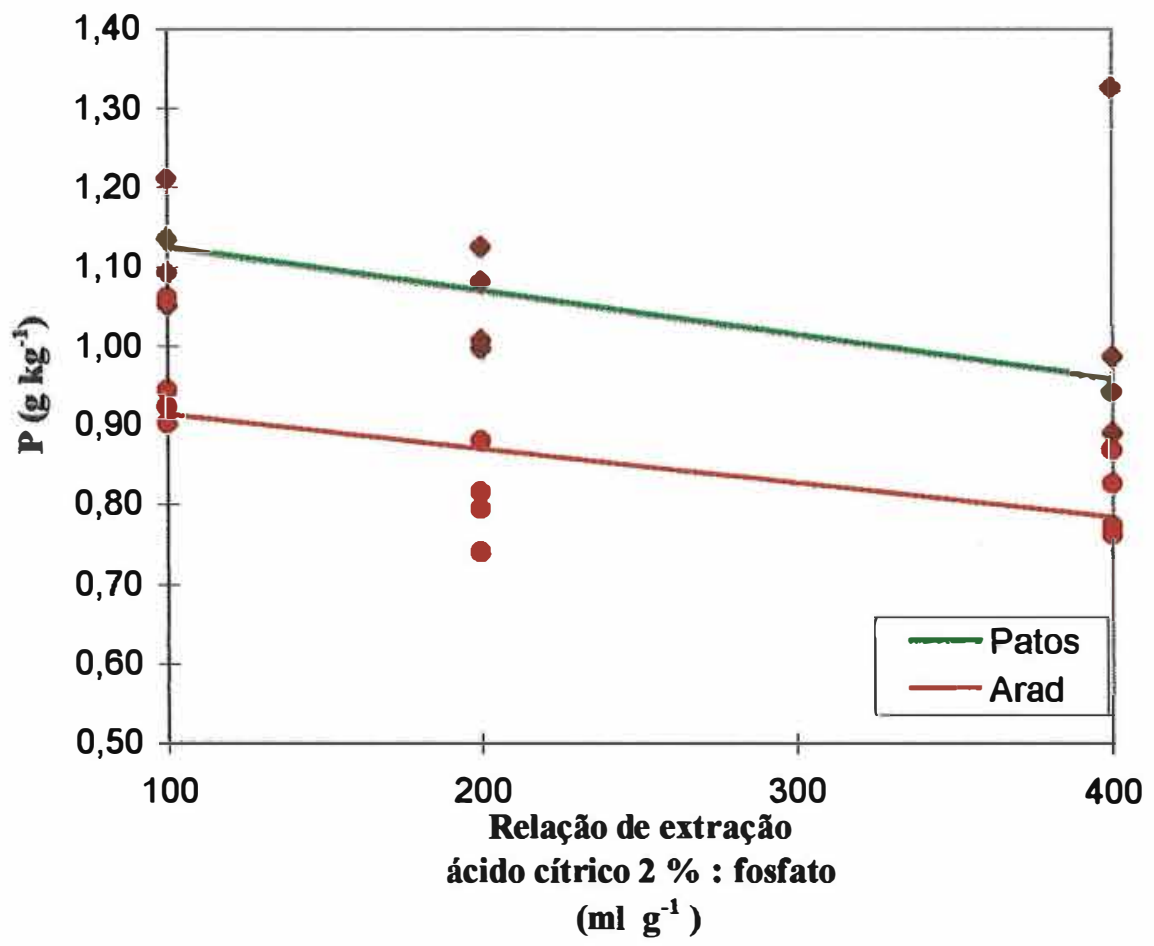

Figura 10 - Teores de fósforo obtidos no primeiro plantio de milho em diferentes relações de extração para os fosfatos Patos e Arad.

Patos $\quad Y=1,178+0,055 X \quad R^{2}=0,52$

Arad $\quad Y=0,953-0,043 \times \quad R^{2}=0,57$

Quanto às doses de fósforo, os teores de fósforo para os fosfatos Alvorada e Arad foram crescentes com o aumento das doses utilizadas e, para o fosfato Patos, eles decresceram (Figura 11). Isso pode significar que para os fosfatos de maior solubilidade em ácido cítrico $2 \%$, podem ser utilizadas doses maiores de $\mathrm{P}$ tendo-se aumento no teor encontrados nas plantas ou, como no caso do fosfato Alvorada, não influenciar no teor.

As plantas absorveram maior quantidade de fósforo na dose de $\mathrm{P}$ de $100 \mathrm{mg} \mathrm{kg}^{-1}$ do fosfato Patos, diminuindo o seu acúmulo com a elevação das doses. Ou seja, deve haver uma quantidade máxima de fosfato Patos, que pode ser utilizada, para que não seja diminuída a quantidade de $\mathrm{P}$ absorvida na parte aérea. Entretanto, não se pode dizer que isso causou prejuízos na produção de material seco obtida com o fosfato Patos, pois não houve efeito das relações de extração e das doses de fósforo utilizadas (Figura 11).

Malavolta et al. (1974) mostraram que, em vários trabalhos, utilizando os teores de $\mathrm{P}$ em folhas de milho provenientes de plantas adubadas e não adubadas com fósforo, 
não foram obtidas grandes diferenças entre eles. No presente trabalho, os teores encontrados não concordaram com a produção de material seco e quantidade de $\mathbf{P}$ encontrada. Isso se deve ao efeito da diluição do material seco, estando a quantidade de $\mathrm{P}$ absorvida mais diretamente relacionada com a produção de material seco.

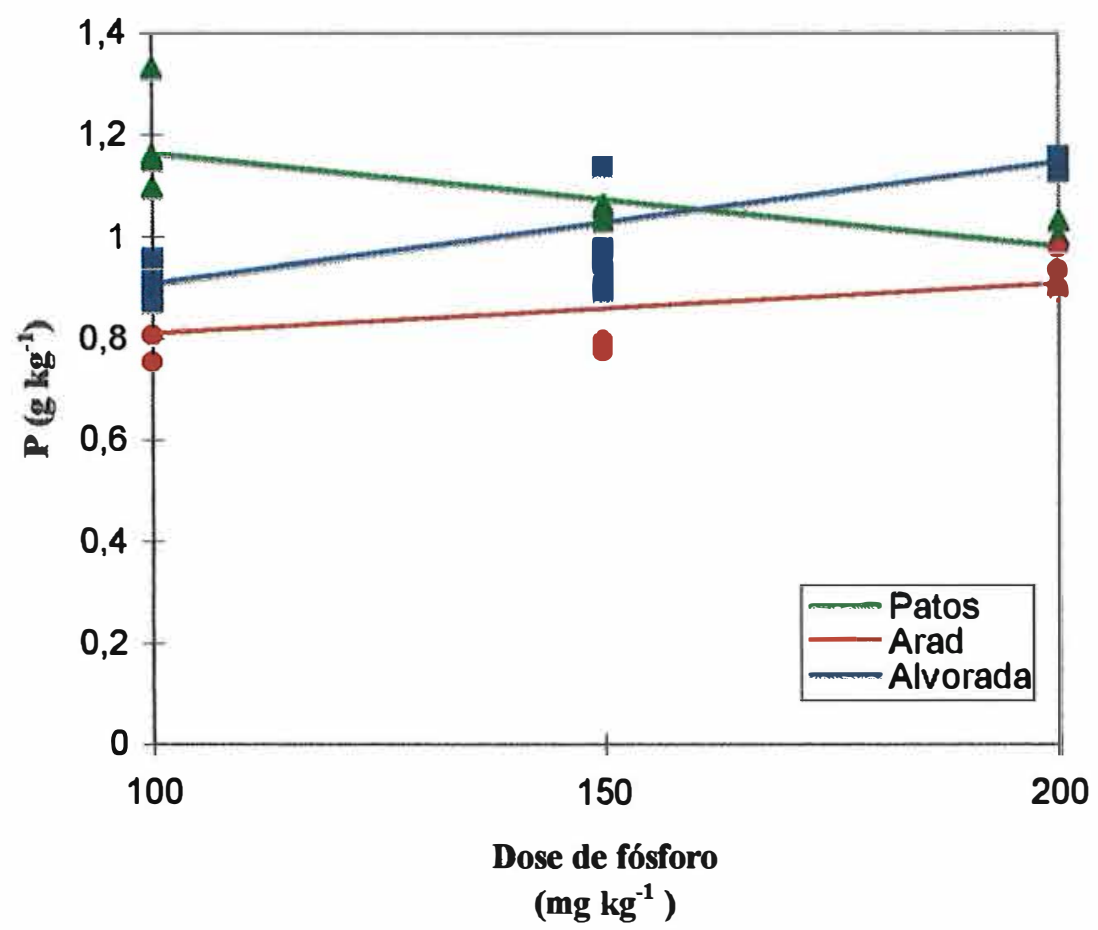

Figura 11 - Teores de fósforo obtidos no primeiro plantio de milho em diferentes doses de fósforo dos fosfatos Alvorada, Patos e Arad.

$\begin{array}{lll}\text { Alvorada } & \mathbf{Y}=\mathbf{0 , 7 8 5}+\mathbf{0 , 1 1 9} \mathbf{X} & \mathbf{R}^{2}=0,91^{*} \\ \text { Patos } & \mathbf{Y}=\mathbf{1 , 2 5 0}+\mathbf{0 , 0 9 1} \mathbf{X} & \mathbf{R}^{2}=\mathbf{0 , 9 9} \text { ** } \\ \text { Arad } & \mathbf{Y}=\mathbf{0 , 7 5 6}+\mathbf{0 , 0 4 9} \mathbf{X} & \mathbf{R}^{2}=\mathbf{0 , 6 0}\end{array}$

\subsubsection{Quantidade de fósforo}

A análise de variância para a quantidade de fósforo absorvida indicou que houve efeito de todos os fatores e interações, exceto para a interação fosfato $\mathrm{x}$ dose $\mathrm{x}$ relação (Tabela 12). A interação fosfato $\mathrm{x}$ dose $\mathrm{x}$ relação de extração não foi significativa, sugerindo que, para os fosfatos, não houve efeito na absorção de fósforo, quando foi utilizada a combinação dos fatores doses e relações de extração na adubação, devido a 
não realização da incubação conforme ocorreu com a produção de material seco. Os resultados concordaram com a produção de material seco, indicando que a quantidade de fósforo absorvida pode ter sido o fator limitante à produção.

Comparando-se as quantidades de $\mathrm{P}$ acumuladas pelos diferentes fosfatos, foi verificado que o fosfato Alvorada foi melhor que Arad, SPT, Catalão, Patos e testemunha (ordem decrescente, Tabela 16). 0 efeito dos fosfatos, doses, relações de extração foi idêntico ao efeito desses parâmetros sobre a produção de material seco, conforme observaram De Felipo et al. (1981), ao estudar o efeito dos fosfatos Araxá, Catalão, Patos e Tapira sobre a produção de material seco e absorção de fósforo em casa-devegetação.

Tabela 16 Quantidade de fósforo absorvida pelo milho no primeiro plantio para os fosfatos utilizados.

\begin{tabular}{lcc}
\hline Fosfatos & Média $\left(\mathbf{m g}\right.$ vaso $\left.^{-1}\right)$ & Teste Duncan \\
\hline Alvorada & 22,90 & A \\
Arad & 17,20 & B \\
SPT & 14,00 & C \\
Catalão & 9,70 & D \\
Patos & 6,20 & E \\
Testemunha & 0,90 & F \\
\hline
\end{tabular}

Médias seguidas pela mesma letra não diferem entre si ao nível de $5 \%$ de probabilidade.

Quanto às doses, a quantidade de fósforo absorvida pelo milho aumentou com a elevação das doses dos fosfatos Alvorada, Arad e Catalão (Figura 12), conforme também observaram Goedert \& Lobato (1984), trabalhando com doses de $\mathrm{P}_{2} \mathrm{O}_{5}$ total (88 e 350 $\mathrm{kg} \mathrm{ha}^{-1}$ ) dos fosfatos Patos, Araxá, Abaeté e Catalão. O fosfato Alvorada superou o fosfato Arad e Catalão no primeiro plantio. E o fosfato Patos não teve efeito, não havendo diferença da utilização de doses de fosfato, que variaram de 8,02 até $32 \mathrm{~g}$ vaso $^{-1}$ devido à sua menor reatividade, granulometria ou utilização de doses insuficientes para a obtenção de resultados.

Os resultados de quantidade de fósforo absorvida pelo milho concordaram com a produção de material seco, conforme Perez \& Neptune (1987), que obtiveram em todos os níveis de $\mathrm{P}$ estudados, correlação alta entre material seco e absorção de fósforo como no presente trabalho. 
A relação de extração também influenciou a quantidade de fósforo absorvida. $\mathrm{O}$ fosfato Alvorada apresentou maior acúmulo de fósforo que Arad e Catalão e a relação 1:100 foi a de maior disponibilidade de fósforo às plantas para todos os fosfatos, exceto Patos que não teve efeito, concordando com os resultados de produção de material seco (Figura 13).

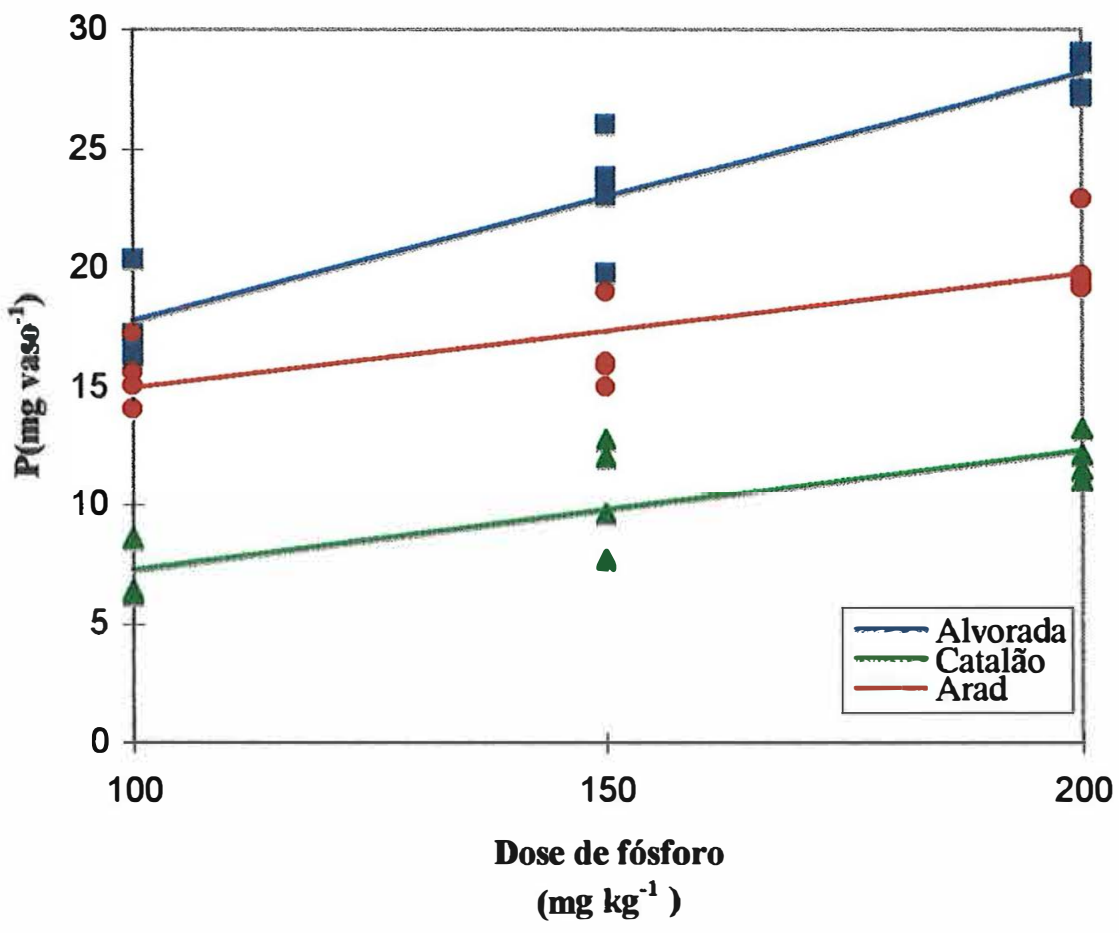

Figura 12 - Quantidade de fósforo absorvida (g/ vaso) no primeiro plantio de milho em diferentes doses para os fosfatos Alvorada, Catalão e Arad.

Alvorada

Catalão

Arad

$$
\begin{array}{ll}
\mathbf{Y}=12,480+5,200 X & \mathbf{R}^{2}=0,99^{* *} \\
\mathbf{Y}=4,580+2,560 X & \mathbf{R}^{2}=0,94^{* *} \\
\mathbf{Y}=12,440+\mathbf{2 , 4 1 0} \mathbf{X} & \mathbf{R}^{2}=0,87^{* *}
\end{array}
$$




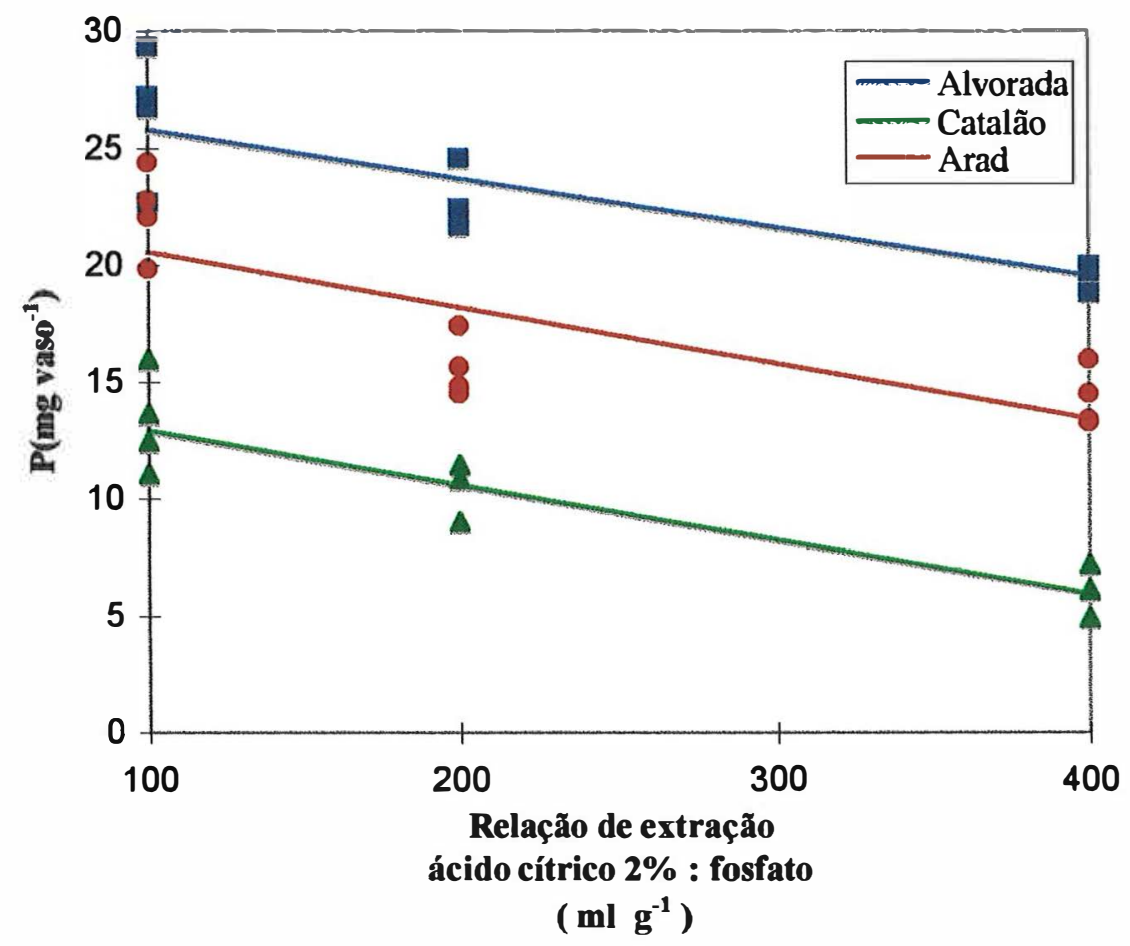

Figura 13 - Quantidade de fósforo acumulado no primeiro plantio de milho, para diferentes relaçōes, para os fosfatos Alvorada, Catalão e Arad.

$\begin{array}{lll}\text { Alvorada } & \mathbf{Y}=27,740+2,080 X & \mathbf{R}^{2}=0,92^{* *} \\ \text { Catalão } & \mathbf{Y}=7,775+2,320 \times & \mathbf{R}^{2}=0,98^{* *} \\ \text { Arad } & \mathbf{Y}=\mathbf{2 2 , 7 9 0}+\mathbf{2 , 3 7 0} \mathbf{X} & \mathbf{R}^{2}=0,71^{*}\end{array}$

\subsection{4 Índice de eficiência agronômica ( IEA )}

Os índices de eficiência agronômica foram maiores para o fosfato Alvorada, seguido de Arad, Catalão e Patos (Tabela 17), seguindo a tendência da solubilidade em ácido cítrico $2 \%$ (relação 1:100). Pode-se distingir 2 grupos em termos de IEA (\%): solubilidade alta (Alvorada e Arad) e baixa (Catalão e Patos). Esse maior índice de eficiência agronômica dos fosfatos Alvorada e Arad é devido às suas altas reatividades, comparadas as dos outros fosfatos. 
Tabela 17 Índices de eficiência agronômica dos fosfatos utilizados obtidos no primeiro plantio

\begin{tabular}{lcc}
\hline Fosfatos & IEA(\%) & Teste Tukey \\
\hline Alvorada & 126,10 & A \\
Arad & 113,06 & B \\
Catalão & 55,49 & C \\
Patos & 27,24 & D \\
\hline
\end{tabular}

DMS=2,77 Médias seguidas pela mesma letra não diferem entre si ao nível de $5 \%$ deprobabilidade.

Os resultados foram influenciados pelo efeito dos fatores e interações, exceto para fosfato $\mathrm{x}$ dose $\mathrm{x}$ relação de extração, concordando com os resultados de material seco e quantidade de fósforo absorvida (Tabela 11).

À medida que houve aumento das doses de fosfato, os índices aumentaram para todos os fosfatos, exceto Patos (Figura 14). Blanco et al.(1965),também, verificaram que, com o aumento das doses do fosfato Alvorada, a produção relativa da soja (efeito residual) elevou de 90 para 100 para o fosfato Alvorada, de 83,9 para 90,0 para a apatita de Araxá e para o SPS diminuiu para 80,0.

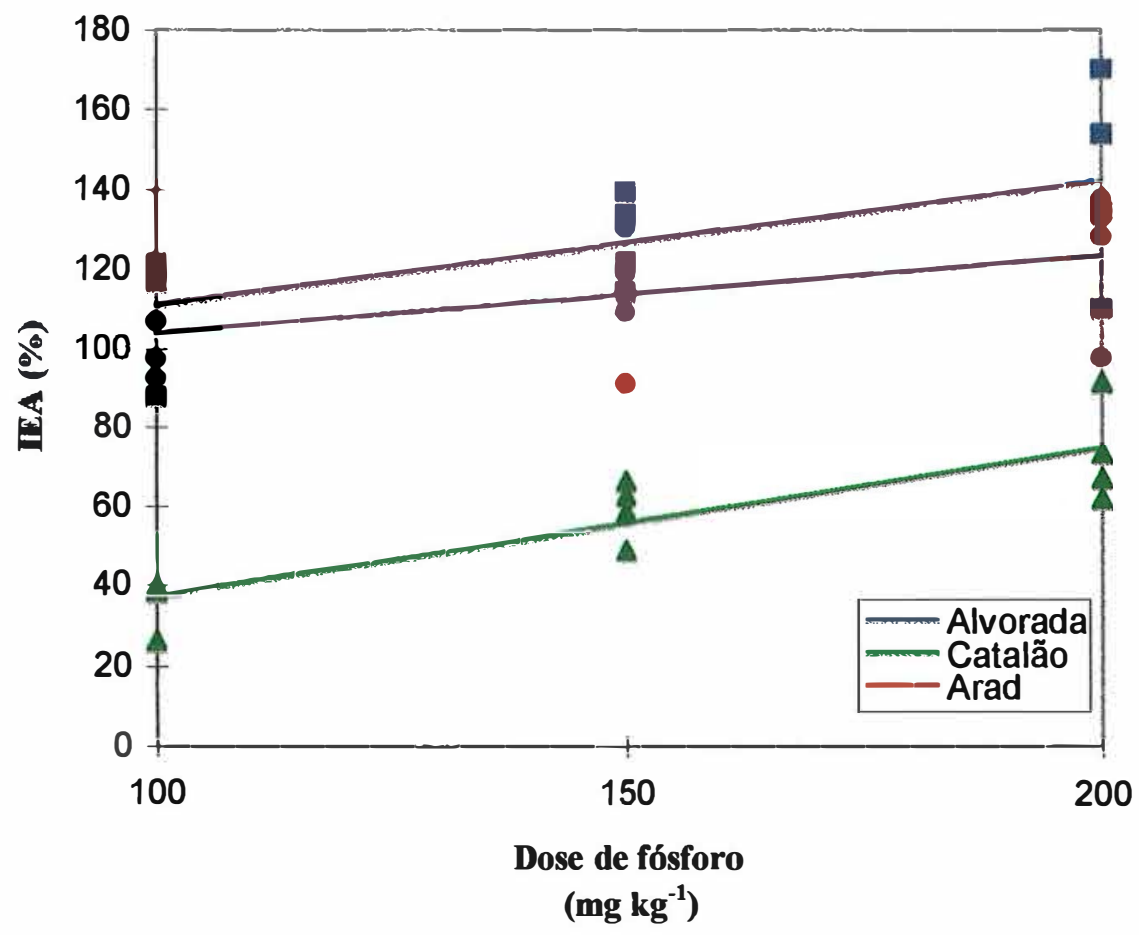

Figura 14 - Índice de Eficiência Agronômica (\%) no primeiro plantio de milho em diferentes doses para os fosfatos Alvorada, Catalão e Arad.

$\begin{array}{llll}\text { Alvorada } & \mathbf{Y}=\mathbf{9 4 , 4 5 0}+\mathbf{1 5 , 8 2 0} \mathbf{X} & \mathbf{R}^{2}=\mathbf{0 , 9 9} * * \\ \text { Catalão } & \mathbf{Y}=\mathbf{1 7 , 7 2 9}+\mathbf{1 8 , 8 8 1} \mathbf{X} & \mathbf{R}^{2}=\mathbf{0 , 9 8}^{* *} \\ \text { Arad } & \mathbf{Y}=\mathbf{9 3 , 2 7 9}+\mathbf{9 , 8 9 2} \mathbf{X} & \mathbf{R}^{2}=\mathbf{0 , 9 8}\end{array}$


O índice de eficiência agronômica, também, foi influenciado pelas relações de extração para os fosfatos Alvorada, Arad e Catalão (Figura 15) e a relação 1:100 apresentou a maior disponibilidade de fósforo às plantas. Para o fosfato Patos, não foi significativo devido à sua menor reatividade .

No presente estudo, os índices de eficiência agronômica do fosfato Catalão foram superiores aos do fosfato Patos, concordando com Braga et al. (1991), que avaliando no primeiro plantio de soja, obtiveram IEA(\%) de 28 para Catalão e de 8 para Patos., quando foram utilizados na dose de $\mathrm{P}_{2} \mathrm{O}_{5}$ total de $400 \mathrm{~kg} \mathrm{ha}^{-1}$. Já Goedert (1983), em dois experimentos de campo com trigo, com a dose de de $\mathrm{P}_{2} \mathrm{O}_{5}$ total de $200 \mathrm{~kg} \mathrm{ha}{ }^{-1}$, obtiveram IEA(\%) para os fosfatos Araxá, Patos e Catalão de 23, 16 e 8.

Os resultados obtidos podem ter sido devido à maior parte das partículas terem diâmetro maior, comparado ao fosfato Catalão, aliado à provável diferença do fosfato Patos na composição química dos fosfatos utilizados, pois há variação entre os fosfatos, mesmo dentro de uma mesma jazida.

Assim, a utilização de doses previamente fixadas e iguais para todos os fosfatos não deve ser um bom parâmetro para a melhor utilização de fosfatos naturais diferentes. A solubilidade dos fosfatos naturais em ácido cítrico $2 \%$ na relação $1: 100$ pode ser utilizada como parâmetro para avaliar sua possível disponibilidade de fósforo no solo. 


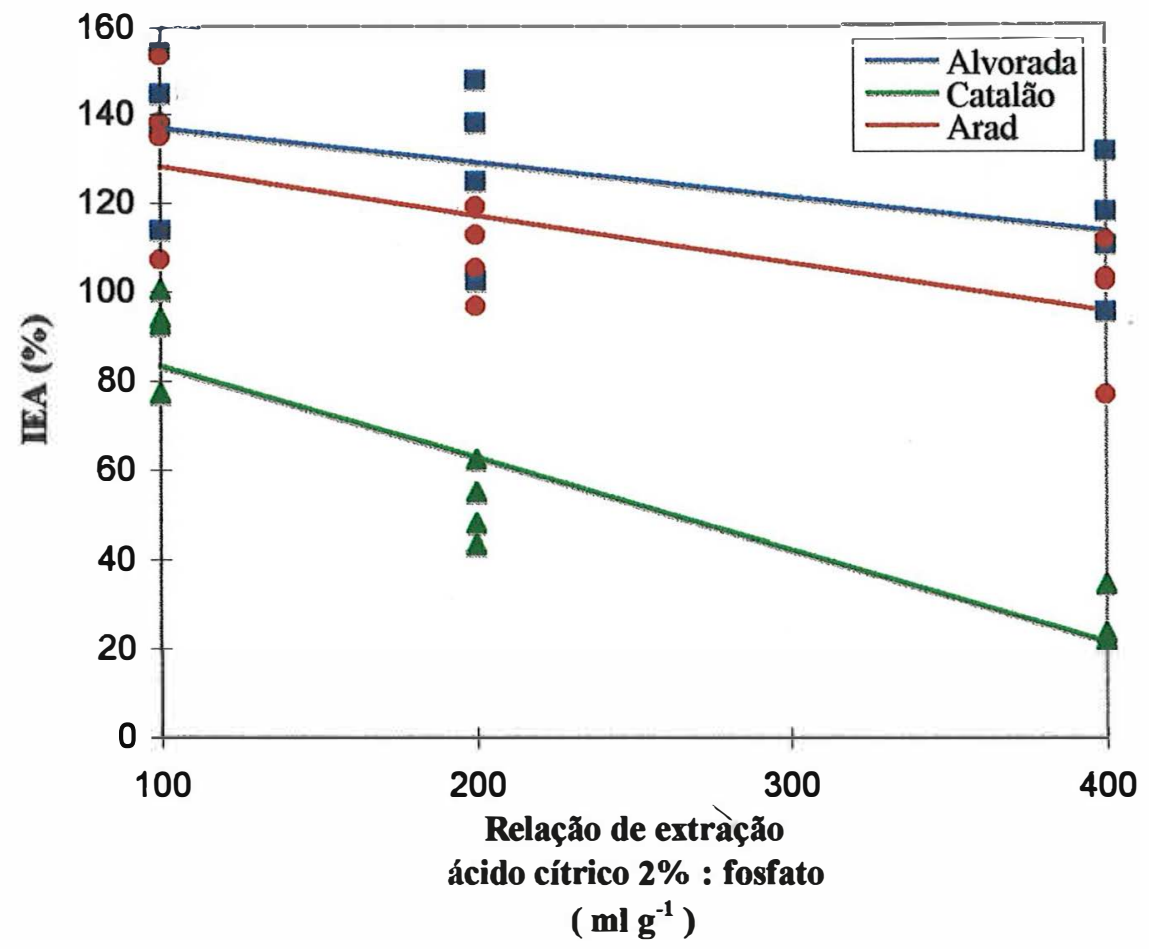

Figura 15 - Índice de Eficiência Agronômica (\%) no primeiro plantio de milho em diferentes relações de extração para os fosfatos Alvorada, Catalão e Arad.

$\begin{array}{llll}\text { Alvorada } & \mathbf{Y}=\mathbf{1 4 3 , 8 6 2}+\mathbf{7 , 6 1 4} \mathbf{X} & \mathbf{R}^{2}=0,99 * * \\ \text { Catalão } & \mathbf{Y}=\mathbf{1 0 3 , 2 5 2}+\mathbf{2 0 . 4 6 9} \mathbf{X} & \mathbf{R}^{2}=\mathbf{0 , 9 0} 0^{* *} \\ \text { Arad } & \mathbf{Y}=\mathbf{1 3 7 , 7 2 8}+\mathbf{1 0 , 5 7 1} \mathbf{X} & \mathbf{R}^{2}=\mathbf{0 , 8 2} \text { ** }\end{array}$

\subsubsection{Outros nutrientes}

\subsubsection{Teor e quantidade de nitrogênio}

A concentração de nitrogênio presente no material seco foi diferente para os fosfatos naturais. Os valores decresceram do fosfato Patos, seguido por Catalão, Arad e Alvorada pelo efeito de diluição do material seco. $\mathrm{O}$ acúmulo de nitrogênio pelo milho também diferiu para os fosfatos, devido à maior solubilidade e disponibilidade de fósforo dos fosfatos Alvorada e Arad, que causaram maior aumento de material seco, absorção total de fósforo e de nitrogênio (Tabela 18). 
Tabela 18 Teores e quantidades médias de nitrogênio absorvidos pelo milho no primeiro plantio.

\begin{tabular}{|c|c|c|}
\hline Fosfato & Teor $\left(\mathrm{g} \mathrm{kg}^{-1}\right)$ & Quantidade (mg vaso ${ }^{-1}$ ) \\
\hline Patos & $20,46 \mathrm{~A}$ & $117,20 \mathrm{C}$ \\
\hline Catalão & $16,84 \mathrm{~B}$ & $157,50 \mathrm{~B}$ \\
\hline Arad & $14,32 \mathrm{C}$ & $283,10 \mathrm{~A}$ \\
\hline Alvorada & $11,92 \mathrm{D}$ & $262,00 \mathrm{~A}$ \\
\hline
\end{tabular}

A quantidade de nitrogênio absorvida pelo miho foi influenciada por todos os fatores (Tabela 12). As doses utilizadas para cada fosfato e a interação fosfato $\mathrm{x}$ dose $\mathrm{x}$ relação, no entanto, não apresentaram efeito sobre a absorção de nitrogênio. $O$ comportamento dos fosfatos sobre a absorção de nitrogênio foi diferente para as quantidades de fosfato aplicadas em função da relação de extração (solubilidade em ácido cítrico 2\%). À medida que a relação de extração variou de 1:100 (maior quantidade de fosfato adicionada) para 1:400 (menor quantidade de fósforo adicionada), a quantidade de nitrogênio absorvida diminuiu para os fosfatos Alvorada, Arad e Catalão (Figura 16). E quando o fósforo deixou de ser limitante, com a quantidade de fosfato aplicada com base na relação 1:100, houve maior produção de material seco e absorção de fósforo e nitrogênio.

Para o fosfato Patos, não houve efeito, provavelmente, devido à sua menor solubilidade, que não causou efeito na produção de material seco e, consequentemente, na absorção de nitrogênio pelas plantas. 


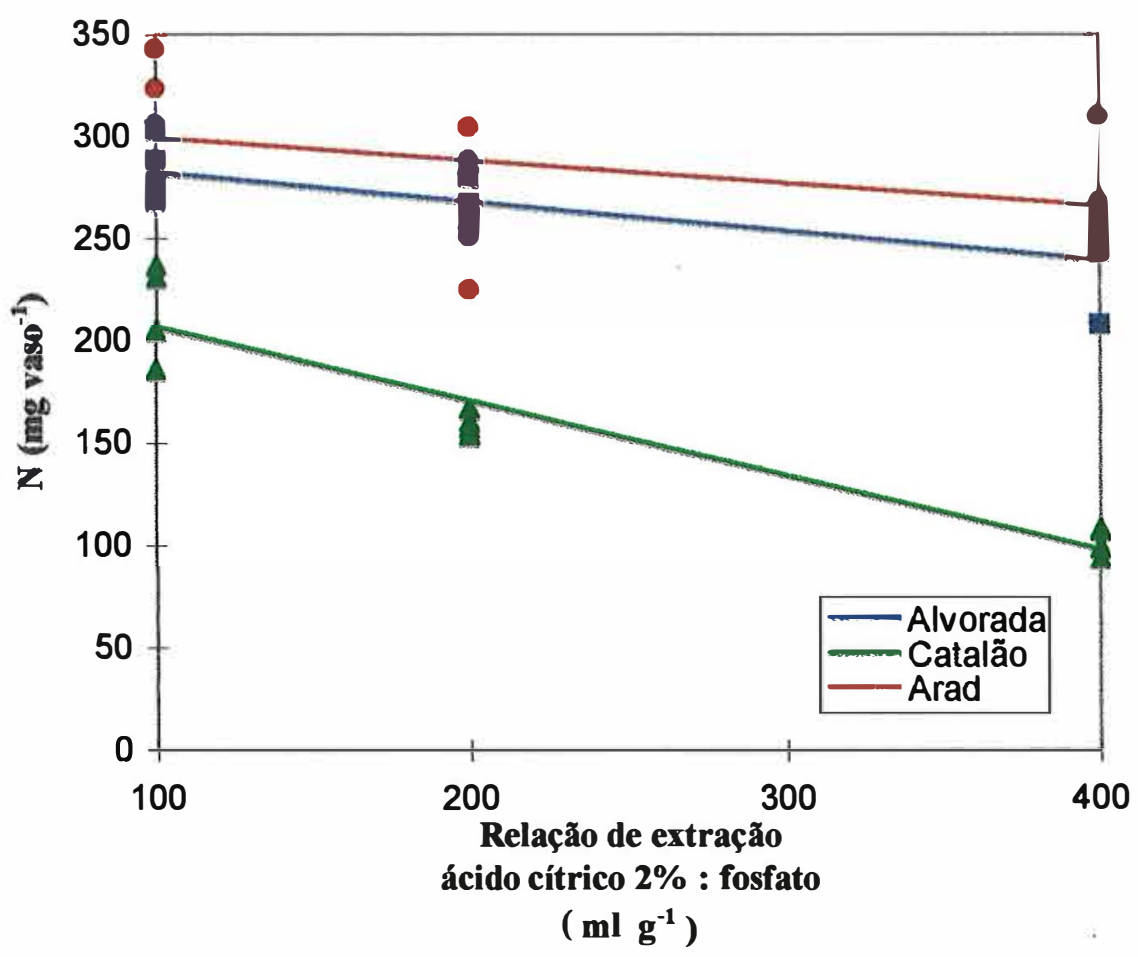

Figura 16 - Quantidade de nitrogênio absorvido pelo milho no primeiro plantio de milho em diferentes relaçōes de extração.

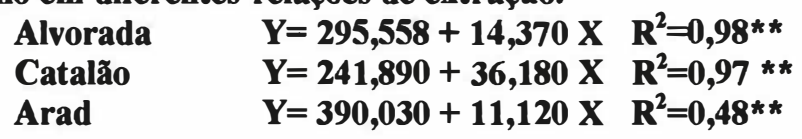

\subsubsection{Teor e quantidade de potássio}

As plantas de milho apresentaram diferentes teores de potássio para os fosfatos naturais. Para o fosfato Patos, foram encontradas concentrações superiores àquelas dos fosfatos Catalão, Arad e Alvorada devido ao efeito de diluição do material seco (Tabela 19).

A quantidade de potássio absorvida para o fosfato Alvorada superou Arad, Catalão e Patos. Isto ocorreu devido à sua solubilidade e disponibilidade de fósforo, aumentando a produção de material seco e à absorção total do nutriente. 
Tabela 19 Teores e quantidades médias de potássio absorvidos pelo milho no primeiro plantio.

\begin{tabular}{lcc}
\hline Fosfato & Teor $\left(\mathrm{g} \mathrm{kg}^{-1}\right)$ & Quantidade $\left(\mathrm{mg} \mathrm{vaso}^{-1}\right)$ \\
\hline Patos & $37,62 \mathrm{~A}$ & $215,2 \mathrm{D}$ \\
Catalão & $28,97 \mathrm{~B}$ & $250,8 \mathrm{C}$ \\
Arad & $14,94 \mathrm{C}$ & $293,4 \mathrm{~B}$ \\
Alvorada & $14,66 \mathrm{C}$ & $319,8 \mathrm{~A}$ \\
\hline \multicolumn{2}{l}{\begin{tabular}{l} 
Médias seguidas pela mesma letra não diferem entre si pelo teste de Tukey (5\%). \\
\multicolumn{2}{c}{ DMS $=2,31 \mathrm{~g} \mathrm{~kg}^{-1}$} & DMS $=2,11 \mathrm{mg} \mathrm{vaso}^{-1}$
\end{tabular}}
\end{tabular}

As quantidades de potássio foram influenciadas por todos os fatores, exceto doses $\mathrm{x}$ relação de extração (Tabela 12). $\mathrm{O}$ comportamento dos fosfatos diferiu para as relações de extração e doses utilizadas.

Para o fosfato de Arad, 16,70 $\mathrm{g}_{\text {vaso }}{ }^{-1}$ (relação $1: 100$, dose $200 \mathrm{mg} \mathrm{kg}^{-1}$ ) forneceu as quantidades de fósforo necessárias para aumentar a quantidade de potássio absorvida (Figura 17), concordando com o tratamento de maior produção de material seco.

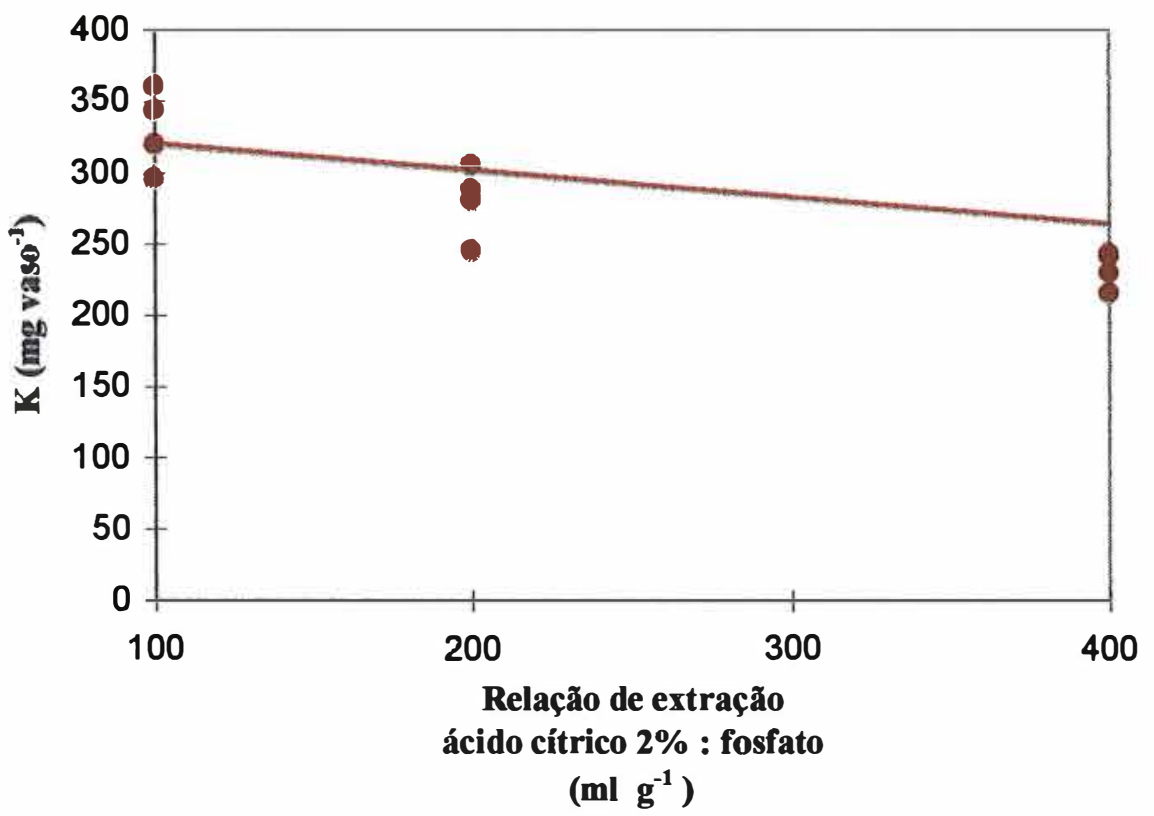

Figura 17 - Quantidade de potássio absorvido pelo milho no primeiro plantio de milho em diferentes relações de extração para o fosfato Arad utilizado na dose de $P$ de $200 \mathrm{mg} \mathrm{kg}^{-1}$

Arad $\quad Y=337,500-18,600 X \quad R^{2}=0,73^{*}$ * 
O comportamento do fosfato Catalão foi diferente, havendo efeito para todas as doses utilizadas, pela menor reatividade do fosfato, que precisou de maior quantidade de fosfato para atingir o maior acúmulo de potássio. A absorção de $\mathrm{K}$ reduziu à medida que decresceram as quantidades de fosfato aplicadas em função da relação de extração, ou seja, as maiores produções e absorções de potássio foram atingidas com a maior quantidade de fosfato aplicada (relação 1:100) pela maior produção de material seco (Figura 18).

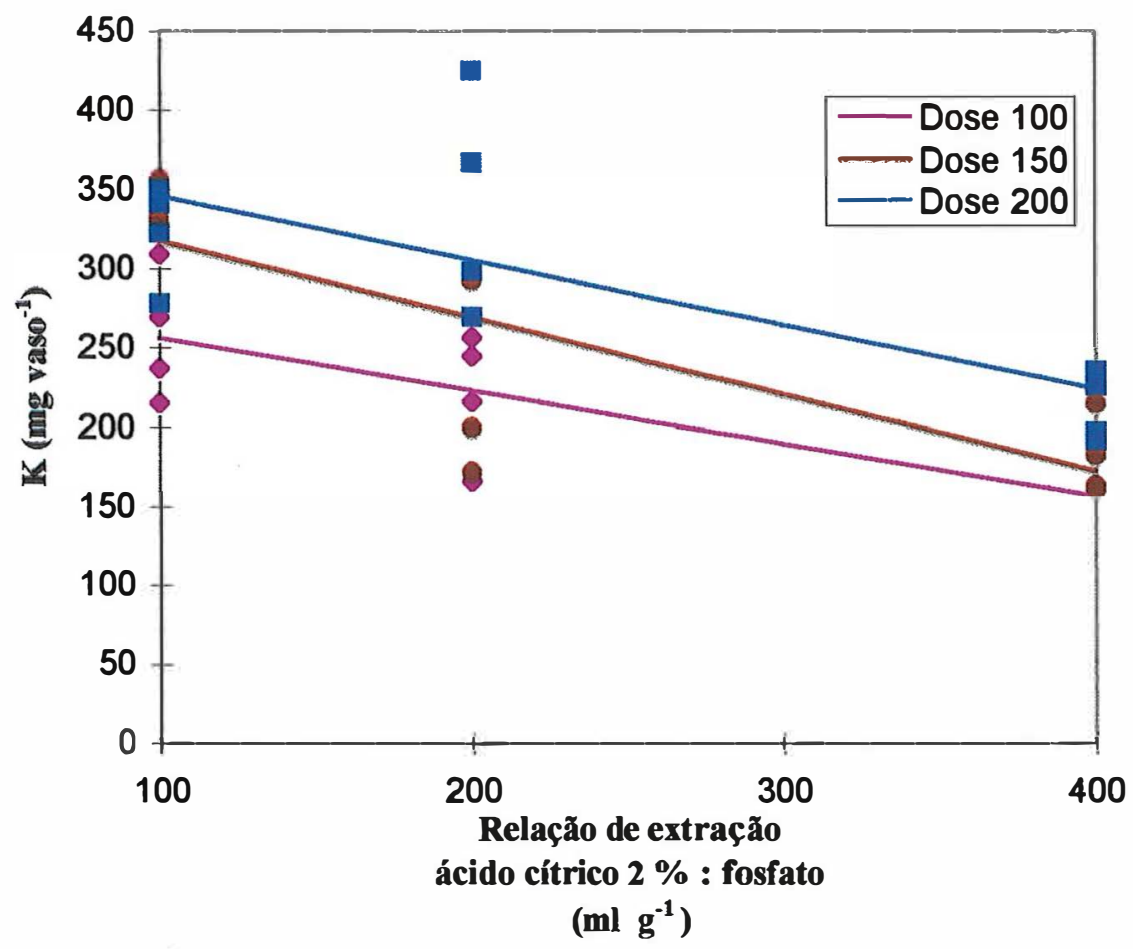

Figura 18 - Quantidade de potássio absorvido pelo milho no primeiro plantio de milho em diferentes relações de extração e doses de fósforo para o fosfato Catalão. Dose 100

Dose 150 $Y=287,600+33,100 \times R^{2}=0,98$ * *

Dose 200

$Y=364,200+48,200 X \quad R^{2}=0,89^{\text {* * }}$

$Y=384,500+40,500 X \quad R^{2}=0,80$ ** 


\subsubsection{Teor e quantidade de cálcio}

Os teores médios de cálcio encontrados na parte aérea do milho foram adequados (1,5 a $3 \mathrm{~g} \mathrm{~kg}^{-1}$, Malavolta et al., 1974). O fosfato Arad obteve maior acúmulo de cálcio, seguido de Catalão, Patos e Alvorada (Tabela 20). Os resultados seguiram a ordem decrescente de solubilidade em ácido ć́trico $2 \%$ e dos teores de cálcio presentes nos fosfatos naturais: 3,$87 ; 3,54 ; 3,80 \mathrm{e} 2,68 \mathrm{~g} \mathrm{~kg}^{-1}$.

Tabela 20 Teores e quantidades médias de cálcio absorvidos pelo milho no primeiro plantio.

\begin{tabular}{|c|c|c|}
\hline Fosfato & Teor $\left(\mathrm{g} \mathrm{kg}^{-1}\right)$ & Quantidade (mg vaso ${ }^{-1}$ ) \\
\hline Arad & $2,38 \mathrm{~A}$ & $47,40 \mathrm{~A}$ \\
\hline Catalão & $1,82 \mathrm{~B}$ & $19,20 \mathrm{C}$ \\
\hline Patos & $1,70 \mathrm{~B}$ & 9,90 D \\
\hline Alvorada & $1,67 \mathrm{~B}$ & $37,10 \mathrm{~B}$ \\
\hline
\end{tabular}

As quantidades de cálcio absorvidas pelo milho foram influenciadas por todos os fatores, exceto para fosfato $\mathrm{x}$ dose $\mathrm{e}$ fosfato $\mathrm{x}$ dose $\mathrm{x}$ relação (tabela 12). Para $\mathrm{o}$ fosfato Patos, não houve efeito sobre o acúmulo de cálcio na planta, seguindo o mesmo comportamento da produção de material seco.

A relação de extração 1:100 (maior quantidade de fosfato aplicada) foi a de maior resultado para os fosfatos Arad e Catalão, decrescendo à medida que as quantidades de fosfatos aplicadas foram diminuídas (relação 1:400).

O melhor resultado obtido para o fosfato Arad, comparado a Catalão, pode ser devido à sua composição química e solubilidade, o que não ocorreu para o fosfato Alvorada, o qual não obteve efeito (Figura 19). O resultado obtido concorda com Hellums et al. (1989) que obtiveram que a efetividade da resposta do cálcio pelo milho quando foram utilizados fosfatos naturais, seguiu a ordem de sua reatividade. 


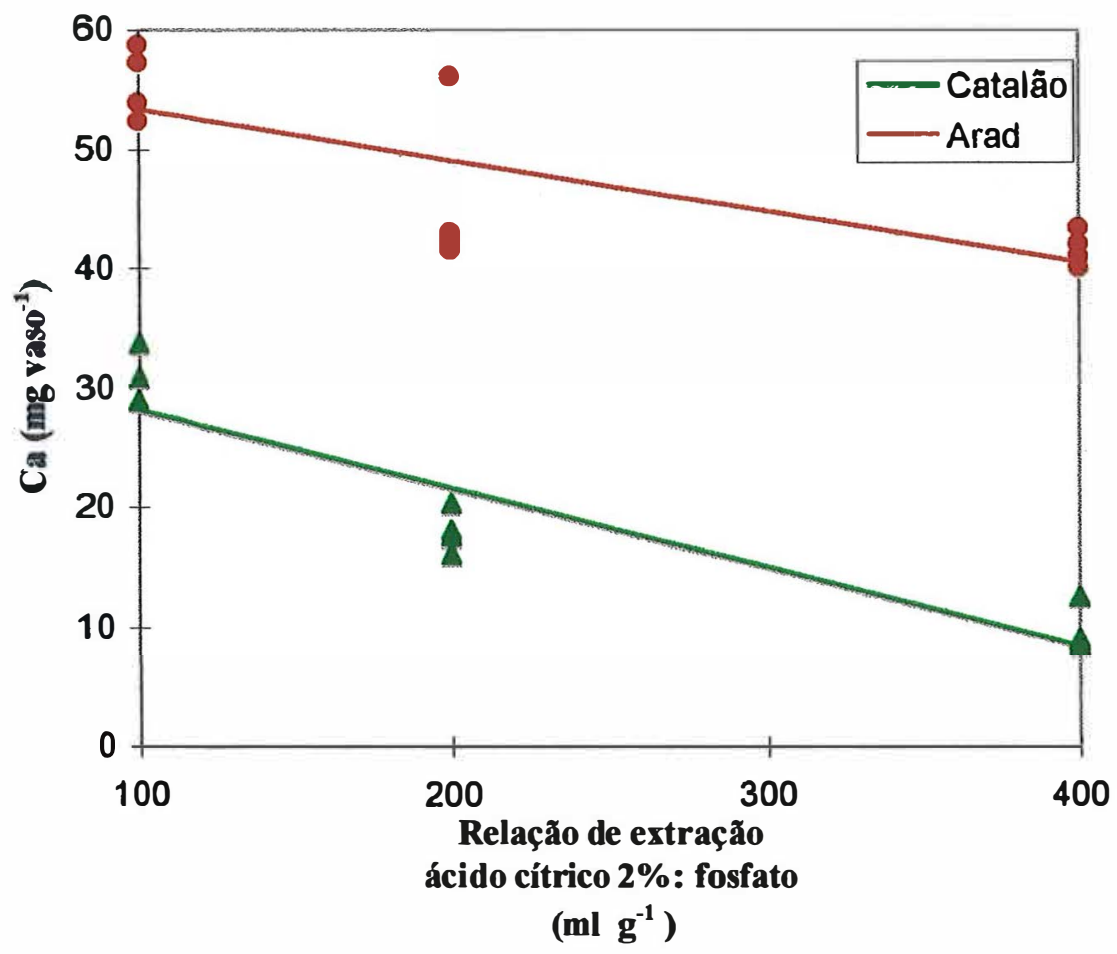

Figura 19 - Quantidade de cálcio absorvida pelo milho no primeiro plantio de milho em diferentes relações de extração para os fosfatos Catalão e Arad.

$$
\begin{array}{lll}
\text { Catalão } & \mathbf{Y}=34,470+6,540 \times & \mathbf{R}^{2}=0,91 \text { ** } \\
\text { Arad } & \mathbf{Y}=57,380+4,260 X & \mathbf{R}^{2}=0,88 \text { * }
\end{array}
$$

\subsubsection{Teor e quantidade de magnésio}

A concentração de magnésio encontrada na parte aérea do milho foi adequada ( 1 a $3 \mathrm{~g} \mathrm{~kg}^{-1}$, Malavolta et al., 1974) e não diferiu para os fosfatos naturais utilizados (Tabela 21). Nos tratamentos com os fosfatos Alvorada e Arad, as plantas absorveram quantidades de magnésio superiores àquelas apresentadas para os fosfatos Catalão e Patos, resultantes de sua maior produção de material seco (Tabela 21). 
Tabela 21 Teores e quantidades médias de Mg absorvidos pelo milho no primeiro plantio.

\begin{tabular}{|c|c|c|}
\hline Fosfato & Teor $\left(\mathrm{g} \mathrm{kg}^{-1}\right)$ & Quantidade (mg vaso ${ }^{-1}$ ) \\
\hline Arad & $1,05 \mathrm{~A}$ & $20,90 \mathrm{~A}$ \\
\hline Alvorada & $1,82 \mathrm{~A}$ & $21,50 \mathrm{~A}$ \\
\hline Patos & $1,70 \mathrm{~A}$ & $9,80 \mathrm{~B}$ \\
\hline Catalão & $1,67 \mathrm{~A}$ & $5,60 \mathrm{C}$ \\
\hline
\end{tabular}

As quantidades de magnésio absorvidas foram influenciadas por todos os fatores $\mathrm{e}$ apenas pelas interações fosfato $\mathrm{x}$ dose $\mathrm{e}$ fosfato $\mathrm{x}$ dose $\mathrm{x}$ relação de extração (tabela 11). Para o fosfato Alvorada, o acúmulo de magnésio pelo milho foi maior com $8,00 \mathrm{~g}$ de fosfato/vaso (relação $1: 100$, dose $100 \mathrm{mg} \mathrm{kg}^{-1} \mathrm{de} \mathrm{P}$ ), que não correspondeu à de maior produção de Material seco. As plantas podem ter atingido a suficiência do nutriente, pois as doses 150 e 200 não apresentaram efeito sobre a quantidade de magnésio absorvida (figura 20).

Para os fosfatos Arad e Catalão, as quantidades absorvidas de magnésio decresceram à medida que foram reduzidas as quantidades de fosfato aplicadas para todas as doses de fósforo utilizadas (figuras 21 e 22). Entretanto, a utilização de 12,53 g/vaso do fosfato Arad (relação 1:100, dose $150 \mathrm{mg} \mathrm{kg}^{-1}$ de P) foi a de maior resultado devido a planta, provavelmente, ter atingido o nível de suficiência de magnésio. Para o fosfato Catalão foi necessário 41, $97 \mathrm{~g} /$ vaso (relação $1: 100$, dose $200 \mathrm{mg} \mathrm{kg}^{-1} \mathrm{P}$ ) devido à sua menor solubilidade. 


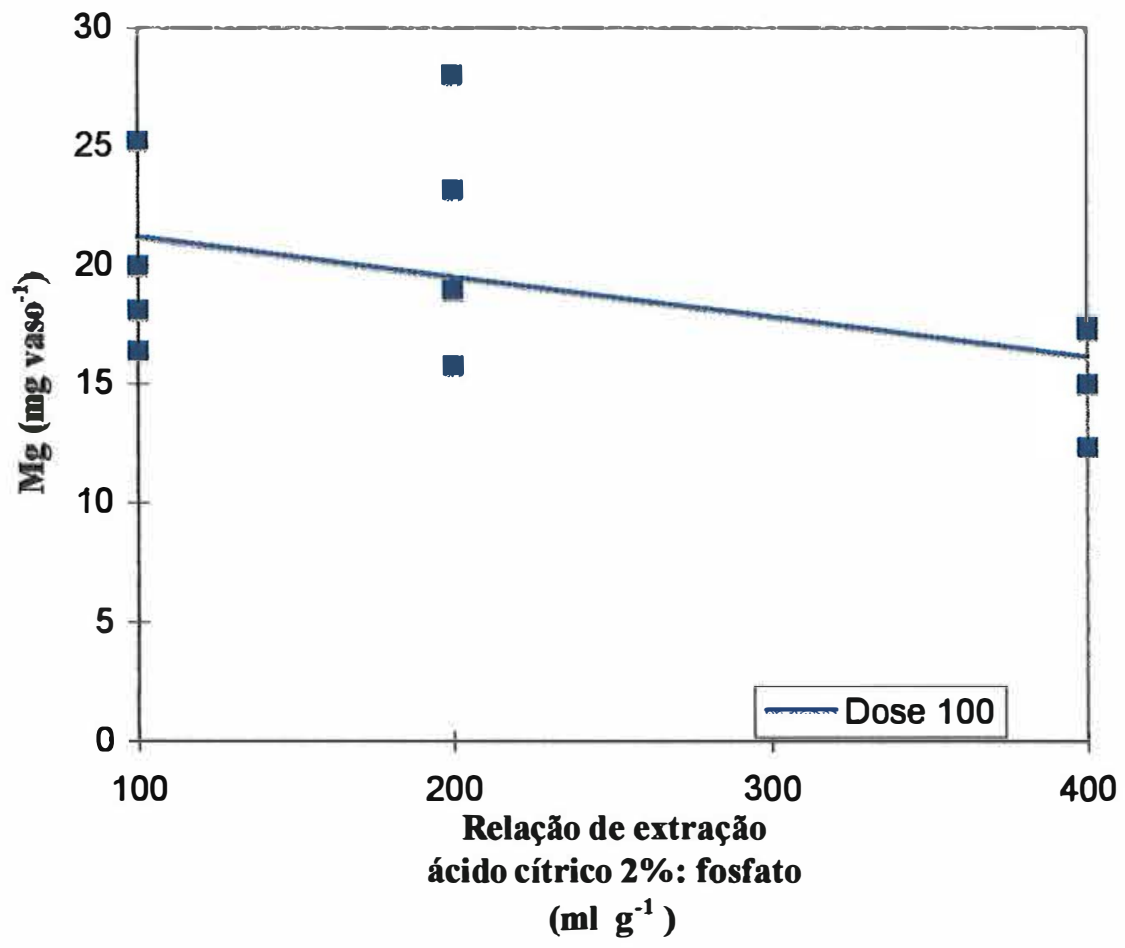

Figura 20 - Quantidade de magnésio absorvida pelo milho no primeiro plantio de milho diferentes relações de extração para o fosfato Alvorada na dose de $P$ de $100 \mathrm{mg} \mathrm{kg}^{-1}$. Alvorada $\quad Y=27,700+1,680 X \quad R^{2}=0,69^{*} *$ 


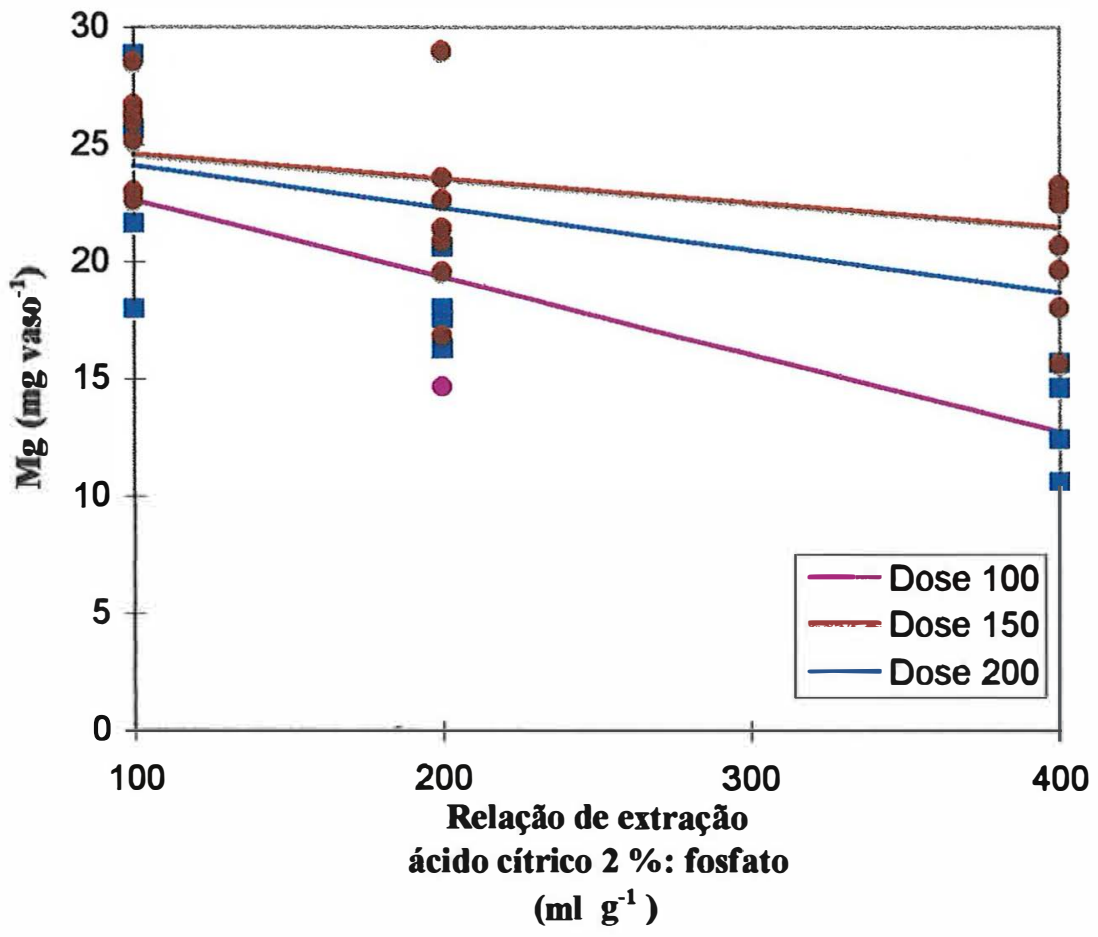

Figura 21 - Quantidade de magnésio absorvida pelo milho no primeiro plantio de milho em diferentes relações de extração e doses para o fosfato Arad.

Dose 100

Dose 150

Dose 200
$Y=25,810+3,280 \times R^{2}=0,95 *$ *

$Y=25,490+1,020 X R^{2}=0,57 *$ *

$Y=25,760+1,790 \times R^{2}=0,78$ ** 


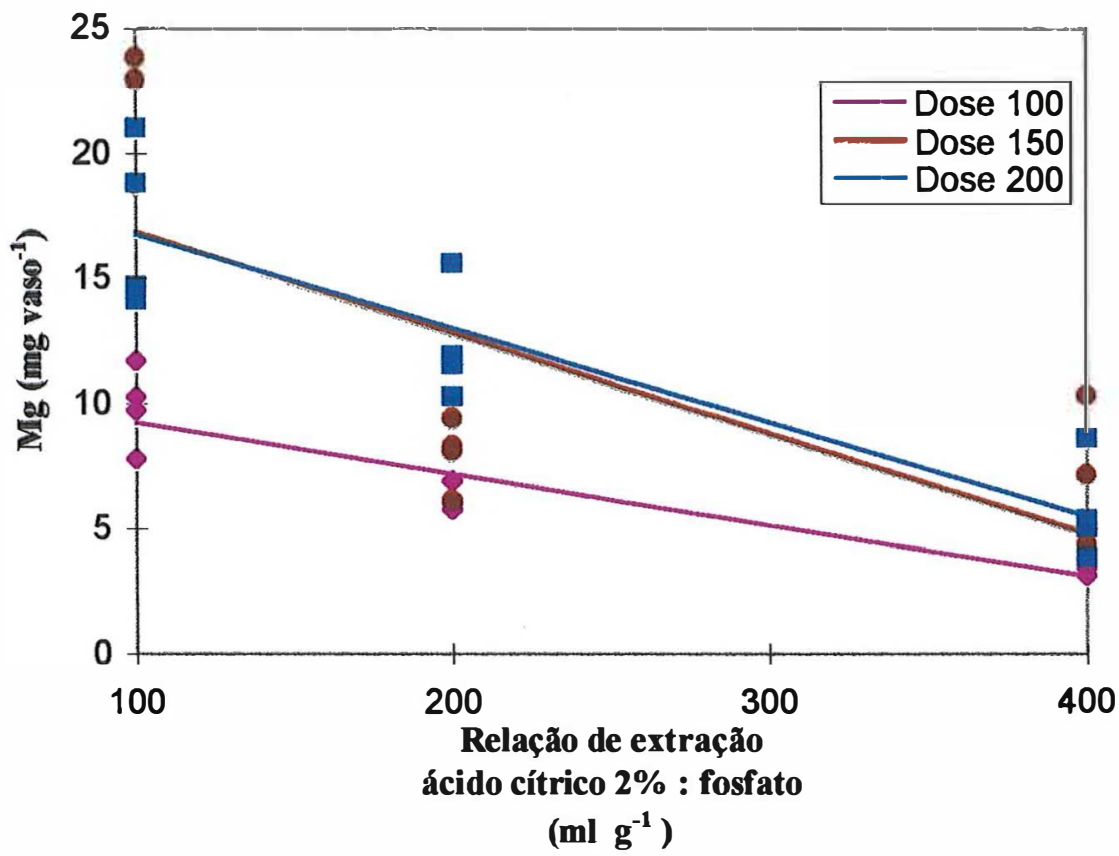

Figura 22 - Quantidade de magnésio absorvida pelo milho no primeiro plantio de milho em diferentes relações de extração e doses de fósforo para o fosfato Catalão.

$$
\begin{array}{lll}
\text { Dose } 100 & \mathbf{Y}=11,160+2,040 \times & \mathbf{r}^{2}=0,93 \\
\text { Dose } 150 & \mathbf{Y}=\mathbf{2 0 , 7 5 0}+4,010 \times & \mathbf{R}^{2}=\mathbf{0 , 6 7} \text { * } \\
\text { Dose } 200 & \mathbf{Y}=\mathbf{2 0 , 4 0 0 + 3 , 7 5 0} \times \mathbf{R}^{2}=\mathbf{0 , 9 9} \text { ** }
\end{array}
$$

\subsubsection{Teor e quantidade de enxofre}

Os teores de enxofre apresentados pelo milho foram adequados $\left(1 \mathrm{a} 3 \mathrm{~g} \mathrm{~kg}^{-1}\right.$, Malavolta et al. 1974 ) e o fosfato Patos obteve maior resultado, seguido de Catalão, Arad e Alvorada devido ao efeito de diluição do material seco. As quantidades obtidas para o fosfato Arad foram superiores àquelas apresentadas pelo fosfato Alvorada com 6,3 $\mathrm{g} \mathrm{kg}^{-1}$ devido à sua solubilidade e teor de enxofre $\left(8,7 \mathrm{~g} \mathrm{~kg}^{-1} \mathrm{de} \mathrm{S}\right)$. $\mathrm{O}$ resultado foi apresentado na tabela 22 . 
Tabela 22 Teores e quantidades médias de enxofre absorvidos pelo milho no primeiro plantio.

\begin{tabular}{|c|c|c|}
\hline Fosfato & Teor $\left(\mathrm{g} \mathrm{kg}^{-1}\right)$ & Quantidade (mg vaso ${ }^{-1}$ ) \\
\hline Patos & $2,23 \mathrm{~A}$ & $11,60 \mathrm{C}$ \\
\hline Catalão & $1,32 \mathrm{~B}$ & $11,90 \mathrm{C}$ \\
\hline Arad & $1,23 \mathrm{C}$ & $23,30 \mathrm{~A}$ \\
\hline Alvorada & $0,91 \mathrm{D}$ & $20,80 \mathrm{~B}$ \\
\hline
\end{tabular}

As quantidades de enxofre absorvidas foram influenciadas por todos os fatores, exceto fosfato $\mathrm{x}$ dose $\mathrm{x}$ relação (Tabela 11). A elevação das doses de fósforo, aumentou o acúmulo de enxofre para os fosfatos Alvorada e Patos. Para os fosfatos Catalão e Arad, as doses não tiveram efeito (Figura 23).

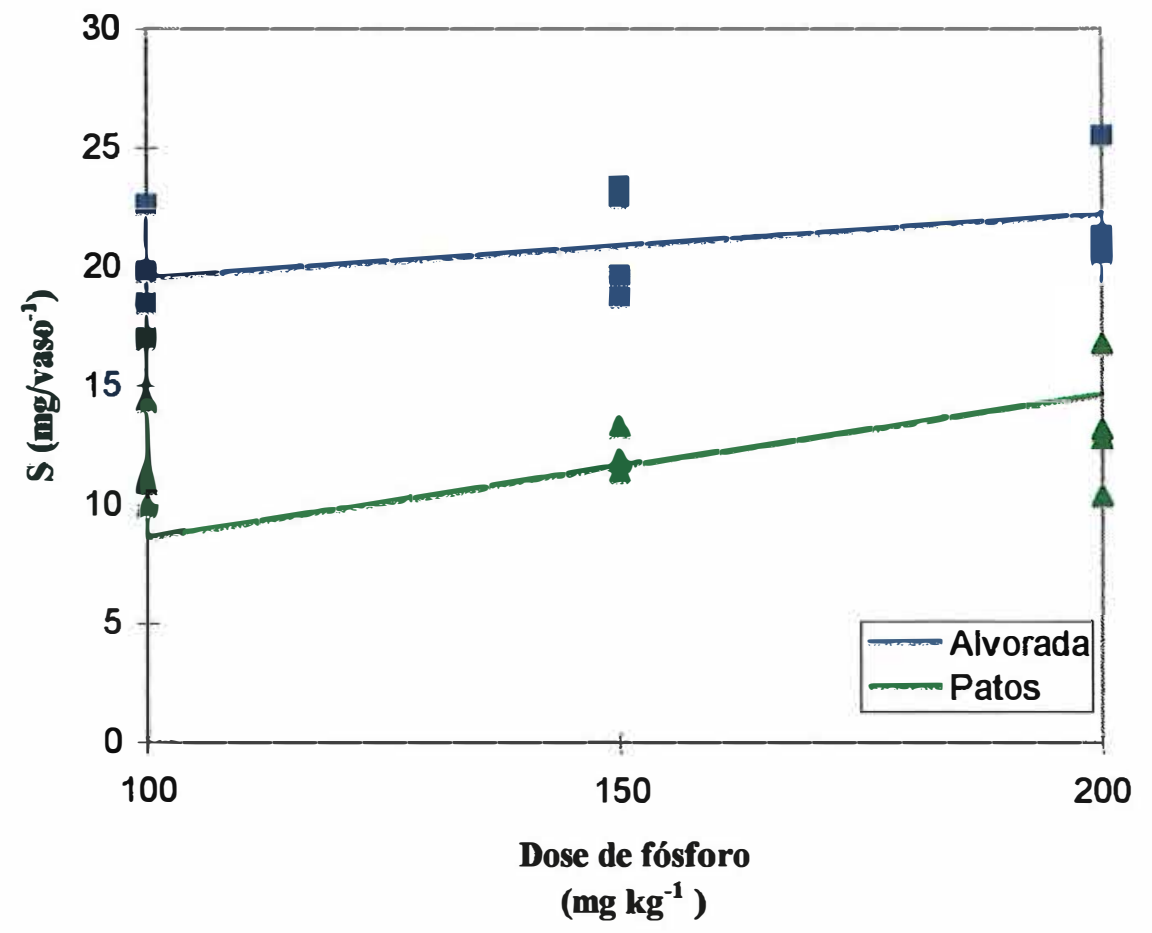

Figura 23 - Quantidade de enxofre absorvida pelo milho no primeiro plantio de milho em diferentes doses de fósforo dos fosfatos Alvorada, Patos e Arad.
Alvorada
Patos
$Y=18,100+1,350 \times R^{2}=0,97$ *
$\mathbf{Y}=\mathbf{5 , 5 1 0}+\mathbf{3 , 0 2 0} \times \mathbf{R}^{2}=\mathbf{0 , 9 9 * *}$ 
Para os fosfatos Arad e Catalão, houve interação positiva entre a quantidade de fosfato aplicada de acordo com a solubilidade em ácido cítrico a $2 \%$ e a absorção de enxofre (Figura 24). Para os fosfatos Patos e Alvorada, isso não ocorreu.

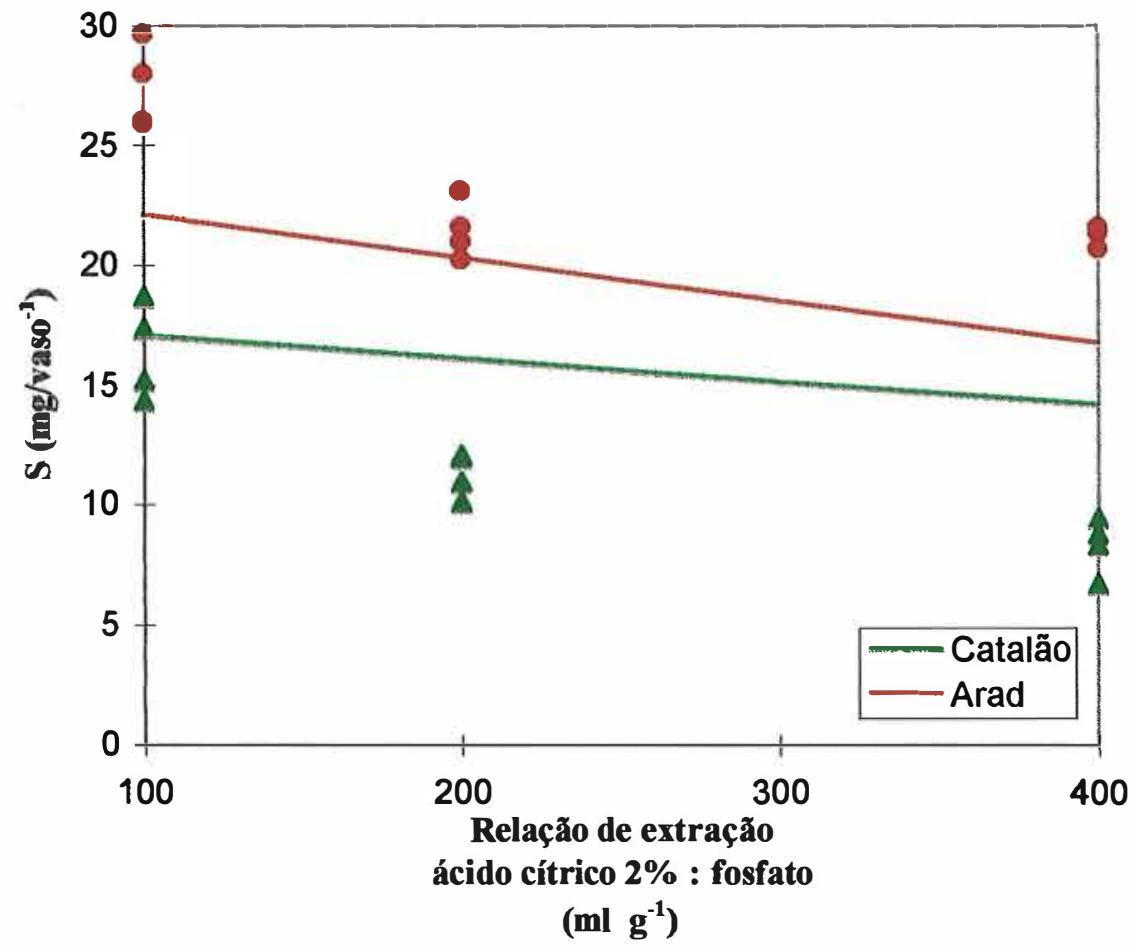

Figura 24 - Quantidade de enxofre absorvida pelo milho no primeiro plantio de milho em diferentes relações de extração dos fosfatos Catalão e Arad.

Catalão

Arad
$\mathbf{Y}=17,930+0,957 \times \mathbf{R}^{2}=0,88$ **

$Y=23,790+1,770 \times R^{2}=0,60$ ** 


\subsection{Segundo plantio}

O crescimento do milho, avaliado pela produção de material seco, índice de eficiência agronômica e acúmulo de nutrientes pelo milho, encontram-se nas tabelas 23 e 24. Os resumos das análises de variância encontram-se na tabela 25.

Tabela 23 Produçāo de material seco e concentraçāo de nutrientes absorvidos pelo millho no segundo plantio (médja de 4 repetiçōes).

\begin{tabular}{|c|c|c|c|c|c|c|c|c|}
\hline \multirow[t]{2}{*}{ Trt. } & \multirow[t]{2}{*}{$\overline{\text { Fosf. }}$} & \multirow{2}{*}{$\begin{array}{c}\text { Matéria } \\
\text { Seca } \\
\text { (g vaso-1) }\end{array}$} & $\bar{N}$ & $\mathbf{P}$ & $\bar{K}$ & $\mathrm{Ca}$ & $\overline{\mathbf{M g}}$ & $\mathbf{S}$ \\
\hline & & & \multicolumn{6}{|c|}{$\left(\mathrm{g} \mathrm{kg}^{-1}\right)$} \\
\hline 1 & $\mathbf{A}$ & 14,24 & 16,96 & 1,39 & 18,32 & 5,94 & 4,40 & 1,06 \\
\hline 2 & L & 13,67 & 17,78 & 1,54 & 18,94 & 6,20 & 5,10 & 1,11 \\
\hline 3 & $\mathbf{V}$ & 16,50 & 16,80 & 1,44 & 15,18 & 5,93 & 3,90 & 1,02 \\
\hline 4 & O & 13,33 & 20,49 & 1,32 & 21,95 & 4,57 & 5,00 & 1,09 \\
\hline 5 & $\mathbf{R}$ & 13,67 & 18,41 & 1,23 & 18,12 & 6,43 & 4,50 & 1,11 \\
\hline 6 & A & 14,91 & 17,85 & 1,52 & 16,95 & 6,03 & 4,70 & 1,09 \\
\hline 7 & D & 13,20 & 24,04 & 1,45 & 27,88 & 4,59 & 5,70 & 1,29 \\
\hline 8 & A & 15,00 & 20,47 & 1,48 & 20,09 & 5,11 & 5,20 & 1,17 \\
\hline 9 & & 14,13 & 17,39 & 1,24 & 17,79 & 5,68 & 4,40 & 1,04 \\
\hline 10 & & 8,82 & 25,16 & 1,05 & 25,87 & 5,08 & 4,80 & 1,19 \\
\hline 11 & & 11,53 & 23,08 & 1,13 & 18,40 & 4,72 & 5,30 & 1,17 \\
\hline 12 & C & 12,46 & 17,81 & 0,99 & 18,53 & 4,63 & 4,20 & 1,19 \\
\hline 13 & A & 3,87 & 26,70 & 0,76 & 34,37 & 4,78 & 5,70 & 1,27 \\
\hline 14 & $\mathrm{~T}$ & 7,80 & 26,35 & 1,46 & 30,13 & 4,55 & 6,10 & 1,25 \\
\hline 15 & A & 8,05 & 25,67 & 1,28 & 29,51 & 4,55 & 6,20 & 1,12 \\
\hline 16 & L & 2,92 & 30,31 & 1,22 & 33,43 & 3,97 & 6,20 & 1,18 \\
\hline 17 & $\overline{\tilde{A}}$ & 3,87 & 27,20 & 1,05 & 36,65 & 4,41 & 7,10 & 1,18 \\
\hline 18 & $\mathbf{O}$ & 5,18 & 27,04 & 0,92 & 35,29 & 5,40 & 6,10 & 1,12 \\
\hline 19 & & 3,55 & 28,47 & 1,40 & 27,53 & 5,37 & 5,10 & 1,44 \\
\hline 20 & & 5,00 & 29,37 & 1,35 & 35,08 & 7,45 & 7,20 & 1,24 \\
\hline 21 & $\mathbf{P}$ & 6,56 & 29,92 & 1,12 & 32,76 & 5,50 & 4,50 & 1,20 \\
\hline 22 & A & 3,14 & 28,10 & 0,95 & 39,57 & 5,95 & 6,60 & 1,47 \\
\hline 23 & $\mathrm{~T}$ & 4,10 & 31,64 & 0,90 & 42,50 & 7,27 & 6,90 & 1,76 \\
\hline 24 & $\mathbf{O}$ & 6,60 & 27,70 & 0,95 & 33,70 & 6,74 & 5,70 & 1,70 \\
\hline 25 & $\mathbf{S}$ & 3,10 & 31,80 & 1,12 & 38,52 & 4,90 & 7,20 & 1,54 \\
\hline 26 & & 3,55 & 28,37 & 1,07 & 38,02 & 5,59 & 6,40 & 1,09 \\
\hline 27 & & 3,77 & 29,17 & 0,99 & 35,49 & 5,97 & 6,20 & 1,29 \\
\hline 28 & & 13,73 & 17,53 & 1,33 & 18,31 & 6,77 & 5,40 & 1,14 \\
\hline 29 & & 13,44 & 20,25 & 1,25 & 18,33 & 7,45 & 5,20 & 1,21 \\
\hline 30 & & 13,92 & 18,62 & 1,28 & 16,53 & 7,25 & 5,00 & 1,09 \\
\hline 31 & A & 13,48 & 21,56 & 1,24 & 19,61 & 7,02 & 5,90 & 1,20 \\
\hline 32 & $\mathbf{R}$ & 13,35 & 20,77 & 1,26 & 21,53 & 6,30 & 5,70 & 1,35 \\
\hline 33 & A & 13,62 & 22,31 & 1,22 & 19,22 & 6,72 & 5,30 & 1,44 \\
\hline 34 & D & 12,46 & 24,01 & 1,32 & 18,14 & 5,57 & 5,30 & 1,42 \\
\hline 35 & & 15,16 & 21,35 & 1,29 & 19,24 & 6,37 & 5,40 & 1,41 \\
\hline 36 & & 12,84 & 20,14 & 1,23 & 17,37 & 5,87 & 5,10 & 1,30 \\
\hline 37 & $\overline{\mathrm{SPT}}$ & 10,38 & 23,64 & 0,84 & 34,78 & 4,10 & 9,20 & 2,06 \\
\hline 38 & TE* & 1,21 & 33,63 & 0,80 & 27,68 & 4,18 & 5,80 & 1,76 \\
\hline
\end{tabular}

\footnotetext{
$\mathrm{TE}^{*}=$ Testemunha
} 


\begin{tabular}{|c|c|c|c|c|c|c|c|c|}
\hline \multirow[t]{2}{*}{ Trt. } & \multirow[t]{2}{*}{ Fosf. } & \multirow{2}{*}{$\begin{array}{l}\text { IEA } \\
(\%)\end{array}$} & $\mathbf{N}$ & $\mathbf{P}$ & $\mathbf{K}$ & $\mathbf{C a}$ & $\mathbf{M g}$ & $\mathbf{S}$ \\
\hline & & & \multicolumn{6}{|c|}{$\left(\mathrm{mg}\right.$ vaso $\left.^{-1}\right)$} \\
\hline 1 & & 141,15 & 240,98 & 19,93 & 256,40 & 82,39 & 62,40 & 15,00 \\
\hline 2 & A & 135,10 & 243,12 & 21,07 & 258,20 & 84,54 & 68,90 & 15,10 \\
\hline 3 & L & 165,25 & 276,11 & 23,73 & 248,48 & 97,48 & 63,80 & 16,70 \\
\hline 4 & V & 131,45 & 272,41 & 17,69 & 289,78 & 61,45 & 67,60 & 14,50 \\
\hline 5 & O & 135,10 & 251,46 & 16,89 & 247,21 & 87,79 & 61,50 & 14,60 \\
\hline 6 & $\mathbf{R}$ & 148,29 & 266,04 & 22,63 & 251,97 & 89,68 & 69,80 & 16,10 \\
\hline 7 & A & 130,04 & 319,76 & 19,02 & 375,41 & 60,19 & 77,00 & 17,20 \\
\hline 8 & D & 149,23 & 307,45 & 22,15 & 301,70 & 76,57 & 78,00 & 17,60 \\
\hline 9 & $\mathrm{~A}$ & 140,01 & 244,85 & 17,28 & 245,75 & 79,66 & 62,40 & 14,80 \\
\hline 10 & & 83,37 & 221,96 & 9,24 & 228,22 & 44,81 & 42,30 & 10,50 \\
\hline 11 & & 122,17 & 236,48 & 11,40 & 229,26 & 50,37 & 55,40 & 13,80 \\
\hline 12 & C & 112,26 & 221,97 & 14,12 & 213,65 & 57,75 & 52,30 & 14,40 \\
\hline 13 & A & 30,60 & 103,35 & 2,96 & 133,03 & 18,50 & 22,10 & 4,90 \\
\hline 14 & $\mathrm{~T}$ & 72,49 & 205,57 & 11,40 & 211,31 & 35,49 & 47,60 & 9,7 \\
\hline 15 & A & 75,16 & 206,66 & 10,28 & 202,90 & 36,63 & 50,30 & 9,00 \\
\hline 16 & L & 20,47 & 88,51 & 3,57 & 97,63 & 11,59 & 18,30 & $3,5-$ \\
\hline 17 & $\tilde{\mathbf{A}}$ & 30,60 & 105,29 & 4,08 & 141,84 & 17,07 & 27,50 & 3,90 \\
\hline 18 & $\mathbf{0}$ & 44,56 & 140,09 & 4,76 & 182,83 & 27,94 & 31,80 & 5,80 \\
\hline 19 & & 27,19 & 100,00 & 5,03 & 98,54 & 19,10 & 18,30 & 5,10 \\
\hline 20 & & 42,59 & 147,00 & 6,59 & 182,27 & 38,55 & 27,60 & 6,20 \\
\hline 21 & $\mathbf{P}$ & 59,28 & 197,35 & 7,97 & 223,00 & 35,91 & 29,60 & 11,10 \\
\hline 22 & A & 22,81 & 89,14 & 3,13 & 121,67 & 18,13 & 21,40 & 4,80 \\
\hline 23 & $\mathrm{~T}$ & 25,00 & 129,72 & 3,07 & 174,25 & 29,81 & 28,30 & 7,20 \\
\hline 24 & O & 42,64 & 182,80 & 6,91 & 222,45 & 44,48 & 37,40 & 7,90 \\
\hline 25 & $\mathbf{S}$ & 23,83 & 98,57 & 2,95 & 119,41 & 15,19 & 22,30 & 4,80 \\
\hline 26 & & 27,19 & 100,73 & 3,29 & 134,99 & 19,84 & 22,90 & 3,90 \\
\hline 27 & & 29,50 & 108,06 & 3,96 & 131,79 & 22,39 & 22,80 & 4,90 \\
\hline 28 & & 135,71 & 240,38 & 18,14 & 249,89 & 92,37 & 74,00 & 15,80 \\
\hline 29 & & 132,70 & 271,41 & 16,79 & 244,90 & 99,58 & 69,80 & 16,20 \\
\hline 30 & & 137,77 & 257,44 & 17,79 & 227,02 & 99,67 & 69,20 & 15,10 \\
\hline 31 & A & 133,00 & 285,54 & 16,65 & 261,79 & 92,17 & 79,60 & 16,20 \\
\hline 32 & $\mathbf{R}$ & 131,60 & 277,34 & 16,83 & 287,41 & 84,11 & 76,80 & 18,10 \\
\hline 33 & A & 134,54 & 305,62 & 16,69 & 254,85 & 90,60 & 72,60 & 19,80 \\
\hline 34 & D & 122,17 & 304,03 & 16,38 & 233,31 & 68,47 & 66,30 & 18,00 \\
\hline 35 & & 150,96 & 326,28 & 19,71 & 288,44 & 93,65 & 81,20 & 21,20 \\
\hline 36 & & 126,20 & 258,50 & 15,68 & 222,06 & 75,30 & 66,20 & 16,80 \\
\hline 37 & SPT & 100,00 & 242,31 & 8,68 & 368,14 & 41,56 & 98,40 & 21,70 \\
\hline 38 & TE* & - & 40,59 & 0,99 & 32,98 & 5,05 & 6,80 & 2,10 \\
\hline
\end{tabular}

Tabela 25 Resumo das análises da variância da produção de material seco, índice de efíciência agronômica dos fosfatos e do acúmulo de nutrientes na parte aérea do milho no segundo plantio.

\begin{tabular}{|c|c|c|c|c|c|c|c|c|c|}
\hline \multirow{2}{*}{$\begin{array}{l}\text { Causa da } \\
\text { Variação }\end{array}$} & \multicolumn{9}{|c|}{ Valor F } \\
\hline & GL & $\begin{array}{c}\text { Matéria } \\
\text { seca }\end{array}$ & IEA(\%) & $\mathbf{N}$ & $\mathbf{P}$ & $\mathbf{K}$ & $\mathbf{C a}$ & Mg & $\mathbf{S}$ \\
\hline Fosfato(F) & 3 & $366,10^{* * *}$ & $389,92 * *$ & $66,69 * *$ & $223,95^{* * 3}$ & $21,80^{* *}$ & $344,56^{* *}$ & $96,73 * *$ & $151,69 * *$ \\
\hline Dose de P(D) & 2 & $18,28 * *$ & $19,00 * *$ & $3,07 \mathrm{~ns}$ & $6,67^{* *}$ & $1,88 \mathrm{~ns}$ & $29,42 * *$ & $0,5 \operatorname{lns}$ & $8,50 * *$ \\
\hline Relação de extração(R) & 2 & $51,03 * *$ & $53,23 * *$ & $19,23 * *$ & $19,63 * *$ & $25,33 * *$ & $71,42 * *$ & $12,98 * *$ & $26,26 * *$ \\
\hline Bloco(B) & 3 & $9,59 * *$ & $9.83 * *$ & $1,41 \mathrm{~ns}$ & $3,59 *$ & $0,35 \mathrm{~ns}$ & $1,77 \mathrm{~ns}$ & $1,58 \mathrm{~ns}$ & $7,54 * *$ \\
\hline F $\times D$ & 6 & $12,69 * *$ & $13,39 * *$ & $12,29 * *$ & $3,30 * *$ & $14,82 * *$ & $11,90 * *$ & $5,62 * *$ & $12,63 * *$ \\
\hline $\mathbf{F} \times \mathbf{R}$ & 6 & $21,43 * *$ & $22,88 * *$ & $13,51 * *$ & $6,09 * *$ & $11,46 * *$ & $8,00 * *$ & $5,15^{* *}$ & $21,49 * *$ \\
\hline $\mathrm{D} \times \mathrm{R}$ & 4 & $6,53 * *$ & $6,81^{* *}$ & $6,95 * *$ & $3,96 * *$ & $3,97 * *$ & $5,28 * *$ & $3,91 * *$ & $7,56 * *$ \\
\hline$F \times D \times R$ & 12 & $13,79 * *$ & $14,66 * *$ & $7,60 * *$ & $3,33 * *$ & $8,82 * *$ & $12,13 * *$ & $3,89^{* *}$ & $12,16^{* *}$ \\
\hline
\end{tabular}

**Significativo ao nível de $1 \%$ deprobabilidade

* Significativo ao nivel de $5 \%$ de probabilidade

n.s. Não signif cativos ao nível de $5 \%$ deprobabilidade. 


\subsubsection{Produção de matéria seca}

No segundo plantio, a produção de material seco apresentou efeito de todos os fatores e interações, mostrando que houve diferença no comportamento dos fosfatos (Tabela 24). $O$ efeito de fosfato $x$ dose $x$ relação, no entanto, foi significativo apenas para o fosfato Alvorada, o mais solúvel em ácido cítrico $2 \%$, com os fosfatos Patos, Catalão e Arad apresentando comportamentos diferentes.

A produção média de material seconão diferiu para os fosfatos Alvorada e Arad, seguidos por SPT e Catalão, Patos e testemunha (Tabela 26). Os resultados concordaram com a solubilidade em ácido cítrico $2 \%$ (relação $1: 100$ ), conforme ocorrido no primeiro plantio. Isso foi também verificado por Vasconcelos et al. (1980), que encontraram alta correlação entre a produção de sorgo granífero, no segundo plantio, em função de doses e teores de fósforo solúvel em ácido cítrico $2 \%$ para os fosfatos de Gafsa, Araxá, Abaeté, Catalão e Jacupiranga.

Tabela 26 Produção de material seco pelo milho no segundo plantio para os fosfatos utilizados.

\begin{tabular}{lcc}
\hline Fosfato & Material seco(g vaso $\left.\mathbf{0}^{-1}\right)$ & Teste Duncan \\
\hline Alvorada & 14,29 & A \\
Arad & 13,53 & A \\
SPT & 10,38 & B \\
Catalão & 7,17 & B \\
Patos & 4,13 & C \\
Testemunha & 1,21 & D \\
\hline
\end{tabular}

Médias seguidas pela mesma letra não diferem entre si.

A interação fosfato $\mathrm{x}$ dose $\mathrm{x}$ relação de extração mostrou que houve efeito para os fosfatos Alvorada, Patos e Catalão, quando foram utilizado nas doses de 200, 200, 150 e 200, respectivamente. A relação 1:100 apresentou a maior produção de material seco (Figuras 24, 25 e 26).

Os resultados obtidos concordam com o primeiro plantio, indicando que para os fosfatos Alvorada, Catalão e Patos, a relação 1:100 foi útil na determinação da disponibilidade de fósforo às plantas. As médias de produção do segundo plantio, entretanto, foram inferiores às do segundo plantio. 
Para o fosfato Arad, não houve influência das doses e relações de extração de fósforo provavelmente pela sua granulometria. Devido à menor superficie exposta e maior quantidade de fósforo comparada a do fosfato Alvorada, sua produção tende a ser melhor com o tempo que a de Alvorada, que vai, provavelmente, sofrer mais fixação.

Quanto ao comportamento do fosfato Alvorada, Ramos (1982) obteve que, a partir do segundo ano, passou a ser mais eficiente que os superfosfatos. Sua melhor eficiência, segundo o mesmo autor, pode estar relacionada a aspectos qualitativos (como mineralogia) dos compostos fosfatados, pois em termos quantitativos não se diferenciava do fosfato de Gafsa.

A menor produção de material seco do SPT no segundo plantio, a exemplo do primeiro plantio, pode ter decorrido da não correção do $\mathrm{pH}$ antes do plantio, o que pode ter causado diminuição na sua eficiência e aumento da solubilização dos fosfatos naturais. As rochas fosfáticas possuem, também, uma solubilização mais lenta no solo ocorrendo um aumento gradativo do seu efeito residual, sendo maior que o das fontes solúveis (Volkweiss \& Raij, 1977). Aliado a estes fatores, tem-se ainda que o superfosfato triplo é um adubo acidificante, que deve ter diminuído ainda mais no segundo plantio sua eficiência, conforme foram apresentados resultados em vários trabalhos.

Feitosa \& Raij (1975), que fizeram a incubação dos fosfatos por 60 dias antes do plantio, não corrigiram o $\mathrm{pH}$ do solo e utilizaram a adubação com base na porcentagem de $\mathrm{P}_{2} \mathrm{O}_{5}$ total. Observaram que o superfosfato triplo e o fosfato Araxá apresentaram os menores valores, não diferindo da testemunha para o milho, quando comparados com superfosfato simples, fosfato diamônio, termofosfato e fosfato de Gafsa.

Raij \& Diest (1980), também,verificaram que o SPT teve sua eficiência reduzida com um período de 75 dias de incubação em solo com $\mathrm{pH}$ 4,9. Isso pode ser uma evidência de que a mobilização do fosfato natural ocorra durante esse período, desde que a imobilização do fosfato dissolvido para formas não-lábeis em formas lábeis seja apropriada para que isso ocorra.

A produção de material seco obtido com a utilização dos fosfatos Alvorada, Catalão e Patos aumentou com as doses de fósforo utilizadas, conforme já verificado por 
Léon et al. (1986), que avaliaram, por métodos de laboratório e de respostas de 3 cultivos de Panicum maximum, o potencial de rochas fosfáticas nas doses de 50, 100, 200 e $400 \mathrm{mg} \mathrm{vaso}^{-1}$. $\mathrm{O}$ aumento das doses produziu aumento de material seco, tendo-se uma resposta quadrática para o fosfato Catalão até 200 e o fosfato Patos foi melhor que Catalão, aumentando sua produção até 400. O fosfato Patos superou Araxá, Abaeté, Jacupiranga, Catalão e Tapira.

A produção de material secodos fosfatos Patos e Catalão também foi influenciada pelas relações de extração, sendo o maior resultado na relação 1:100, decrescendo com 0 aumento da quantidade de ácido cítrico utilizada (Figura 26). A adubação realizada com base na relação 1:100 obteve maior produção de material seco para Catalão, comparada com a de Patos, também no segundo plantio. Isso pode ser explicado pela maior solubilidade em ácido cítrico $2 \%$ e disponibilidade de $\mathrm{P}$ às plantas. Ou seja, esse resultado parece estar associado mais à solubilidade na relação 1:100 que à quantidade de fosfato utilizada .

Assim, pode-se inferir que a utilização da solubilidade em ácido cítrico $2 \%$ (1:100) foi um importante parâmetro para a obtenção do comportamento de fosfatos naturais de diferentes origens geológicas nos dois plantios. Quando não são conhecidas as características do fosfato como origem, composição química, granulométrica e estrutura cristalográfica (que pode ser conhecida por difração de Raio $\mathrm{X}$ ), como é o caso da utilização dos adubos comerciais em que tais análises geralmente não são realizadas, a solubilidade em ácido cítrico $2 \%$ (relação $1: 100$ ) pode ser um parâmetro importante antes da utilização dos fosfatos. 


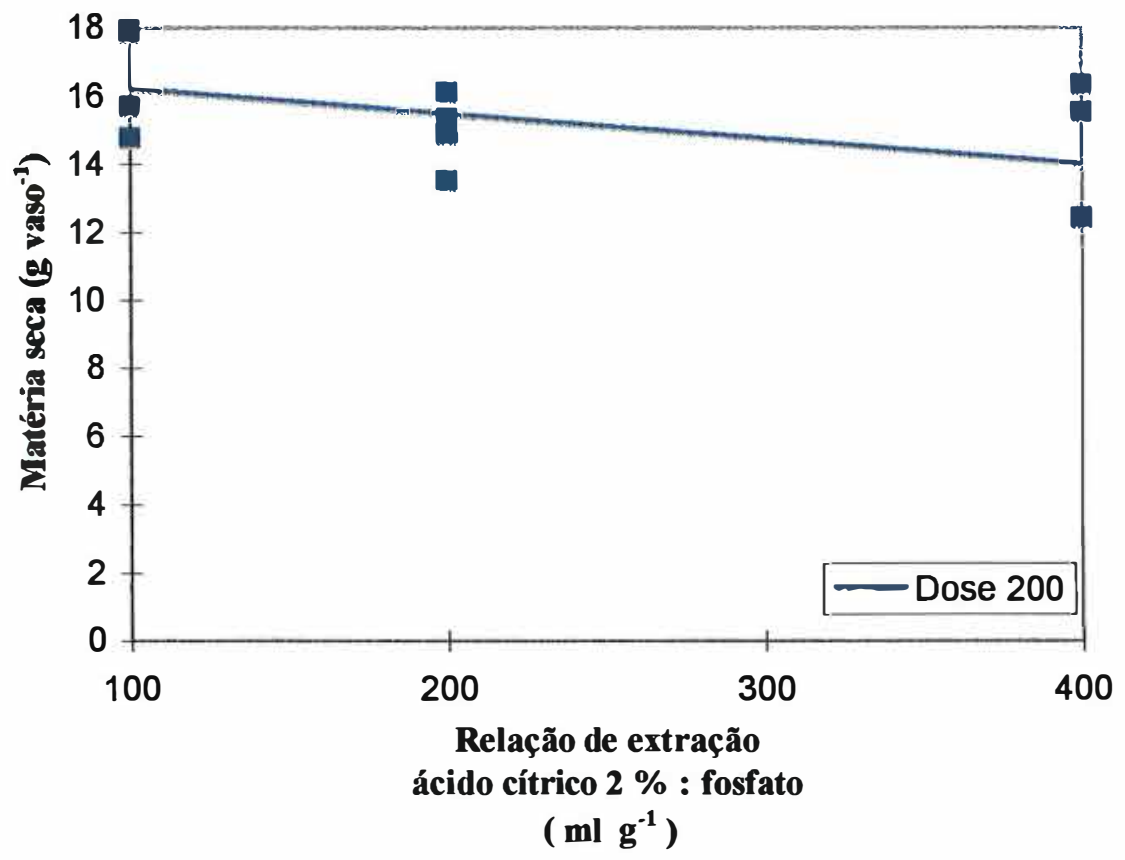

Figura 24 - Produção de material seco $\left(\mathrm{g} \mathrm{vaso}^{-1}\right)$ das plantas de milho no segundo plantio em diferentes relaçōes de extração para o fosfato Alvorada na dose de $P 200 \mathbf{~ m g ~ k g}^{-1}$. Dose 200 $Y=16,889-0,732 \times R^{2}=0,99 *$ *

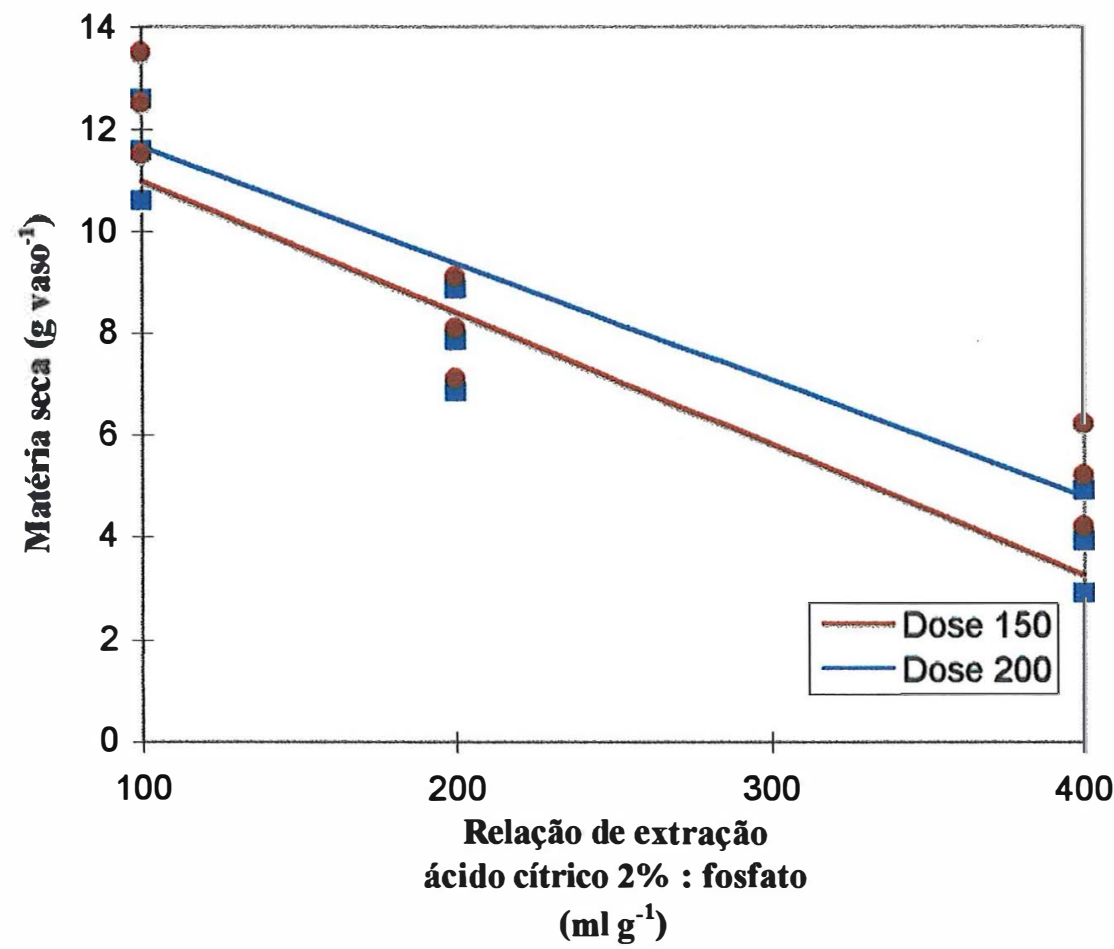

Figura 25 - Produção de material seco $\left(\mathrm{g}\right.$ vaso $\left.^{-1}\right)$ das plantas de milho para diferentes doses em diferentes relações de extração para o fosfato Catalão no segundo plantio.

Dose 150 $Y=13,495-2,469 \times R^{2}=0,96^{*}$ *

Dose 200 $Y=13,890-2,280 X R^{2}=0,91$ * * 


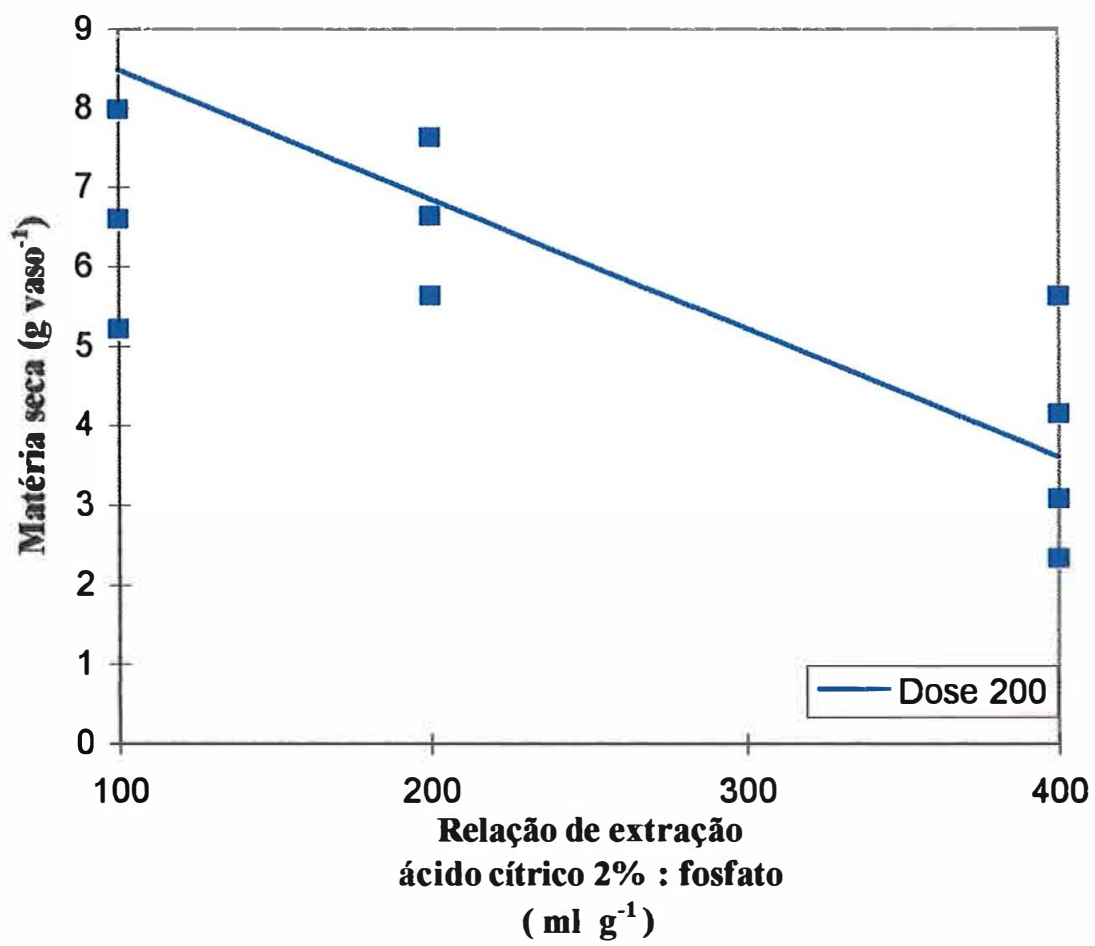

Figura 26 - Produção de material seco $\left(\mathrm{g} \mathrm{vaso}^{-1}\right)$ das plantas de milho no segundo plantio em diferentes relações de extração para o fosfato Patos na dose de $P$ de $200 \mathbf{m g ~ k g}^{-1}$. Dose $200 \quad Y=10,069-1,623 \times R^{2}=0,99 * *$

\subsubsection{Teor de fósforo}

Os resultados da comparação dos teores médios de fósforo nas plantas, obtidos com os fosfatos, são apresentados na tabela 27.

Tabela 27 Teores de fósforo absorvidos pelo milho no primeiro plantio para os fosfatos utilizados.

\begin{tabular}{lcc}
\hline \multicolumn{1}{c}{ Fosfato } & Teor médio de $\mathbf{P}\left(\mathbf{g ~ k g}^{-1}\right)$ & Teste Duncan \\
\hline Alvorada & 1,40 & A \\
Arad & 1,27 & AB \\
Catalão & 1,09 & B \\
Patos & 1,07 & B \\
SPT & 0,83 & C \\
Testemunha & 0,79 & C \\
\hline
\end{tabular}

Médias seguidas pela mesma letra não diferem entre si. 
O fosfato Alvorada superou os fosfatos Arad, Catalão, Patos, SPT e a testemunha. Para todos os fosfatos, exceto SPT, os níveis encontram-se adequados (1 a 3 $\mathrm{g} \mathrm{kg}^{-1}$ ). Os resultados não corroboraram com a produção de material seco e a quantidade total de $\mathrm{P}, \mathrm{o}$ que deve ter ocorrido pelo efeito da diluição de material seco

\subsubsection{Quantidade de fósforo}

As quantidades de fósforo absorvidas pelas plantas, oriundas do fosfato Alvorada, foram superiores às dos fosfatos Arad, Catalão,superfosfato triplo, Patos e da testemunha, concordando com a ordem decrescente de solubilidade em ácido cítrico a 2 \% e a produção do material seco produzido no segundo plantio.

Tabela 28 Quantidade de fósforo absorvida pelo milho no segundo plantio para os fosfatos

\begin{tabular}{lcc}
\hline \multicolumn{1}{c}{ Fosfato } & P (mg vaso $\left.{ }^{-1}\right)$ & Teste Duncan \\
\hline Alvorada & 19,70 & A \\
Arad & 17,20 & B \\
Catalão & 8,90 & C \\
SPT & 8,70 & C \\
Patos & 5,50 & D \\
Testemunha & 1,70 & E \\
\hline
\end{tabular}

Médias seguidas pela mesma letra não diferem entre si.

A análise de variância para a quantidade de fósforo absorvida indicou que houve efeito de todos os fatores e das interações. A decomposição fosfato $\mathrm{x}$ dose $\mathrm{x}$ relação apresentou efeito para todos os fosfatos, concordando com a produção de material seco do segundo plantio (Tabela 25).

Para o fosfatos Alvorada e Patos, a maior quantidade de fósforo absorvida foi obtida com a relação 1:100, dose de $P$ de $200 \mathrm{mg} \mathrm{kg}^{-1}$ (Figuras 27 e 29). Isso significa que o efeito residual desses fosfatos está em função da maior dose aplicada inicialmente, regida pela solubilidade na relação $1: 100$. 


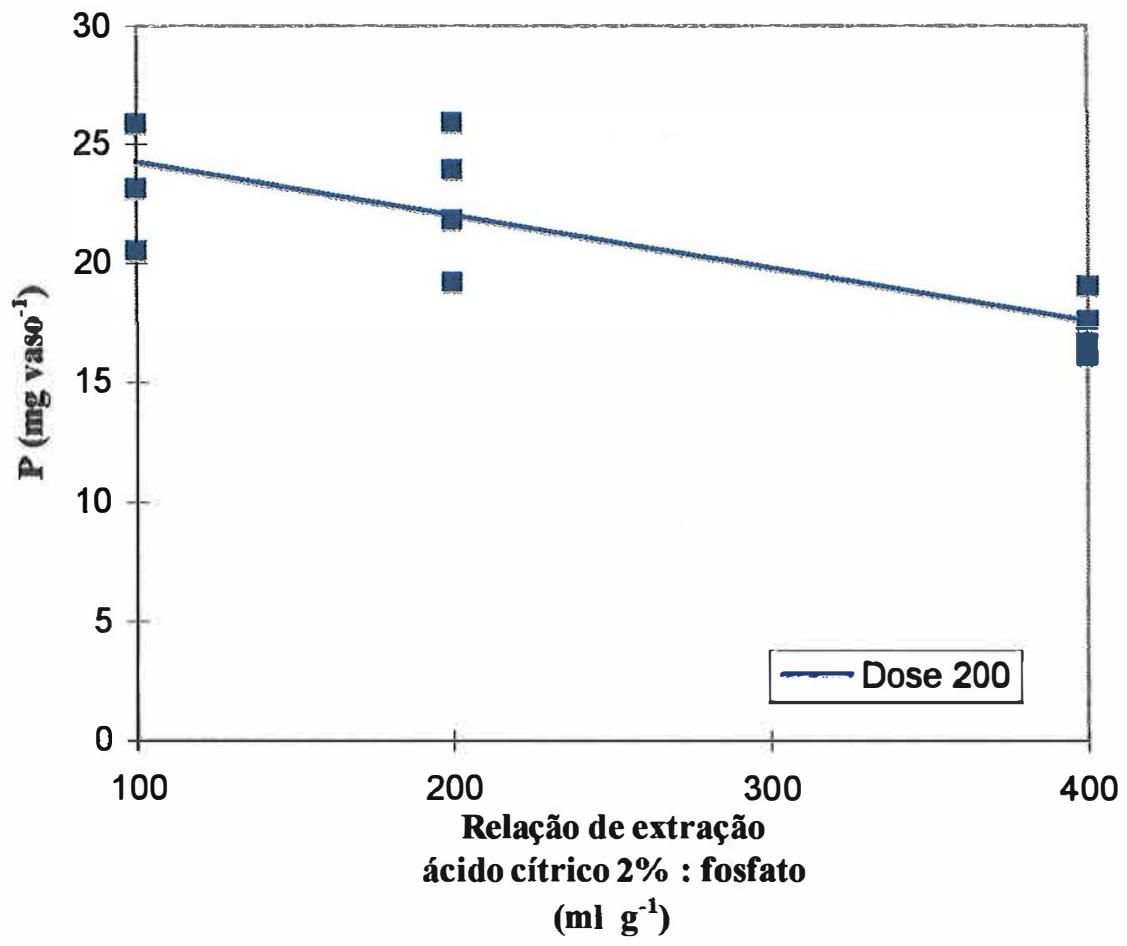

Figura 27 - Quantidade de fósforo acumulada pelas plantas de milho no segundo plantio em diferentes relações de extração para o fosfato Alvorada na dose de $P$ de $200 \mathrm{mg} \mathrm{kg}^{-1}$. Dose 200 $\mathbf{Y}=\mathbf{2 6 , 3 5 0}-\mathbf{2 , 2 1 0} \times \mathbf{R}^{2}=0,97$ *

Para o fosfato Catalão, a maior quantidade de fósforo foi absorvida na relação 1:100, dose de $\mathbf{P}$ de $150 \mathrm{mg} \mathrm{kg}^{-1}$. A maior produção de material seco para o fosfato Catalão, entretanto, ocorreu com a dose de $P$ de $200 \mathrm{mg} \mathrm{kg}^{-1}$, ou seja, não aumentou a quantidade de fósforo absorvido com a maior dose, talvez por causa da interação com outros nutrientes. 


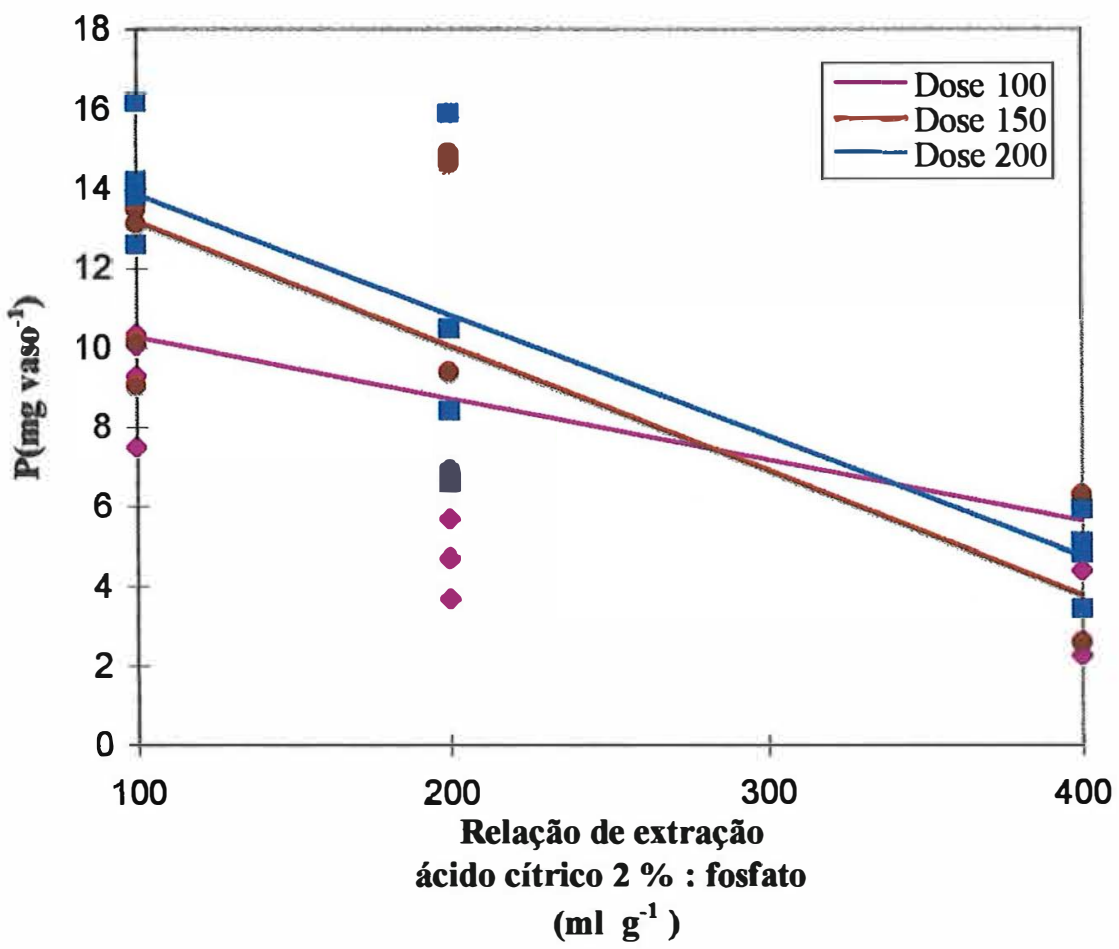

Figura 28 - Quantidade de fósforo acumulada pelas plantas de milho no segundo plantio em diferentes relações de extração para o fosfato Catalão na dose de $P$ de $200 \mathrm{mg} \mathrm{kg}^{-1}$. Dose 100 Dose 150 Dose 200 $Y=11,750-1,540 \times R^{2}=0,51 * *$
$Y=18,910-3,880 \times$
$Y=14,070-1,960 \times R^{2}=0,95 * *$
$R^{2}=0,96 * *$

Para o fosfato Arad, as doses e as relações de extração não tiveram efeito na quantidade de fósforo absorvida, provavelmente, devido a maior parte de suas partículas terem tamanho maior, quando comparada aos demais fosfatos.

Com isso, pode-se dizer que em função da origem do fosfato e das suas características químicas, granulométricas e mineralógicas, há diferenças de comportamento dos fosfatos naturais. Para os fosfatos brasileiros Alvorada, Patos e Catalão (ígnea-residual, sedimentar e ígnea), a solubilidade em ácido cítrico $2 \%$ (relação 1:100) foi um importante parâmetro na avaliação da sua disponibilidade de fósforo às plantas de milho nos dois plantios. E para o fosfato Arad, a relação de extração 1:100 o efeito no segundo plantio pode ter sido devido a sua granulometria que interferiu na disponibilidade. 


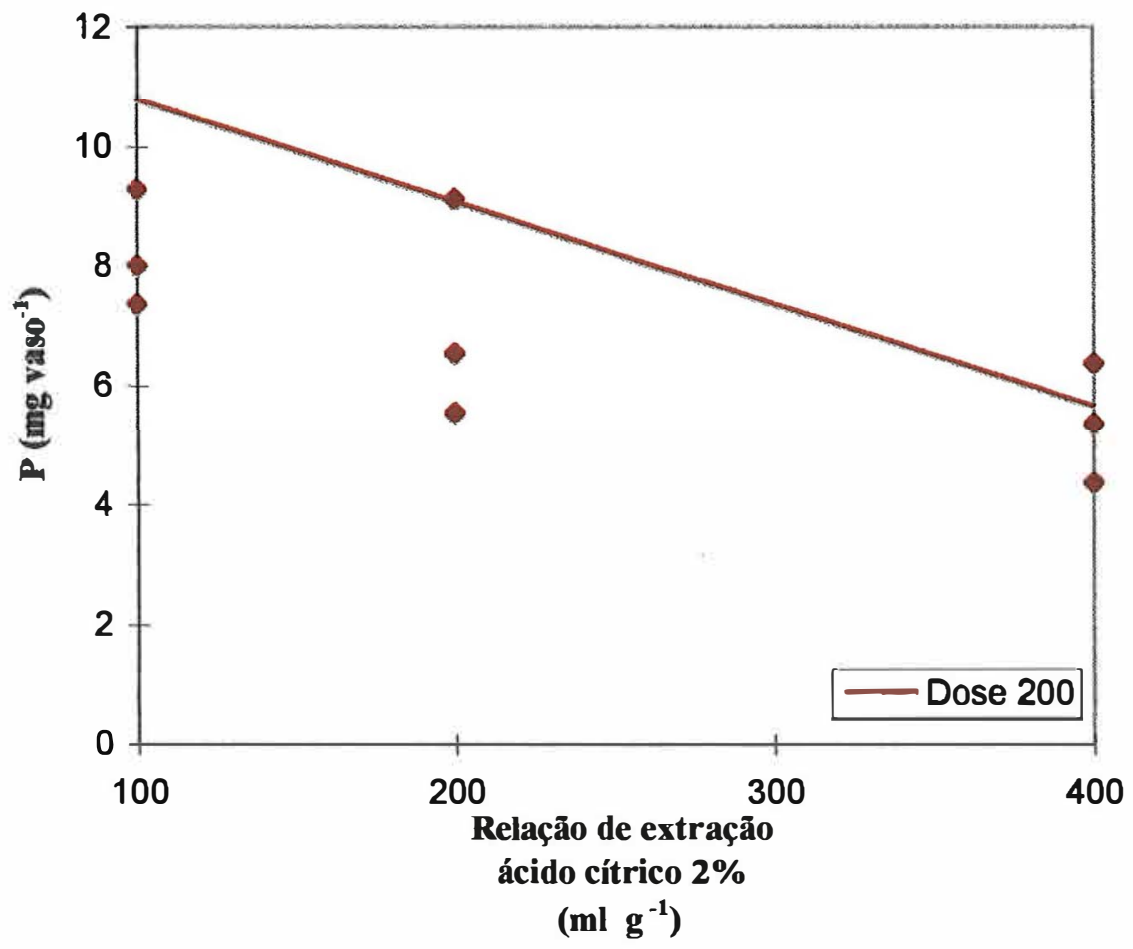

Figura 29 - Quantidade de fósforo acumulada pelas plantas de milho no segundo plantio em diferentes relações de extração para o fosfato Patos na dose de $P$ de $200 \mathrm{mg} \mathrm{kg}^{-1}$. Dose $200 \quad Y=12,470-1,710 \times R^{2}=0,75^{* *}$

\subsection{4 Índice de eficiência agronômica (IEA)}

$\mathrm{O}$ fosfato Alvorada apresentou índice de eficiência agronômica superior aos dos fosfatos Arad, Catalão e Patos, corroborando com os resultados de produção de material seco e absorção total de fósforo no segundo plantio (Tabela 29).

Tabela 29 Índices de eficiência agronômica dos fosfatos utilizados obtidos no segundo plantio

\begin{tabular}{lcc}
\hline Fosfatos & IEA(\%) & Teste Duncan \\
\hline Alvorada & 142,89 & A \\
Arad & 133,84 & B \\
Catalão & 65,74 & C \\
Patos & 33,34 & D \\
\hline
\end{tabular}

DMS $=7,89$

Médias seguidas da mesma letra não diferem entre si ao nível de $5 \%$ de probabilidade 
Os índices de eficiência agronômica foram influenciados por todos os fatores e interações estudadas (Tabela 25) e os tratamentos de maior índice de eficiência agronômica foram os de maiores produção de material seco e absorções totais de fósforo.

Para os fosfatos Alvorada, Catalão e Patos, a relação 1:100 representou a de maior IEA(\%), para as doses de $\mathrm{P}$ de 200,150 e $200 \mathrm{mg} \mathrm{kg}^{-1}$, respectivamente (Figuras 30, 31 e 32). Para o fosfato Patos, o efeito sobre a produção de material seco e índice de eficiência agronômica foi constatado somente no segundo plantio devido, provavelmente, à sua menor solubilidade. Para o fosfato Arad, não houve efeito das interações no segundo plantio.

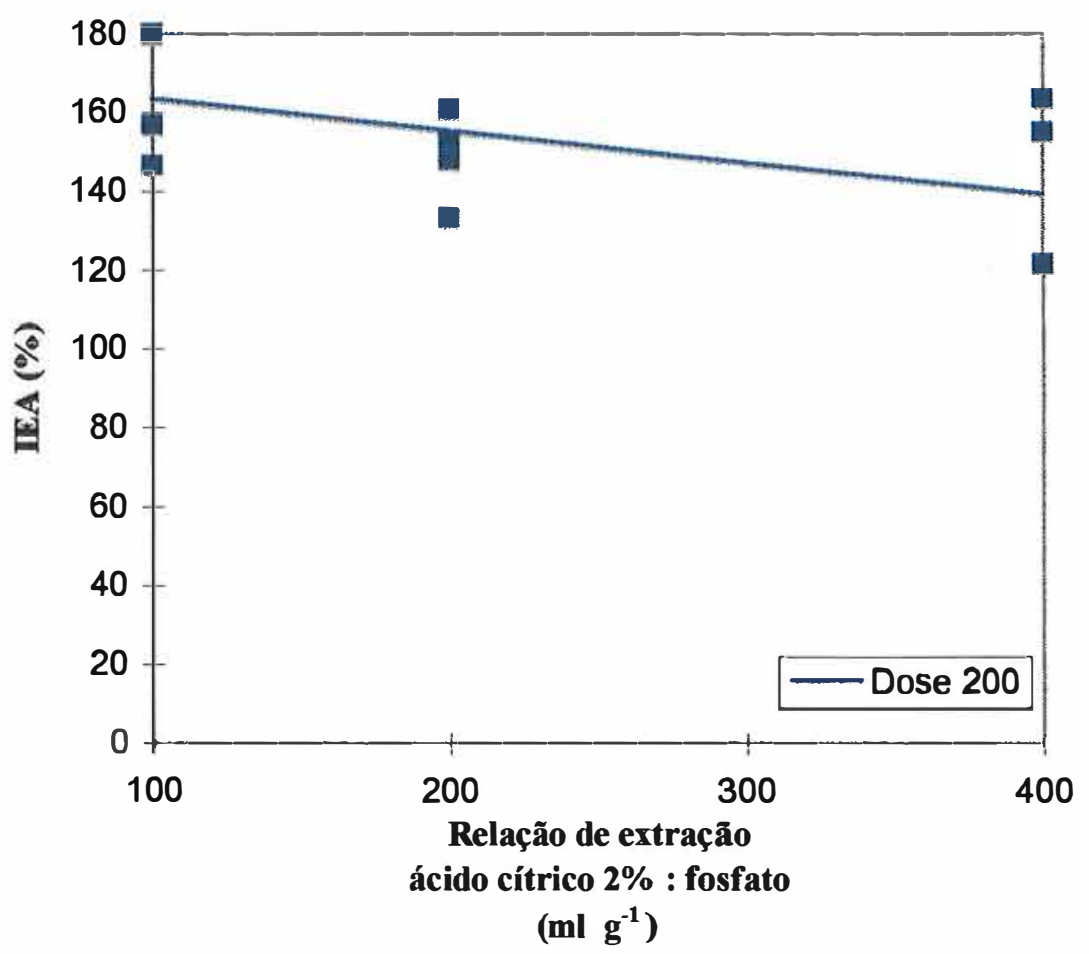

Figura 30 - Índice de Eficiência Agronômica do segundo plantio de milho em diferentes relações de extração para o fosfato Alvorada na dose de $P$ de $200 \mathrm{mg} \mathrm{kg}^{-1}$. Dose 200 $Y=170,947-8,016 \times R^{2}=0,86^{* *}$

O comportamento do fosfato Alvorada, superior aos demais fosfatos naturais, $\mathrm{o}$ que foi verficado também por Blanco et al. (1965), que estudaram o efeito residual de fertilizantes fosfatados na cultura da soja. $\mathrm{O}$ fosfato Alvorada aumentou sua produção relativa ao superfosfato simples de 90 para100 \%, a apatita de Araxá aumentou de 83,9 
para 90,0 e, e o SPS diminuiu para 78,8 e $80,0 \%$, sendo o valor 100 atribuído ao superfosfato simples. Muzilli (1982), entretanto, apresentou resultados em seu trabalho, em que o fosfato Alvorada obteve efeito mais pronunciado apenas no segundo plantio e teve sua eficiência aumentada com o tempo, o que pode ser devido às diferenças encontradas no fosfato utilizado.

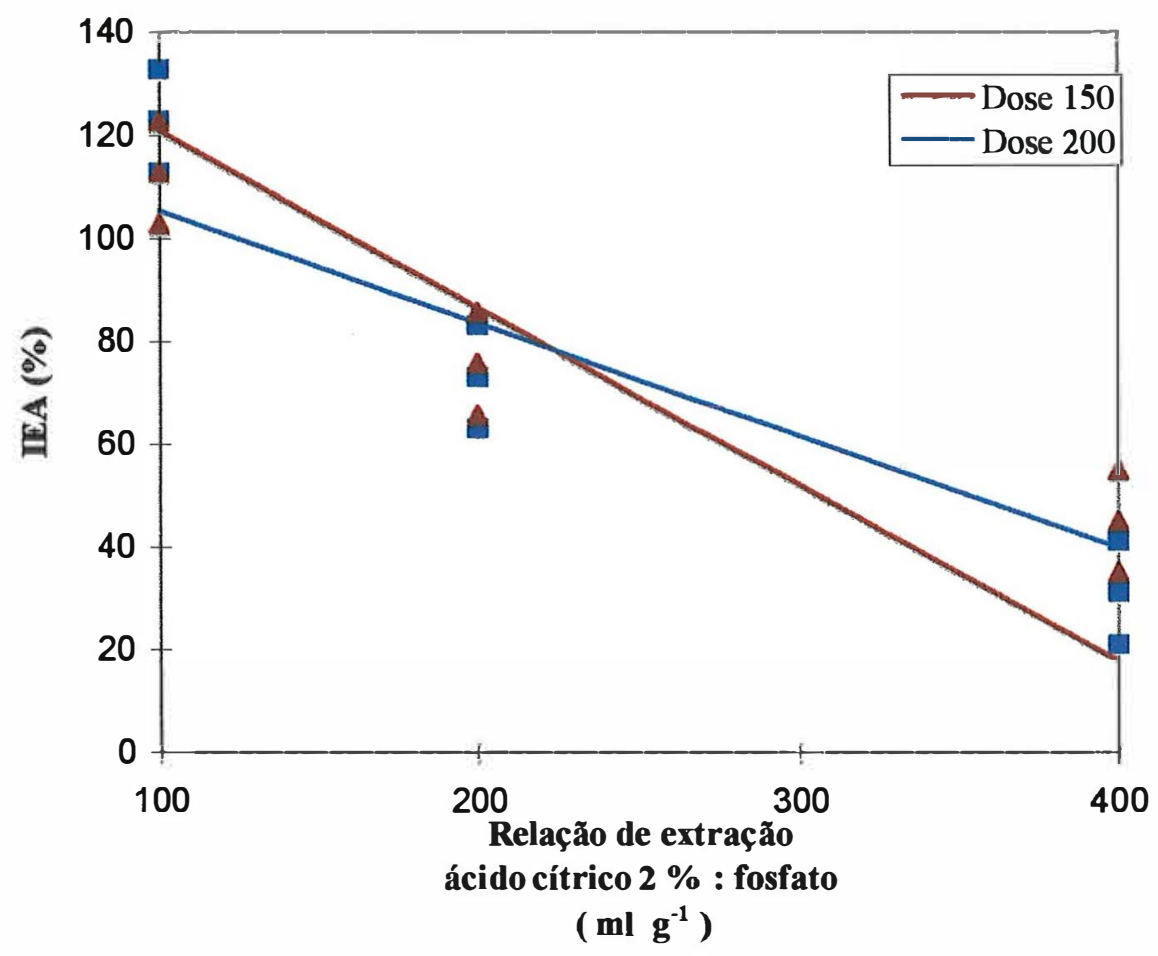

Figura 31 - Índice de Eficiência Agronômica do segundo plantio de milho em diferentes doses e relações de extração para o fosfato Catalão.

Dose $150 \quad Y=154,661-34,292 \times R^{2}=0,99$ **

Dose $200 \quad Y=126,667-21,812 X R^{2}=0,92^{* *}$

Quanto aos resultados dos fosfatos Catalão e Patos, eles não estão de acordo com Goedert (1983), que, durante 6 anos estudou a eficiência agronômica de fosfatos naturais, aplicando no início a dose de $\mathrm{P}_{2} \mathrm{O}_{5}$ total de $200 \mathrm{~kg} \mathrm{ha}^{-1} \mathrm{e}$ obteve índices de eficiência para o fosfato Patos de 84 a 89, de $82 \%$ para Araxá e $69 \%$ para Catalão. Braga et al. (1991), também, obtiveram maior eficiência do fosfato Patos em relação ao fosfato Catalão. Já Goedert \& Lobato (1984), obtiveram para culturas anuais os IEA(\%) de 45 e 56 para o fosfato Patos e 8 e 26 para fosfato Catalão nas doses de $\mathrm{P}_{2} \mathrm{O}_{5}$ total de 88 e $350 \mathrm{~kg} \mathrm{ha}^{-1}$. 
Os resultados dos fosfatos naturais, entretanto, foram superiores aos apresentados por vários pesquisadores pela realização de apenas dois cultivos de milho, o que é insuficiente para a observação de efeito residual. No presente trabalho, o fosfato Catalão ter superado o fosfato Patos, no presente trabalho, pode ser devido à diferença na sua composição química e granulométrica, comparada aos fosfatos usados por esses pesquisadores.

A utilização de doses previamente fixadas e iguais para todos os fosfatos ou baseadas no teor de fósforo total não deve ser um bom parâmetro para melhor utilização dos fosfatos naturais visto à sua variação entre composição química e mineralógica entre os fosfatos e, até mesmo, dentro da mesma fonte. A solubilidade dos fosfatos naturais em ácido cítrico $2 \%$ na relação $1: 100$ pode ser utilizada como parâmetro para avaliar sua possível disponibilidade de fósforo no solo também para o efeito residual dos fosfatos.

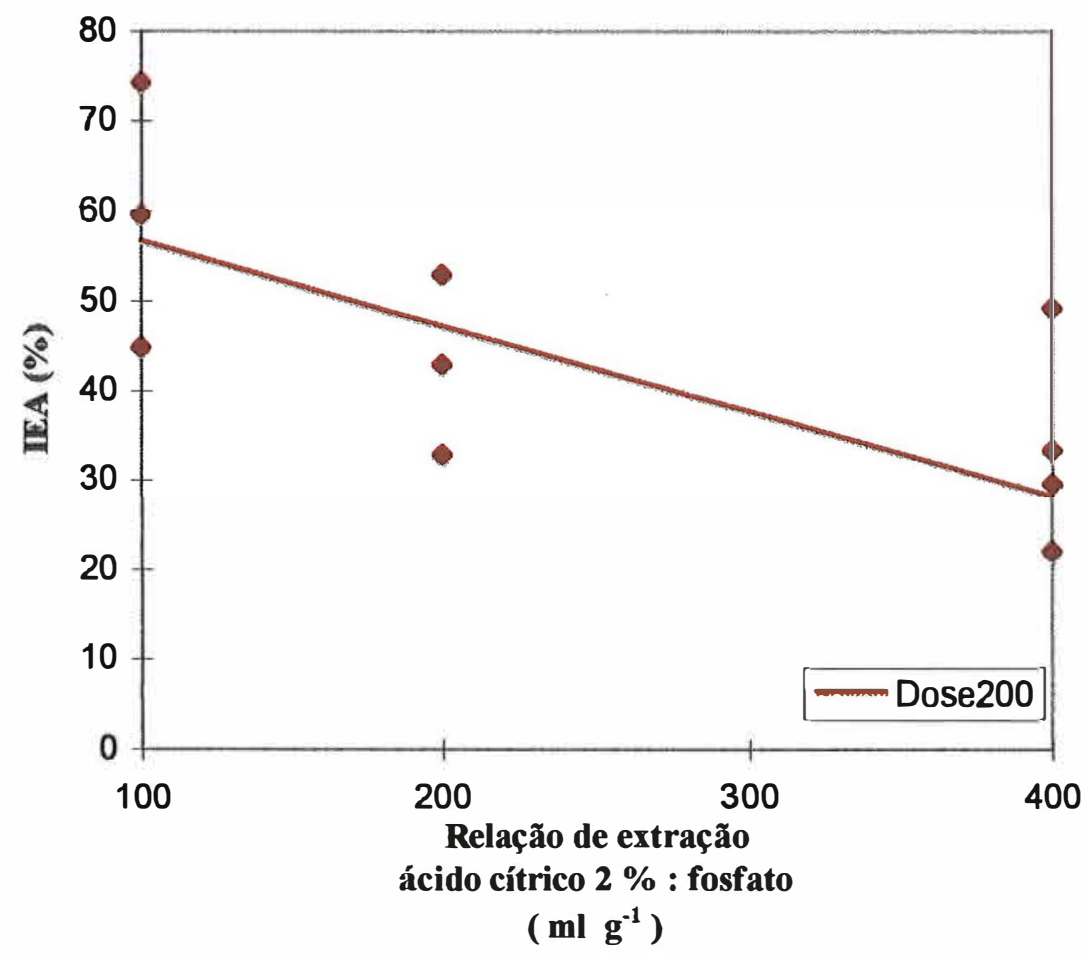

Figura 32 - Índice de Eficiência Agronômica do segundo plantio de milho em diferentes relações de extração para o fosfato Patos na dose de $P$ de $200 \mathrm{mg} \mathrm{kg}^{-1}$.

Dose 100 $Y=11,750-1,540 \times R^{2}=0,51$ * *

Dose $150 \quad Y=18,910-3,880 \times R^{2}=0,95^{*}$ * 


\subsubsection{Outros macronutrientes}

\subsubsection{Teor e quantidade de nitrogênio}

A concentração de nitrogênio foi adequada para todos os fosfatos e elas foram maiores para o fosfato Patos, seguido de Catalão, Arad e Alvorada devido ao efeito de diluição do material seco, conforme ocorreu no primeiro plantio. Considerando que a parte aérea incluiu colmo e folhas, os teores foram adequados $\left(20 \mathrm{a}^{2} \mathrm{~g} \mathrm{~kg}^{-1} \mathrm{de} \mathrm{N}\right.$, Malavolta et al. 1974). As quantidades de nitrogênio absorvidas foram maiores para os fosfatos Arad e Alvorada, seguidos de Catalão e Patos, concordando com a produção de material seco (Tabela 30 ).

Tabela 30. Teores e quantidades médias de nitrogênio absorvidos pelo milho no segundo plantio

\begin{tabular}{|c|c|c|}
\hline Fosfato & Teor $\left(\mathrm{g} \mathrm{kg}^{-1}\right)$ & Quantidade(mg vaso $\left.{ }^{-1}\right)$ \\
\hline Patos & $29,40 \mathrm{~A}$ & $148,40 \mathrm{C}$ \\
\hline Catalão & $25,48 \mathrm{~B}$ & $203,10 \mathrm{~B}$ \\
\hline Arad & $20,73 \mathrm{C}$ & $280,71 \mathrm{~A}$ \\
\hline Alvorada & $18,91 \mathrm{D}$ & $264,40 \mathrm{~A}$ \\
\hline
\end{tabular}

O comportamento dos fosfatos, avaliados pelas quantidades de nitrogênio absorvidas, foi diferente do obtido primeiro plantio para os fosfatos, sendo que elas foram influenciadas por todos os fatores (Tabela 25 ). $\mathrm{O}$ acúmulo de $\mathrm{N}$ para os fosfatos Alvorada e Arad, não foi influenciado pelos fatores, pois pode ter ocorrido uma possível mineralização de $\mathrm{N}$ das raízes já que elas produziram grande quantidade de material seco no primeiro plantio do milho.

Para os fosfatos Catalão e Patos, a quantidade máxima de $\mathrm{N}$ foi obtida na relação 1:200, dose de $P$ de $200 \mathrm{mg} \mathrm{kg}^{-1}$ (41,97 e $32 \mathrm{~g}$ de fosfato vaso $^{-1}$ ), que foi o tratamento de maior produção de material seco, ou seja, na adubação realizada com maior quantidade de fosfato, houve melhor produção de material secoe as plantas absorveram mais nitrogênio. Para o fosfato Catalão, entretanto, todas as doses de fosfato utilizadas apresentaram efeito sobre o acúmulo de nitrogênio pelo milho, inclusive a dose de $\mathbf{P}$ de $100 \mathrm{mg} \mathrm{kg}^{-1}$, que não influenciou o material seco produzido no segundo plantio. E para o 
fosfato Patos, apenas a maior dose obteve efeito. As diferenças encontradas entre os fosfatos pode ser devido às suas solubilidades (Figuras 33 e 34).

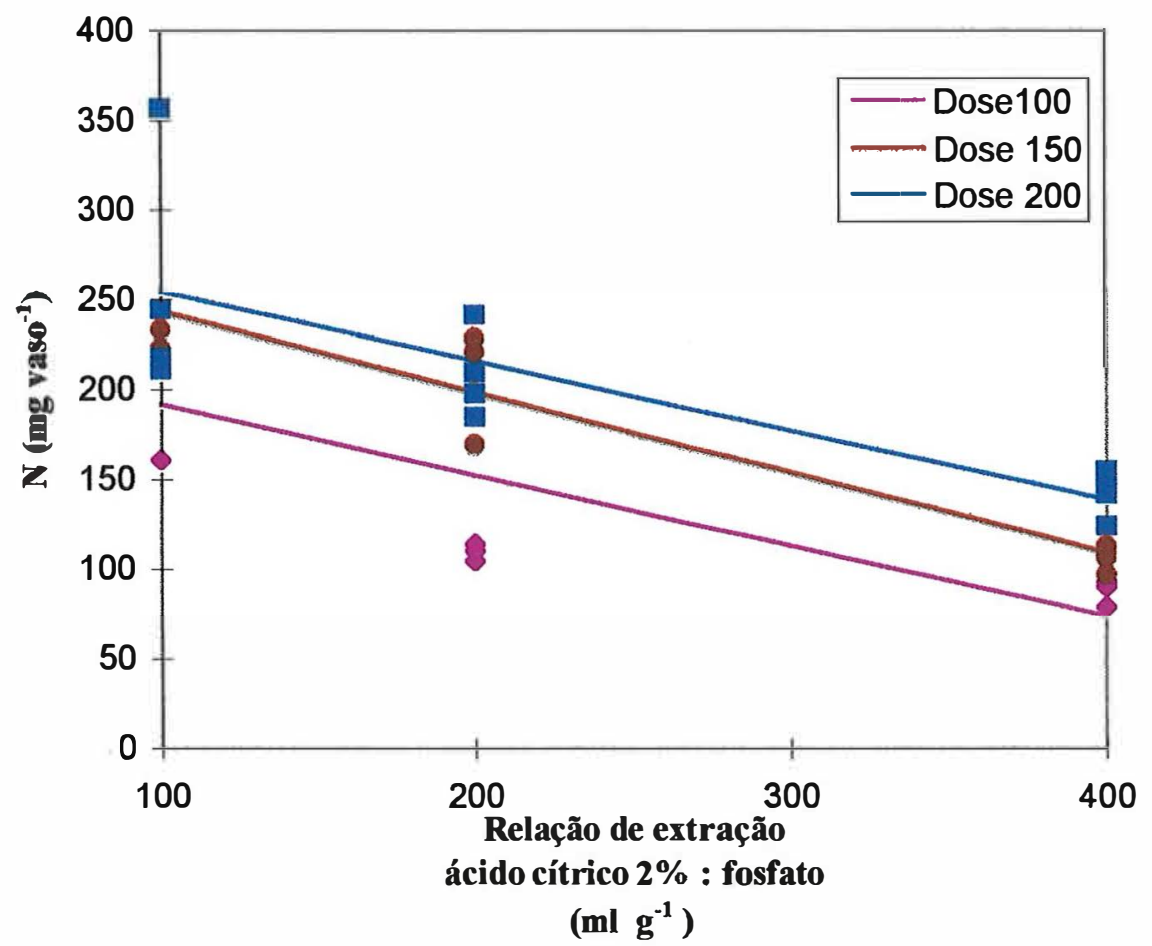

Figura 33 - Quantidade de N absorvida pelo milho no segundo plantio em diferentes relações de extração e doses para o fosfato Catalão

Dose 100

$\mathbf{Y}=229,350-39,182 \times \mathbf{R}^{2}=0,67$ * *

Dose 150

$\mathbf{Y}=\mathbf{2 8 6 , 4 7 5}-\mathbf{4 4 , 6 0 7} \times \mathbf{R}^{2}=0,98$ * *

Dose 150

$Y=291,237-38,441 \times R^{2}=0,97 *$ * 


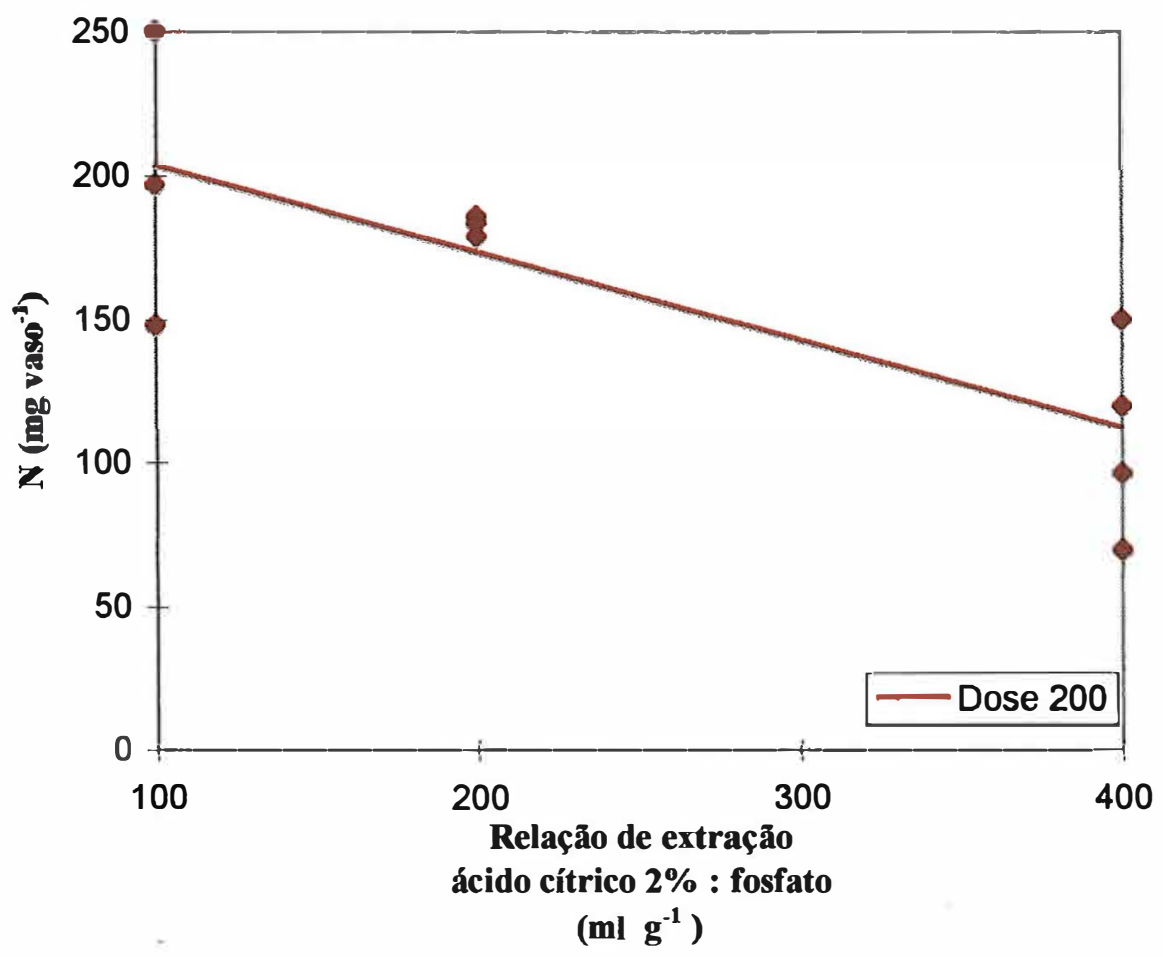

Figura 34 - Quantidade de $\mathbf{N}$ absorvida pelo milho no segundo plantio em diferentes relações de extração e doses para o fosfato Patos.

Dose $200 \quad Y=233,700-30,560 \times R^{2}=0,96$ *

\subsubsection{Teor e quantidade de potássio}

A concentração de $\mathrm{K}$ na parte aérea do milho foi adequada $\left(2 \mathrm{a} 4 \mathrm{~g} \mathrm{~kg}^{-1}\right)$ apenas para os fosfatos Patos e Catalão, que apresentaram maiores valores e, para os fosfatos Alvorada e Arad, não diferiram entre si, o que, provavelmente, é devido ao efeito de diluição do material seco. A quantidade de potássio absorvida pelo milho foi maior para os fosfatos Alvorada e Arad, seguidos de Catalão e Patos (Tabela 31).

Tabela 31. Teores e quantidades médias de potássio absorvidos pelo milho no segundo plantio

\begin{tabular}{lcc}
\hline Fosfato & Teor $\left(\mathbf{g ~ k g}^{-1}\right)$ & \left.${\text { Quantidade }\left(\mathrm{mg} \mathrm{vas}^{-1}\right)}^{-1}\right)$ \\
\hline Patos & $35,91 \mathrm{~A}$ & $178,4 \mathrm{C}$ \\
Catalão & $29,34 \mathrm{~B}$ & $225,2 \mathrm{~B}$ \\
Alvorada & $19,47 \mathrm{C}$ & $275,1 \mathrm{~A}$ \\
Arad & $18,70 \mathrm{C}$ & $250,8 \mathrm{AB}$ \\
\hline
\end{tabular}

Médias seguidas pela mesma letra não diferem entre si pelo teste de Tukey ( $5 \%$ ).

$$
\text { DMS }=2,63 \mathrm{~g} \mathrm{~kg}^{-1} \quad \text { DMS }=3,27 \mathrm{mg}^{-1} \text { vaso }^{-1}
$$


As quantidades de $\mathrm{K}$ absorvidas foram influenciadas por todos os fatores estudados, diferindo do ocorrido no primeiro plantio (Tabela 25). Para o fosfato Alvorada, à medida que a relação de extração variou de 1:100 para 1:400, isto é, as quantidades de fosfato aplicadas foram reduzidas, foi verificado um aumento na absorção de K. Isso pode ter ocorrido porque talvez tenha permanecido uma maior quantidade de potássio no solo na relação 1:400, visto que ela produziu menor quantidade de material seco no primeiro plantio. As outras doses de fósforo não apresentaram efeito, devido à mineralização do $\mathrm{K}$ das raízes das plantas do primeiro plantio que pode ter ocorrido, não influenciando o acúmulo de potássio no segundo plantio (Figura 35).

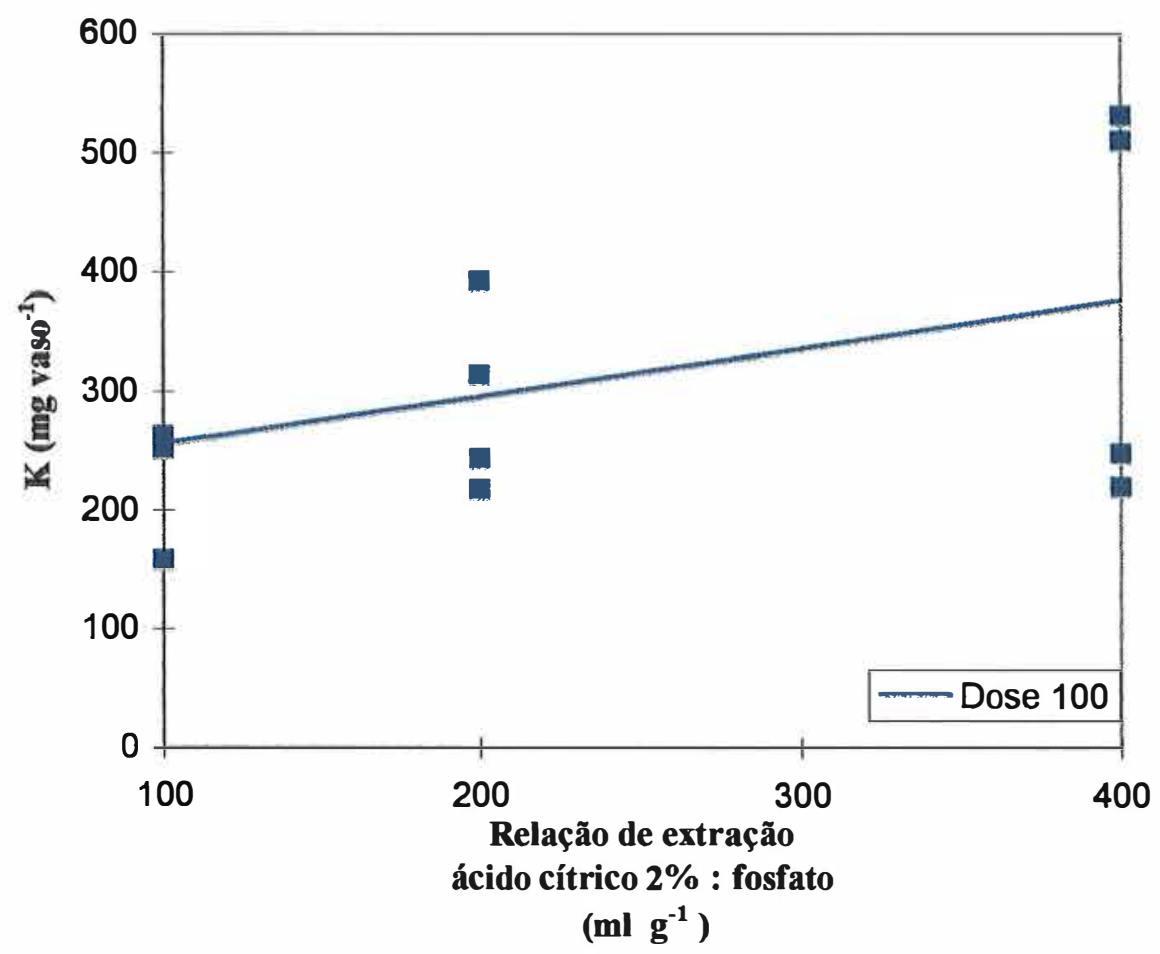

Figura 35 - Quantidade de K absorvida pelo milho no segundo plantio em diferentes relações de extração para o fosfato Alvorada na dose $100 \mathrm{mg} \mathrm{kg}^{-1}$. Dose $100 \quad Y=213,600-40,120 \times R^{2}=0,99 * *$

Para o fosfato Catalão, a maior quantidade de $\mathrm{K}$ absorvida foi com $31,47 \mathrm{~g}$ de fosfato/vaso (relação 1:100, dose 150), o que não concorda com o tratamento de maior produção de material seco. Isso pode ter ocorrido, porque a quantidade de fosfato 
aplicada neste tratamento pode ter contribuído para que as plantas tenham atingido a suficiência em potássio (Figura 36).

Para o fosfato Patos, o tratamento utilizando 32,00 $\mathrm{g} \mathrm{vaso}^{-1}$ (relação 1:100, dose $200 \mathrm{mg} \mathrm{kg}^{-1}$ ) foi a de maior quantidade de potássio absorvida (Figura 37), concordando com o material seco. Para o fosfato Arad, o acúmulo de potássio não obteve efeito, provavelmente, porque o material seco produzido, no segundo plantio, não foi influenciado pelos fatores relação de extração e doses.

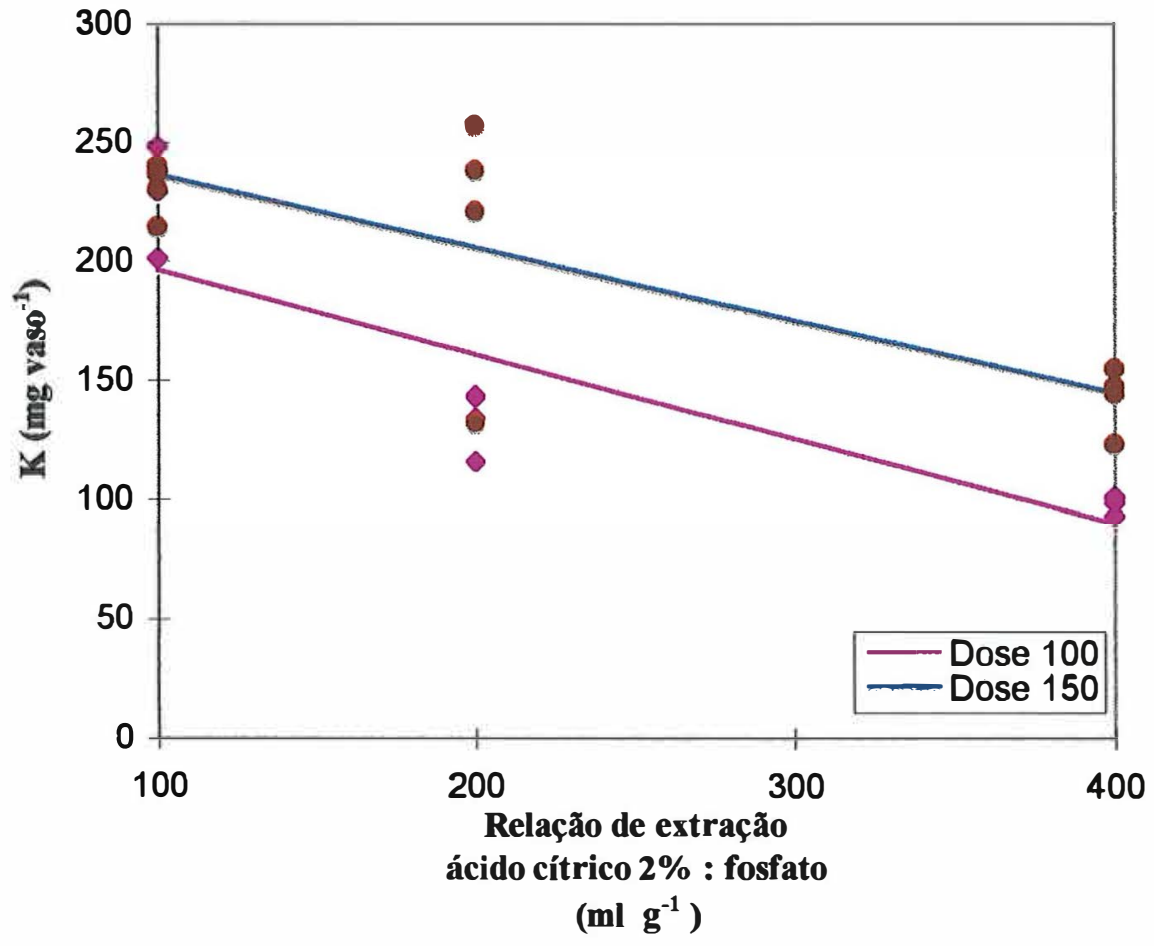

Figura 36 - Quantidade de $\mathrm{K}$ absorvida pelo milho no segundo plantio em diferentes relações de

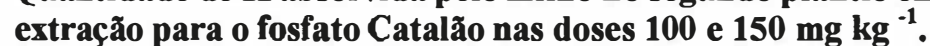

Dose $100 \quad Y=246,325-39,907 X R^{2}=0,82$ **

Dose $150 \quad Y=258,787-26,447 X R^{2}=0,69 *$ * 


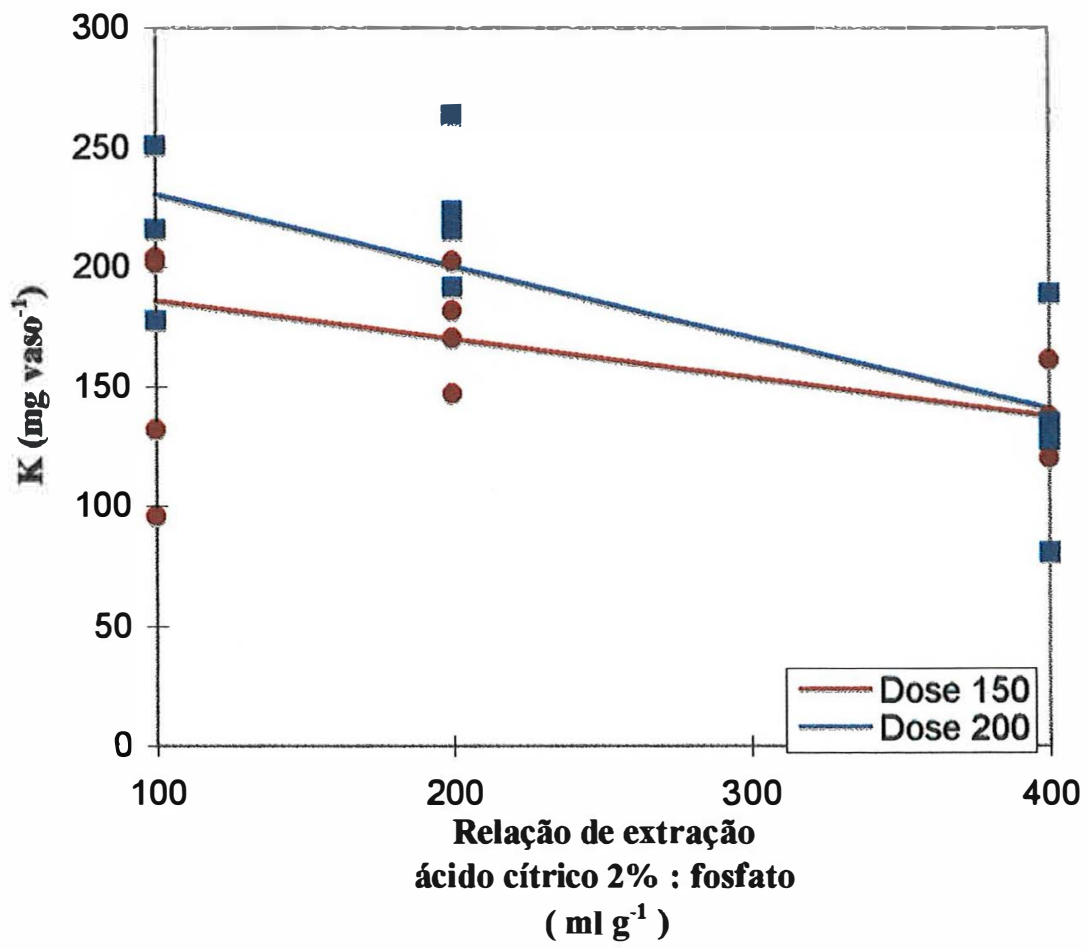

Figura 37 - Quantidade de K absorvida pelo milho no segundo plantio em diferentes relações de extração para o fosfato Patos na dose $200 \mathrm{mg} \mathrm{kg}^{-1}$..

Dose 200

$\mathbf{Y}=259,350-29,967 \times \mathbf{R}^{2}=0,83$ * *

\subsubsection{Teor e quantidade de cálcio}

Os teores de cálcio apresentados pelo milho no segundo plantio foram adequados ( 2 a $5 \mathrm{~g} \mathrm{~kg}^{-1}$ ) para todos os fosfatos, sendo os maiores valores obtidos para o fosfato Arad, seguido de Patos, Alvorada e Catalão (Tabela 32). As quantidades de cálcio absorvidas foram maiores para o fosfato Arad, seguido de Alvorada, Catalão e Patos, pelo efeito de diluição do material seco, devido às suas solubilidades e teores de cálcio das fontes, conforme ocorreu no primeiro plantio.

Tabela 32 Teores e quantidades médias de cálcio absorvidos pelo milho no segundo plantio.

\begin{tabular}{lcr}
\hline Fosfato & Teor $\left(\mathbf{g ~ k g}^{-1}\right)$ & Quantidade $(\mathbf{m g}$ \\
\hline Arad & $6,59 \mathrm{~A}$ & $88,7 \mathrm{~A}$ \\
Patos & $6,08 \mathrm{AB}$ & $31,8 \mathrm{D}$ \\
Alvorada & $5,61 \mathrm{~B}$ & $79,9 \mathrm{~B}$ \\
Catalão & $4,68 \mathrm{C}$ & $39,0 \mathrm{C}$
\end{tabular}

Médias seguidas pela mesma letra não diferem entre si pelo teste de Tukey (5\%).

$$
\mathrm{DMS}=0,62 \mathrm{~g} \mathrm{~kg}^{-1} \quad \mathrm{DMS}=5,80 \mathrm{mg} \mathrm{vaso}^{-1}
$$


As quantidades de cálcio absorvidas pelo milho foram influenciadas por todos os fatores (Tabela 25). Para o fosfato Alvorada, houve diminuição nas quantidades de cálcio absorvidas quando o fósforo foi aplicado na dose $100 \mathrm{mg} \mathrm{kg}^{-1}$, à medida que a relação 1:100 variou para 1:400. Ou seja, aumentando-se a quantidade de fosfato adicionada (relação 1:100), houve aumento da absorção de $\mathrm{Ca}$ apenas com a utilização da dose de $\mathrm{P}$ de $100 \mathrm{mg} \mathrm{kg}^{-1}$, que não concorda com a maior produção de material seco obtida na relação 1:100, dose de $\mathrm{P}$ de $200 \mathrm{mg} \mathrm{kg}^{-1}$. Isso pode ter ocorrido, porque foi a dose que obteve menor extração de $\mathrm{P}$ e $\mathrm{Ca}$, no primeiro plantio, podendo ter permanecido uma maior quantidade de fósforo e cálcio no segundo plantio. A elevação na produção de material seco com doses mais altas de fósforo pode não ter sido suficientemente grandes para compensar o decréscimo no teor de cálcio da planta, não havendo diferença no total acumulado (Figura 38).

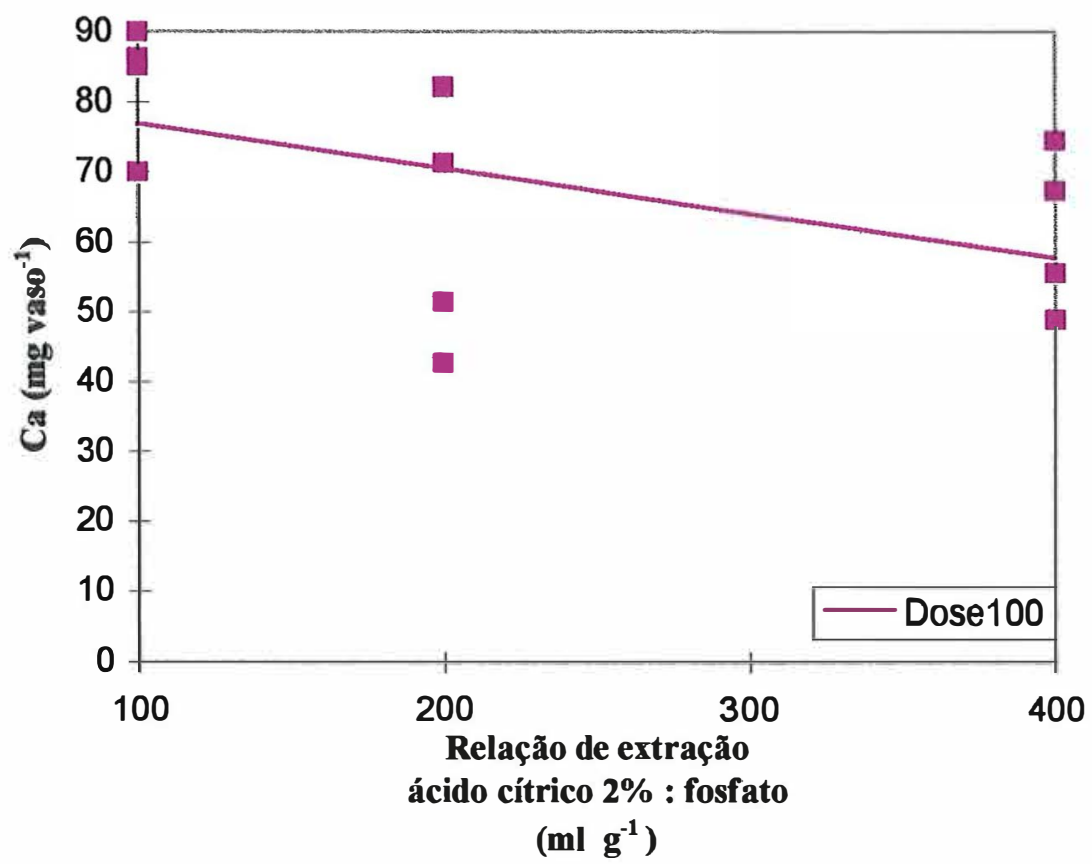

Figura 38 - Quantidade de Ca absorvida pelo milho no segundo plantio em diferentes relações de extração para o fosfato Alvorada na dose $100 \mathrm{mg} \mathrm{kg}^{-1}$.

Dose $100 \quad Y=83,00-6,430 \times R^{2}=0,62$ * 
Para os fosfatos Catalão e Patos, o maior acúmulo de Ca foi na relação 1:100, dose de $\mathrm{P} 200 \mathrm{mg} \mathrm{kg}^{-1}$, o que concorda com o tratamento com a maior quantidade de material seco produzida para cada fosfato (Figuras 39 e 40). Entretanto, todas doses utilizadas do fosfato Catalão tiveram efeito sobre a absorção de cálcio e, para o fosfato Patos, apenas as doses de $\mathrm{P}$ de 150 e $200 \mathrm{mg} \mathrm{kg}^{-1}$, o que pode ser devido à sua menor solubilidade e disponibilidade de fósforo e cálcio.

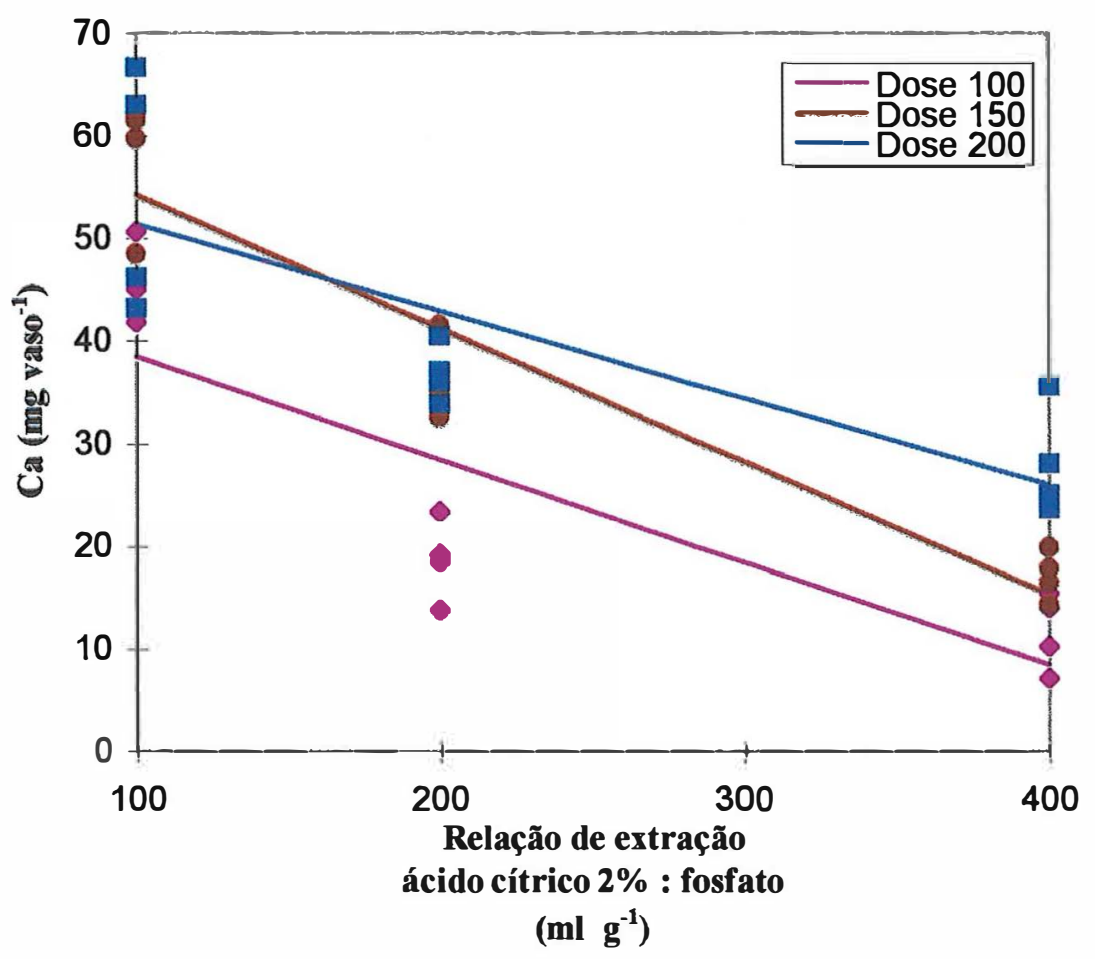

Figura 39 - Quantidade de Ca absorvida pelo milho no segundo plantio em diferentes relações de extração e doses para o fosfato Catalão.

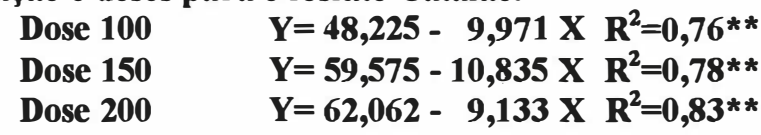




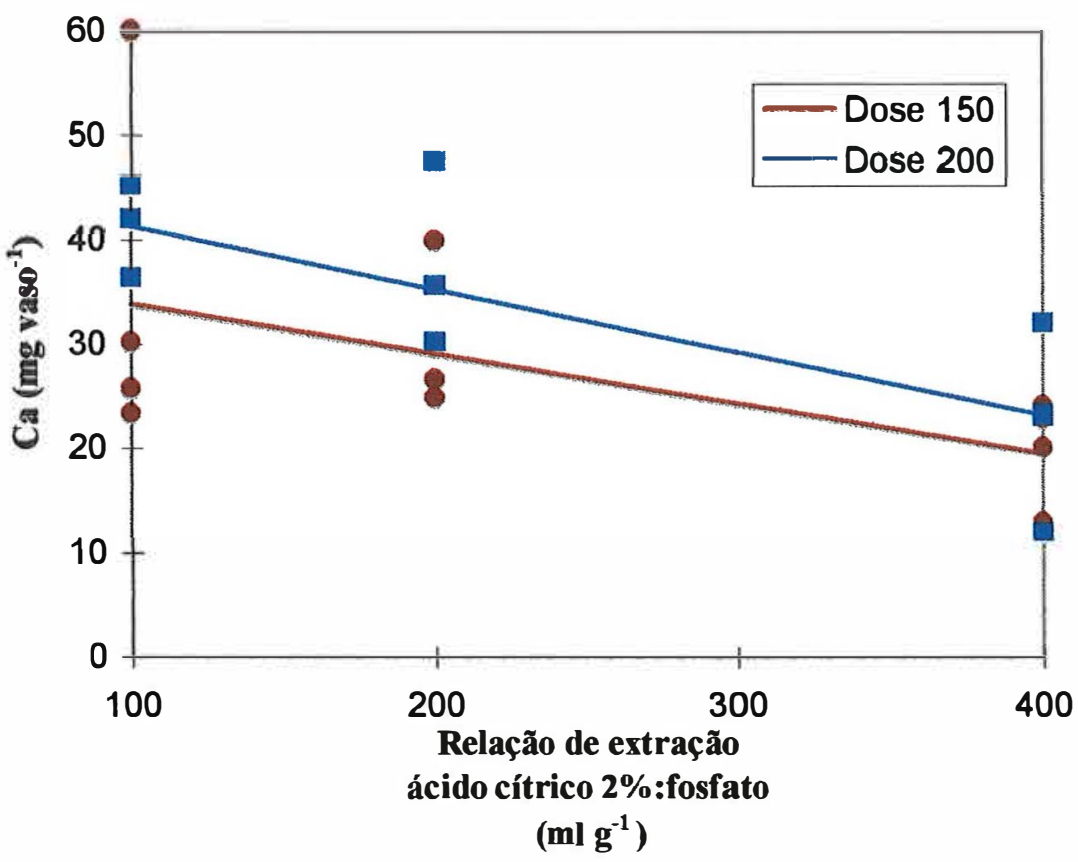

Figura 40 - Quantidade de Ca absorvida pelo milho no segundo plantio em diferentes relações de extração e doses para o fosfato Patos.

$\begin{array}{ll}\text { Dose } 100 & Y=38,400-4,767 \times R^{2}=0,97 * * \\ \text { Dose } 150 & Y=46,870-5,450 \times R^{2}=0,56 \text { * * }\end{array}$

Para o fosfato Arad, apenas a dose de $\mathrm{P}$ de $200 \mathrm{mg} \mathrm{kg}^{-1}$ obteve maior acúmulo de cálcio na relação 1:100. À medida que a quantidade de fosfato aplicada foi diminuída (relação 1:400), houve redução na absorção de cálcio, o que pode ser explicado por sua composição química rica em cálcio. No entanto, a absorção de cálcio não influenciou o material seco produzido (Figura 41). 


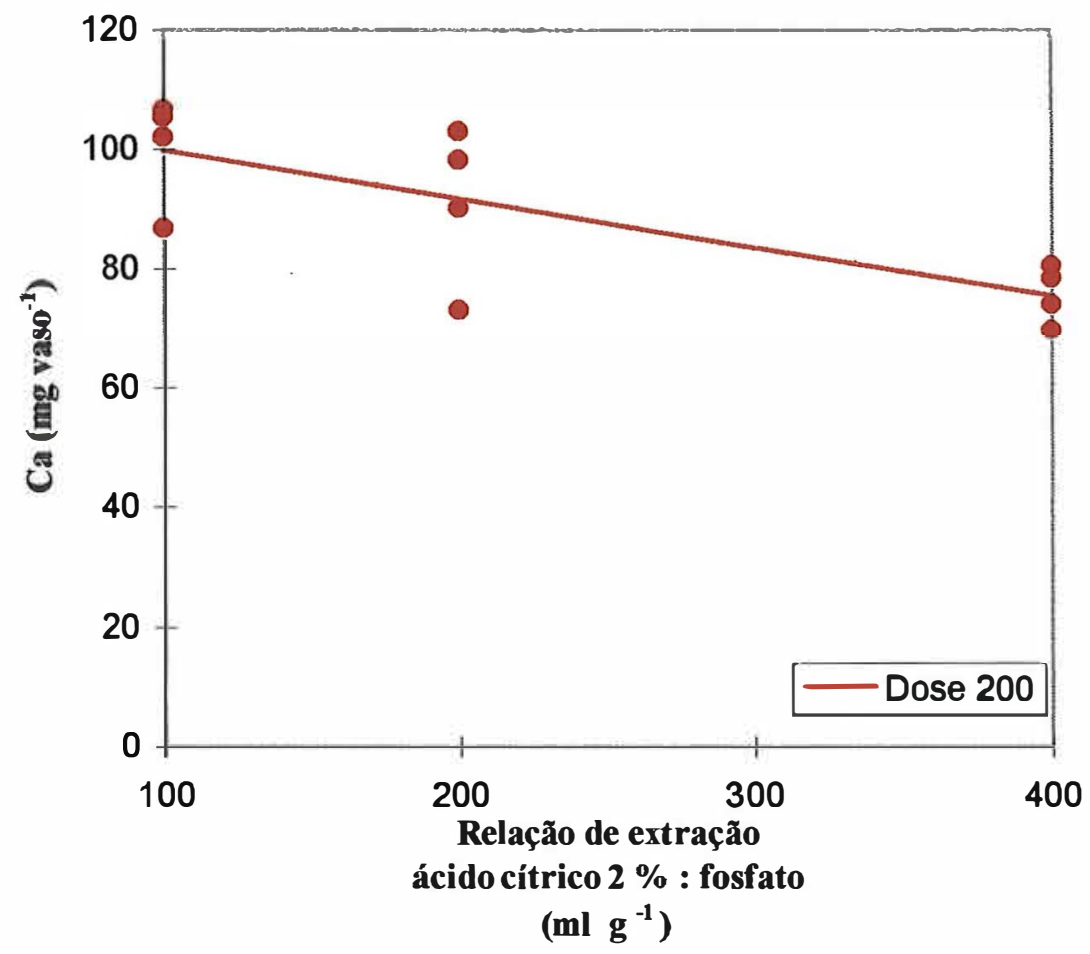

Figura 41 - Quantidade de Ca absorvida pelo milho no segundo plantio em diferentes relações de extração e doses para o fosfato Arad na dose $200 \mathrm{mg} \mathrm{kg}^{-1}$. Dose $200 Y Y=107,320-8,060 \times R^{2}=0,83^{* *}$

\subsubsection{Teor e quantidade de magnésio}

Os teores de magnésio encontrados na parte aérea do milho no segundo plantio foram adequados $\left(0,5 \mathrm{a} 2 \mathrm{~g} \mathrm{~kg}^{-1}\right)$ para todas as fontes. $\mathrm{O}$ fosfato Patos apresentou maior teor seguido de Catalão, Arad e Alvorada devido ao efeito de diluição do material seco. $\mathrm{O}$ acúmulo de magnésio foi maior para os fosfatos Alvorada e Arad, seguidos de Catalão e Patos (Tabela 33).

Tabela 33 Teores e quantidades médias de magnésio absorvidos pelo milho no segundo plantio

\begin{tabular}{lcc}
\hline Fosfato & Teor $\left(\mathrm{g} \mathrm{kg}^{-1}\right)$ & Quantidade $\left(\mathbf{m g ~ v a s o}^{-1}\right)$ \\
\hline Patos & $0,62 \mathrm{~A}$ & $29,0 \mathrm{C}$ \\
Catalão & $0,57 \mathrm{AB}$ & $45,0 \mathrm{~B}$ \\
Arad & $0,55 \mathrm{~B}$ & $72,0 \mathrm{~A}$ \\
Alvorada & $0,48 \mathrm{C}$ & $68,0 \mathrm{~A}$ \\
\hline \multicolumn{2}{l}{ Médias seguidas pela mesma letra não diferem entre si pelo teste de Tukey (5\%). } \\
\multicolumn{2}{c}{ DMS $=0,05 \mathrm{~g} \mathrm{~kg}^{-1}$} & \multicolumn{3}{c}{ DMS $=7,00 \mathrm{mg}^{-1}$ vaso $^{-1}$}
\end{tabular}


As quantidades de magnésio absorvidas pelas plantas foram influenciadas por todos os fatores, exceto doses (Tabela 25). Entretanto, na decomposição das doses duplas e triplas, não houve efeito para os fosfatos.

\subsubsection{Teor e quantidade de enxofre}

A concentração de enxofre foi adequada para todos os fosfatos, sendo que o fosfato Patos apresentou maior resultado, seguido de Arad, Catalão e Alvorada devido ao efeito de diluição do material seco. $\mathrm{O}$ acúmulo de enxofre pelo milho foi maior para os fosfatos Alvorada, Arad, Catalão e Patos (Tabela 34).

Tabela 34 Teores e quantidades médias de enxof re absorvidos pelo milho no segundo plantio

\begin{tabular}{lcr}
\hline Fosfato & Teor $\left(\mathrm{g} \mathrm{kg}^{-1}\right)$ & Quantidade(mg \\
\hline Patos & $1,42 \mathrm{~A}$ & $7,0 \mathrm{D}$ \\
Arad & $1,28 \mathrm{~B}$ & $17,5 \mathrm{~A}$ \\
Catalão & $1,16 \mathrm{C}$ & $9,9 \mathrm{C}$ \\
Alvorada & $1,10 \mathrm{C}$ & $15,7 \mathrm{~B}$
\end{tabular}

Médias seguidas pela mesma letra não diferem entre si pelo teste de Tukey (5\%).

DMS teor $=0,08 \mathrm{~g} \mathrm{~kg}^{-1} \quad$ DMS quantidade $=1,40 \mathrm{mg}^{\text {vaso }}{ }^{-1}$

As quantidades de $\mathrm{S}$ absorvidas pelo milho foram influenciadas por todos os fatores (Tabela 25). Para os fosfatos Alvorada e Arad não houve efeito provavelmente pela maior produção de material seco e de raízes, as quais devem ter sido mineralizadas e absorvidas no segundo plantio.

Para os fosfatos Catalão e Patos, o tratamento de relação 1:100 e dose $150(31,47$ e $24 \mathrm{~g} \mathrm{vaso}^{-1}$ ) foi a de maior acúmulo de $\mathrm{S}$ para ambos os fosfatos (Figuras $43 \mathrm{e} \mathrm{44)} \mathrm{O}$ resultado corrobora com a maior quantidade de material seco produzido. 


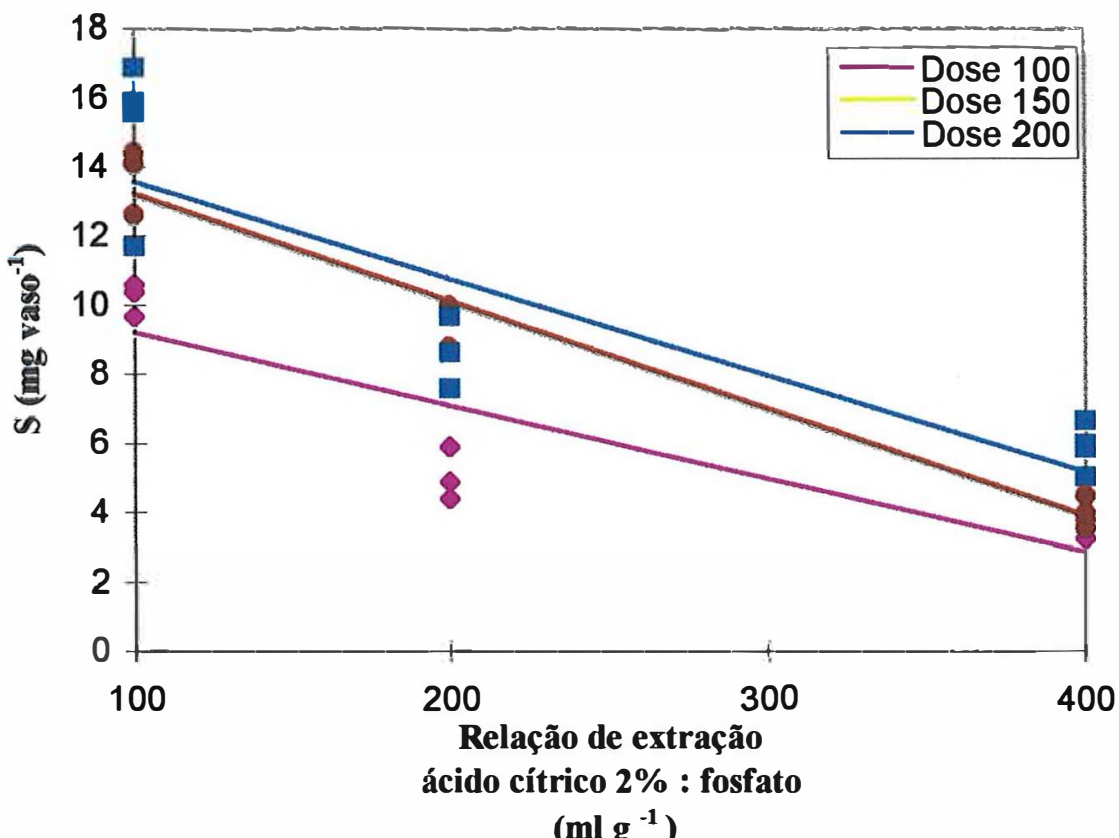

Figura 43 - Quantidade de S absorvida pelo milho no segundo plantio em diferentes relações de extração e doses para o fosfato Catalão.
Dose 100
$Y=11,220-2,110 \times R^{2}=0,76$ * *
Dose 150
$Y=16,670-3,220 \times R^{2}=0,99 *$ *
Dose 200
$Y=16,010-2,880 \times R^{2}=0,89$ * *

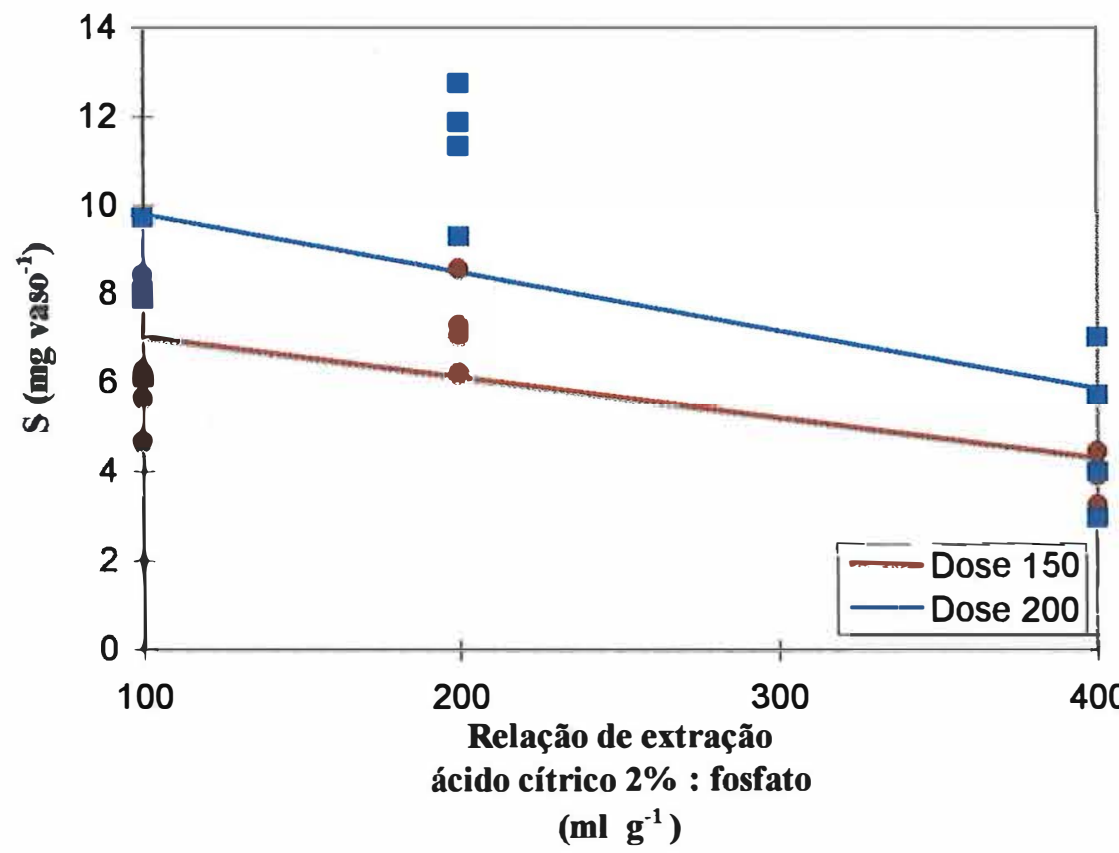

Figura 44 - Quantidade de $S$ absorvida pelo milho no segundo plantio em diferentes relações de extração e doses para o fosfato Patos.

Dose 150

$Y=7,870-0,098 \times R^{2}=0,64^{\text {* * }}$

Dose 200

$Y=12,590-1,990 \times R^{2}=0,96$ * * 


\section{CONSIDERAÇÕES GERAIS}

Os fosfatos naturais podem ser utilizados sob certas condições de solo, cultura e manejo. A viabilidade do seu uso, entretanto, precisa ser considerada quanto à economicidade e o retorno em produção, comparados aos fosfatos solúveis.

Uma das características importantes da viabilidade dos fosfatos naturais é a sua reatividade, que pode ser conhecida através da sua origem geológica e composições mineralógica, química e granulométrica. Essas características promovem comportamentos diferentes dos fosfatos no solo. Assim, a utilização da adubação com base em quantidades iguais de fosfato ou no seu teor total de fósforo, não é adequada, resultando na ineficiência das fontes, pois elas têm comportamento diferente.

A solubilidade em ácido cítrico a $2 \%$ (relação 1:100), recomendado pela legislação brasileira, é um método confiável, rápido e simples para avaliação da reatividade dos fosfatos naturais. No presente trabalho, a adubação fosfatada baseada no teor solúvel em ácido cítrico $2 \%$ (1:100) conseguiu aumentar a eficiência dos fosfatos naturais no primeiro plantio, exceto para o fosfato Patos e no efeito residual, exceto para o fosfato Arad, com alguns deles superando o superfosfato triplo. A solubilidade em ácido cítrico constituiu-se num importante parâmetro para predição do comportamento dos fosfatos naturais no solo. Esse método químico pode ser utilizado para avaliar a real disponibilidade de fósforo dos fosfatos naturais às plantas, pois correlacionou-se com os dados agronômicos.

Portanto, a recomendação de adubação com fosfatos naturais baseada no teor de fósforo solúvel em ácido cítrico a $2 \%$ (relação 1:100) poderia aumentar a sua eficiência. A sua economicidade, comparado ao dos solúveis, entretanto, pode inviabilizar o seu uso por requerer quantidades exageradas de fosfatos naturais em condições de campo. 


\section{CONCLUSÕES}

Para as condições em que o presente trabalho foi desenvolvido, os resultados obtidos nos dois plantios consecutivos de milho, permitiram concluir que:

O fosfato Alvorada apresentou maior solubilidade em ácido cítrico $2 \%$ (relação 1:100), seguido dos fosfatos Arad, Patos e Catalão.

O fosfato Alvorada apresentou a maior produção de material seco, superando os demais fosfatos, inclusive o superfosfato triplo.

A relação de extração 1:100 (fosfato:ácido cítrico 2\%) para os fosfatos naturais correspondeu à maior produção de material seco do milho.

O acúmulo de fósforo pelo milho e os índices de eficiência agronômica dos fosfatos apresentaram as mesmas tendências de produção de material seco, o que não ocorreu para os teores de fósforo absorvido. 
$\mathrm{O}$ acúmulo de nitrogênio, potássio e magnésio foram maiores para os fosfatos Alvorada, Arad, Catalão e Patos, segundo as solubilidades dos fosfatos em ácido cítrico (relação 1:100), nos dois plantios de milho.

A utilização do fosfato Arad propiciou maior extração de cálcio e enxofre pelo milho, superando os outros fosfatos, devido à sua composição química rica em cálcio e enxofre.

A utilização da solubilidade em ácido cítrico $2 \%$ (1:100) é um importante parâmetro para predizer o comportamento de fosfatos naturais de diferentes origens geológicas, avaliados pela produção de material seco, absorção de fósforo e pelo índice de eficência agronômica para os fosfatos estudados no plantio inicial, exceto para Patos e no efeito residual, exceto para Arad.

A recomendação de adubação utilizando quantidades iguais de fosfatos naturais não é adequada, sendo importante a determinação do conteúdo de fósforo solúvel em ácido cítrico a $2 \%$ antes da sua utilização, pois eles têm comportamento variado devido às suas diferenças na composição química e mineralógica. 


\section{REFERÊNCIAS BIBLIOGRÁFICAS}

ABRÃO, J. J. R.; GRIMM, S.S. Avaliação do efeito residual da calagem e da adubação fosfatada num Oxissol durante três anos de cultivo. Agronomia Sulriograndense, v.11, n.1, p.105-127, 1975.

ARMIGER,W.H.; FRIED, M. The plant availability of various sources of phosphate rock. Soil Science Society of America Proceedings, v.2, n.2, p.183-188, 1957.

BIASI, J. SUHETT, G. Influência de diferentes fontes de fósforo na fertilidade do solo, In: CONGRESSO BRASILEIRO DE CIÊNCIA DO SOLO, 17., Manaus, 1979. Resumos. Sociedade Brasileira de Ciência do Solo, 1979. p.34.

BLANCO, H.G.; VENTURINI, W.R.; GARGANTINI, H. Comportamento de fertilizantes fosfatados em diferentes condições de acidez do solo para trigo, com estudo do efeito residual para soja. Bragantia, v.24, n.22, p.261-279, 1965.

BOLLAND, M.D.A. ; WEATHERLEY, A.J.; GILKES, R.J. The long-term residual value of rock phosphate and superphosphate fertilizers for various plant species under field conditions. Soils and Fertilizers, v.53, n.4, p.381, 1990.

BORKERT, C.M.; CORDEIRO, D.S.; SFREDO, G.J.; PALHANO, J.B.; DITTRICH, R.C. Efeito de doses de fósforo de diferentes fosfatos naturais brasileiros na produção de soja, em condições de primeiro cultivo. In: SEMINÁRIO NACIONAL DE PESQUISA DE SOJA, 1, Londrina, 1978. Anais. p.291-297.

BRAGA, N.R.; MASCARENHAS, H.A.A.; BULISANI, E.A.; RAIJ, B.van; FEITOSA, C.T.; HIROCE, R. Eficiência agronômica de nove fosfatos em quatro cultivos consecutivos de soja. Revista Brasileira de Ciência do Solo, v.15, n.3, p.315-319, 1991.

BRAGA, J.M.; YAHNER, J. Estudo comparativo de fosfato de Araxá e superfosfato simples em cultura de milho, em um solo de Viçosa, Minas Gerais. Experimentae, v.8, n.5, p.143-163, 1968.

BRASIL. Secretaria Nacional de Defesa Agropecuária. Inspeção e Fiscalização da produção e do comércio de fertilizantes, corretivos, inoculantes, estimulantes ou biofertilizantes destinados à agricultura: Legislação. s.l. Divisão de Fiscalização de corretivos e fertilizantes, 1983 . 88p. 
BRAITHWAITE, A.C.; EATON, A.C.;GROOM, P.S. Evaluation of double extraction techniques as solubility tests for fertilizer products containing phosphate rock components. Soils and Fertilizers, v.55, n. 10, p.1241, 1992.

BRASIL SOBRINHO, M.O.C. do; MELLO, F.A.F.; COURY, T. Estudo sobre a solubilidade de fosfatos em ácido cítrico a $2 \%$. Anais da Escola Superior de Agricultura "Luiz de Queiroz", v.22, 104-109, 1965.

CÁCERES, N.T.; NAKAYAMA, L.H.I; SILVA, V.M.; GUILHERME, M.A. de S.; BORGES, M.H.; SILVA, F.; PFEIFER,R.; MARCONDES, R.; FALCÃO, N.L; ALCARDE, J.C.; MALAVOLTA, E. Eficiência relativa de fontes de fósforo de diferentes solubilidades. In: CONGRESSO BRASILEIRO DE CIÊNCIA DO SOLO, 23., Goiânia, 1993. Resumos. Campinas: Sociedade Brasileira de Ciência do Solo, 1993. p.217.

CANTARUTTI, R.B.; BRAGA, J.M.; NOVAIS, R.F.; THIEBAUT, J.T.L. Época de aplicação de fosfato natural em relação à calagem num solo com elevado teor de alumínio trocável. Revista Brasileira de Ciência do Solo, v.5, n.2, p.129-133, 1981.

CARO, J.H.; HILL, W.L. Characteristic and fertilizer value of phosphate rock from different fields. Journal of Agricultural and Food Chemistry, v.4, p.684-687, 1956.

CATANI, R.A. Contribuição ao estudo dos fosfatos, sua dosagem, extração e distribuição nos solos do estado de São Paulo. Campinas,1947 65 p. Dissertacão (Mestrado) - Escola Superior de Agricultura "Luiz de Queiroz", Universidade de São Paulo.

CATANI, R.A. Solubilidade de fosfatos naturais em solução de ácido cítrico a $2 \%$ na proporção 1:200. Anais da Escola Superior de Agricultura "Luiz de Queiroz", v.23, n.1, p. 1-14, 1970.

CATANI, R.A.; NASCIMENTO,A.C. Solubilidade de alguns fosfatos naturais. Revista de Agricultura, v.27, n.1-2, p.149-168, 1952.

CAVALCANTI, F.J. de A. Alguns aspectos da fixação de fósforo por solos da região de Piracicaba. Piracicaba, 1974. 62p. Dissertação (Mestrado) - Escola Superior de Agricultura "Luiz de Queiroz", Universidade de São Paulo.

CORDEIRO, D.S.; POTTKER,C.M.; BORKERT,G..; SFREDO, J.; MESQUITA, A.N.; DITTRICH, R.C.; PALHANO,C. Efeito de níveis e fontes de fósforo na produção e no rendimento da soja na região de Dourados (MS). Revista Brasileira de Ciência do Solo, v.3, n.2, p. 100-105. 1979. 
COUTINHO, E.L.M; NATALE,W.; STUPIELLO, J.J.; CARNIER, P.E. Avaliação da eficiência agronômica de fertilizantes fosfatados para a cultura do milho. Científica, v. 10, n.2, p.93-104, 1991.

C.P.A.C. Centro Pesquisa Agropecuária do Cerrado. Relatório Técnico Anual 19791980. Brasília, v.5, p.41-45. 1980.

DE FELIPO, B.V.; SOUSA, J.; BRAGA, J.M.; ALVAREZ, V.H. Efeito do período de incubação de fosfatos naturais no solo sobre a disponibilidade de fósforo para as plantas. Revista Ceres, v.28, n.159, p.515-20, 1981.

DELAZARI, P.C. Disponibilidade de fósforo em solos do estado do Espírito Santo. Viçosa, 1979. 98 p. Dissertação (M.S.). - Universidade Federal de Viçosa.

DYNIA, J.F. Efeito do $\mathrm{pH}$ e da capacidade de retenção de fósforo dos solos na eficiência dos adubos fosfatados. Porto Alegre, 1977. 61p. Dissertação (Mestrado) Faculdade de Agronomia, Universidade Federal do Rio Grande do Sul.

DYNIA, J.F. VOLKWEISS, S.J.; STAMMEL, J.G. Efeito do pH e da capacidade de retenção de fósforo dos solos na eficiência de adubos fosfatados. In: CONGRESSO BRASILEIRO DE CIÊNCIA DO SOLO, 17., Manaus,1979. Resumos. Campinas: Sociedade Brasileira de Ciência do Solo, 1979. p.38.

ESPINOZA, W.A.J.; OLIVEIRA, E.; CONTINI, C. Produção e uso de rochas fosfáticas no Brasil. In: CONGRESSO BRASILEIRO DE CIENCIA DO SOLO, 19, Curitiba, 1983. Resumos. Campinas: Sociedade Brasileira de Ciência do Solo, 1983. p.114.

FEITOSA, C.T.; BITTENCOURT, V.C. de. Disponibilidade de fósforo aplicado ao solo na forma de diferentes fosfatos. In: CONGRESSO BRASILEIRO DE CIÊNCIA DO SOLO, 17., Manaus,1979. Resumos. Campinas: Sociedade Brasileira de Ciência do Solo, 1979. p.34.

FEITOSA, C.T.; RAIJ, B. van; DECHEN, A.R.; ALCARDE, J.C. Determinação preliminar da eficiência relativa de fosfatos para trigo, em casa-de-vegetação. Revista Brasileira de Ciência do Solo, v.2, n.3, p.193-195, 1978.

FEITOSA, C.T.; RAIJ, B.van. Influência da natureza de fosfatos aplicados a dois solos no fósforo solúvel em extratores químicos e disponíveis em trigo e milho. In: CONGRESSO BRASILEIRO DE CIÊNCIA DO SOLO, 15., Campinas, 1975. Anais. Campinas: Sociedade Brasileira de Ciência do Solo, 1975. p.215-220.

FRANCO, M.; BRAGA, J.M.; RIOS, J.N.G.; THIÉBAUT, J.T.L. A Avaliação de fosfatos naturais usando ácido cítrico e ácido fórmico. Revista Ceres, v.26, n. 144, p.152-161, 1979. 
GOEDERT, W.L. Efeito residual de fosfatos naturais em solos de cerrados. Pesquisa Agropecuária Brasileira, v.18, n.9, p.499-506, 1983.

GOEDERT, W.L.; LOBATO, E. Avaliação agronômica de fosfatos em solo de cerrado. Revista Brasileira de Ciência do Solo, v.8, n.1, p.97-102, 1984.

GOEDERT, W.J.; LOBATO, E. Eficiência agronômica de fosfatos em solos de cerrado. In:CONGRESSO BRASLEIRO DE CIÊNCIA DO SOLO, 17., Manaus, 1979. Resumos. Campinas : Sociedade Brasileira de Ciência do Solo, 1979. p.39.

GOEDERT, W.J.; LOBATO, E. Eficiência agronômica de fosfatos em solos de cerrado. Pesquisa Agropecuária Brasileira, v.15, n.3, p.311-318, 1980.

GOEDERT,W.L.; REIN,T.A.; SOUZA, D.M.G. Eficiência agronômica de fosfatos naturais, fosfatos parcialmente acidulados e termofosfatos em solos de cerrado. Pesquisa Agropecuária Brasileira, v.25, n.4, p.521-530, 1990.

GOEPFERT, C.F.; MOURA, R.L. Resposta da cultura da soja (Glycine max (L.) Marril) a doses e fontes de fósforo. In: CONGRESSO BRASILEIRO DE CIÊNCIA DO SOLO, 17., Manaus,1979. Resumos. Campinas: Sociedade Brasileira de Ciência do Solo, 1975. p.36.

GOMES, A.C.; CATANI,R.A.; FREIRE,E.S. Adubação do milho. XIX: Ensaios com diversos fosfatos (5 $5^{\underline{a}}$ série) Bragantia, v.20, n.3, p.35-41, 1961.

HOWELER, R.H.; WOODRUFF, C.M. Dissolution and availability to plants of rock phosphates of igneus and sedimentary origins. Soil Science Society of America Proceedings, v.32, n.1,p.79-82, 1968.

HORWITZ, W. Official Methods of Analysis of Association of Official Analytical Chemists. A.O.A.C.:Washington, 1970. 1015 p.

KOTER, M.; NOWAK, G.; CZAPLA, J. Yields of crops in rotation in the light of 20year investigations on concentrated application of phosphorus. Soils and Fertilizers, v.55, n. 3, p.396,1992.

KHASAWNEH, F.E.; DOLL, E.C. The use of phosphate rocks for direct applications to soils. Advances in Agronomy, v.30, p.159-206, 1978.

KHIIEL, E.J. Manual de Edafologia. São Paulo: Editora Agronômica Ceres, 1979. $262 p$. 
KLUTHCOUSKI,J; OLIVEIRA, I.P.; DUTRA. L.G. Sistema Barreirão - Efeitos da aplicação de fosfatos a lanço e em sulco, no consórcio de arroz 'guarani'e 'braquiarão' In: CONGRESSO BRASILEIRO DE CIÊNCIA DO SOLO, 24., Campinas, 1993. Resumos. Campinas: Sociedade Brasileira de Ciência do Solo, 1993. p.223.

KÖRNDORFER, G.H. Capacidade de fosfatos naturais e artificiais fornecerm fósforo para plantas de trigo. Porto Alegre, 1978. 61 p. Dissertação (Mestrado) - Faculdade de Agronomia, Universidade Federal do Rio Grande do Sul.

LEHR, J.R. Phosphate raw materials and fertilizer: Part I- A look ahead. In: KHASAWNEH, F.E.; SAMPLE, E.C.; KAMPRATH, E.J. The role of phosphorus in agriculture. Madison: American Society of Agronomy, 1980. cap.4, p.81-120.

LÉON, L.A.; FENSTER, W.E.; HAMMOND, L.L. Agonomic potential of eleven phosphates rocks from Brazil, Colômbia, Peru and Venezuela. Soil Science Society of America Journal, v.50, n.2, p.798-802, 1986.

LOPES, A.S.; BARROS, N.F. NOVAIS, R.F. Perspectivas de utilização de fosfatos naturais brasileiros na agricultura . In: ENCONTRO NACIONAL DE ROCHA FOSFÁTICA, 3.,Brasília, 1986. Brasília: IBRAFOS,1986. p.393-402.

LOPES, A. S.; GOEDERT, W.J.; ROBERTO, L.; GUILHERME, G. Use of natural and modified phosphate rocks on annual, perenial and forestry crops in Brazil. Soils and Fertilizers, v.56, n. 5, p.625, 1993

LOPES, A.S.; VASCONCELLOS,C.A.; NOVAIS, R.F. de. Adubação fosfatada em algumas culturas nos estados de Minas Gerais, Espírito Santo e Rio de Janeiro. In: OLIVEIRA, A.J. de; LOURENÇO, S.; GOEDERT, W.J. Adubação fosfatada no Brasil. Brasília: EMBRAPA-DID, 1982. cap.5, p.137-200.

MC CLELLAN, G.H.; GREMILLION, L.R. Evaluation of phosphatic raw materials. . In: KHASAWNEH, F.E.; SAMPLE, E.C.; KAMPRATH, E.J. The role of phosphorus in agriculture. Madison: American Society of Agronomy, 1980. cap.3, p.43-80.

MAGALHÃES,A.F.de J. Fosfatos naturais no Brasil. Documentos - Centro Nacional de Pesquisa de Mandioca e Fruticultura (EMBRAPA-CNPMF). Cruz das Almas, n.53. 1993. 17p.

MAGALHÃES, J.C.A.J.; MELLO, F.A.F.; THOMAZI, M.D. Avaliação agronômica de fosfatos naturais, com ênfase em solos sob vegetação de cerrado- II. Revista de Agricultura, v.42, n.3, p. 205-221, 1987.

MALAVOLTA, E.; ALCARDE, J.C.; PONCHIO,C.O. Em torno da solubilidade dos fosfatos naturais: Mesa redonda sobre fosfatos naturais. Brasília, 1976, $39 \mathrm{p}$. 
MALAVOLTA, E.; HAAG, H.P.; MELLO, F.A.F.de; BRASIL SOBRINHO, M.O.C. Nutrição mineral e adubação de cereais diversos. In: MALAVOLTA, E.; HAAG, H.P.; MELLO, F.A.F.de; BRASL SOBRINHO, M.O.C. Nutrição mineral e adubação de plantas cultivadas. São Paulo: Pioneira, 1974. cap.7, p.325-370, 1974.

MALAVOLTA, E.; VITTI, G.C.; OLIVEIRA, S.A. Avaliação do estado nutricional das plantas. Piracicaba: Associação Brasileira para Pesquisa da Potassa e do Fosfato, 1989. 201p.

MIRANDA, L.T.; VIÉGAS, G.P.; FREIRE, E.S.; IGUE, T. Adubação do milho : Ensaios com diversos fosfatos (10 ${ }^{\stackrel{a}{a}}$ série). Bragantia, v.29, n.88, p.301-308, 1970.

NAKAYAMA, L.H.I;. POTTKER, D.;FABRÍCIO, A.C.; BARBO, C.V.S. Efeito da aplicação de diferentes níveis de fontes fosfatadas na cultura da soja. Informações Agronômicas ,v.30, n.5, p.1-2, 1985.

NOVELINO, J.O. Solubilização da apatita de Araxá, em diferentes tempos de incubação com amostras de cinco Latossolos, na presença e ausência de calagem. Viçosa,1984. 40p. Dissertação (M.S.) - Universidade Federal de Viçosa.

OLIVEIRA, E.L. de; MUZILLI, O.; IGUE, K.; TORNERO, T.T. Avaliação da eficiência agronômica de fosfatos naturais. Revista brasileira de Ciência do Solo, v.8, n. 1, p.63-67, 1984.

PEREZ, A.J.L.; NEPTUNE, A.M.L. Efeitos do fósforo e doses deste nutriente em alguns solos do estado de São Paulo na cultura do milho (Zea mays L.). O solo, v.79,n.1-2, p.61-68, 1987.

GOMES, F.P. Curso de estatística experimental. Piracicaba: Nobel, 1990. 468p.

PONCHIO, C.O. Solubilidade das rochas fosfatadas nacionais em diferentes extratores químicos. Piracicaba, 1978, 105p. Dissertação (Mestrado) - Escola Superior de Agricultura "Luiz de Queiroz", Universidade de São Paulo.

RAIJ, B. van Fertilizantes fosfatados e uso. Informações Agronômicas , v.26, n.1-2, p.1-2, 1981.

RAIJ, B.van; DIEST, A. van. Phosphate supplying power of rock phosphates in an oxissol. Plant and Soil, v.55, n.1, p.97-104, 1980.

RAIJ, B.van; QUAGGIO, J.A.; CANTARELLA, H.; FERREIRA, M.E.; LOPES, A.S.; BATAGLIA, O.C. Análise química do solo para fins de fertilidade. Piracicaba: Fundação Cargill, 1987. 170 p. 
RAMOS, M.G. Avaliação da eficiência de oito fosfatos para as culturas de trigo e soja em um latossolo vermelho-escuro argiloso. Revista brasileira de Ciência do Solo, v.6, n.1, p.38-42, 1982.

RANZANI, G.; FREIRE, O.; KINJO, T. Carta de solos do município de Piracicaba. Piracicaba: Centro de Estudo de Solos, ESALQ/USP, 1966. 85 p.

ROSCOE, E. Jr; QUADER, M.A.; TRUOG, R. Rock phosphate availability as influencied by soil pH. Soil Science Society of America Proceedings, v.19, n.4, p.434-487, 1955.

SARRUGE, J.R.; HAAG, H.P. Análises químicas em plantas. Piracicaba:ESALQ, 1974. $55 \mathrm{p}$.

SAUCHELLI, V. Phosphate in agriculture. New York: Reinhold Publishing Corporation, 1965. $277 \mathrm{p}$.

SMITH, T.J.; SANCHEZ, P.A. Phosphate rock dissolution and availability in cerrado soils as affected by phosphorus sorption capacity. Soil Science Society of America Journal, v.46, p.339-344, 1982.

SOUZA, J. Fosfatos naturais como fonte de fósforo, em diferentes períodos de incubação em dois solos. Viçosa, 1977. 55 p. Dissertação (M.S.) - Universidade Federal de Viçosa.

TANAKA, R.T.; BAHIA, V.G.; COELHO, A.M.; FREIRE, J.C. Seleção de extratores de fósforo do solo em função das respostas das plantas de milho (Zea mays L.) e da adubação com fosfato Patos-de-Minas em condições de casa-de-vegetação. Revista Brasileira de Ciência do Solo, v.5, n.1, p.38-42, 1981.

VASCONCELLOS,C.A.; SANTOS,H.L. dos; PITTA, G.V.; BAHIA FILHO, A.F.de C.; Avaliação da eficiência de fosfatos de rocha na cultura do sorgo. In:CONGRESSO BRASILEIRO DE MILHO E SORGO, 13., Londrina, 1980. Resumo. IAPAR: Londrina, p.132.

VIÉGAS, G.P. Adubação do milho: Ensaio com diversos fosfatos (4 $\stackrel{a}{a}$ série). Bragantia, v.20, n.2, p.15-34, 1961.

VIÉGAS, G.P.; MIRANDA, L.T.; FREIRE, E.S. Adubação do milho : Ensaio com diversos fosfatos $\left(9^{\stackrel{a}{a}}\right.$ série). Bragantia, v.29, n.18, p.191-198, 1970.

VIÉGAS, R.A. Dinâmica de fontes de fósforo aplicadas a solos com diferentes níveis de acidez. m. Viçosa,1990. 66 p. Dissertação (M.S.) - Universidade Federal de Viçosa. 
VOLKWEISS,S.J.; RAIJ, B.van. Retenção e disponibilidade de fósforo em solos. In: SIMPÓSIO SOBRE O CERRADO, 4., Brasília, 1976. Simpósio sobre o cerrado. Belo Horizonte: Itatiaia. p.317-332.

WUTKE, A.C.P.; SCHIMIDT, N.C.; AMARAL, A.Z.; VERDADE, B.C.; IGUE, K. Disponibilidade dos fosfatos em função do $\mathrm{pH}$ do solo. Bragantia, v.21, n.2, p.271284, 1962.

YOST, R.S.; KAMPRATH, E.J.; LOBATO, E.; NADERMAN, G.C.; SOARES, W.V. Residual effect of phosphorus application. p.26-32. In: Tropical soils Research Program. Annual report for 1975, North Carolina, U.S. Agency for International Development. 1976. 311 p. 